\title{
Interventions for involving older patients with multi-morbidity in decision-making during primary care consultations (Review)
}

Butterworth JE, Hays R, McDonagh STJ, Richards SH, Bower P, Campbell J

Butterworth JE, Hays R, McDonagh STJ, Richards SH, Bower P, Campbell J.

Interventions for involving older patients with multi-morbidity in decision-making during primary care consultations.

Cochrane Database of Systematic Reviews 2019, Issue 10. Art. No.: CD013124.

DOI: 10.1002/14651858.CD013124.pub2.

www.cochranelibrary.com 
TABLE OF CONTENTS

HEADER

ABSTRACT

PLAIN LANGUAGE SUMMARY

SUMMARY OF FINDINGS

BACKGROUND

OBJECTIVES

METHODS

Figure 1.

RESULTS

Figure 2.

Figure 3.

Figure 4.

DISCUSSION

\section{AUTHORS' CONCLUSIONS}

\section{ACKNOWLEDGEMENTS}

REFERENCES

CHARACTERISTICS OF STUDIES

DATA AND ANALYSES

Analysis 1.1. Comparison 1 Interventions for involving patients in decision-making about their health care vs usual care for older patients with multi-morbidity, Outcome 1 Health status: high self-rated health (CDC 'Healthy Days Measure') at 6 months. ....

Analysis 1.2. Comparison 1 Interventions for involving patients in decision-making about their health care vs usual care for older patients with multi-morbidity, Outcome 2 Health status: health-related quality of life (EQ-5D-5L measure) at 15 months.

Analysis 1.3. Comparison 1 Interventions for involving patients in decision-making about their health care vs usual care for older patients with multi-morbidity, Outcome 3 Treatment burden (Multi-morbidity Treatment Burden Questionnaire) at 15 months.

Analysis 1.4. Comparison 1 Interventions for involving patients in decision-making about their health care vs usual care for older patients with multi-morbidity, Outcome 4 Patient enablement and engagement: patient activation (Patient Activation Measure) at 6 months.

Analysis 1.5. Comparison 1 Interventions for involving patients in decision-making about their health care vs usual care for older patients with multi-morbidity, Outcome 5 Patient enablement and engagement: medication adherence (Morisky Medication Adherence Scale) at 6 months.

Analysis 1.6. Comparison 1 Interventions for involving patients in decision-making about their health care vs usual care for older patients with multi-morbidity, Outcome 6 Patient evaluation of care/the intervention: care related to priorities (adapted question from General Practice Patient Survey) at 15 months.

Analysis 1.7. Comparison 1 Interventions for involving patients in decision-making about their health care vs usual care for older patients with multi-morbidity, Outcome 7 Carer evaluation of care: carer experience (Carer Experience Questionnaire) at 15 months.

Analysis 1.8. Comparison 1 Interventions for involving patients in decision-making about their health care vs usual care for older patients with multi-morbidity, Outcome 8 Resource use and cost: number of nurse consultations (review of medical records) at 15 months.

Analysis 1.9. Comparison 1 Interventions for involving patients in decision-making about their health care vs usual care for older patients with multi-morbidity, Outcome 9 Quality of care: number of indicators of high-risk prescribing (review of medical records) at 15 months.

Analysis 2.1. Comparison 2 Interventions for involving patients in decision-making about their health care vs attention-control conditions for older patients with multi-morbidity, Outcome 1 Health status: high self-rated health (CDC 'Healthy Days Measure' and another similar 5-point scale, dichotomised) at 6 months.

Analysis 2.2. Comparison 2 Interventions for involving patients in decision-making about their health care vs attention-control conditions for older patients with multi-morbidity, Outcome 2 Patient enablement and engagement: patient activation (Patient Activation Measure) at 6 months.

Analysis 2.3. Comparison 2 Interventions for involving patients in decision-making about their health care vs attention-control conditions for older patients with multi-morbidity, Outcome 3 Patient enablement and engagement: self-efficacy (Self-Efficacy for Managing Chronic Disease Scale) at 6 months.

Analysis 2.4. Comparison 2 Interventions for involving patients in decision-making about their health care vs attentioncontrol conditions for older patients with multi-morbidity, Outcome 4 Patient evaluation of care/the intervention: changed management of their health (patient self-report, 3-point scale dichotomised) at 6 months. 
Analysis 2.5. Comparison 2 Interventions for involving patients in decision-making about their health care vs attention-control conditions for older patients with multi-morbidity, Outcome 5 Resource use and cost: number of general practice visits (patient self-report via questionnaire) at 6 months.

ADDITIONAL TABLES 
[Intervention Review]

\section{Interventions for involving older patients with multi-morbidity in decision-making during primary care consultations}

Joanne E Butterworth¹, Rebecca Hays², Sinead TJ McDonagh¹, Suzanne H Richards ${ }^{3}$, Peter Bower², John Campbell ${ }^{1}$

1University of Exeter Collaboration for Academic Primary Care (APEx), University of Exeter Medical School, Exeter, UK. 2NIHR School for Primary Care Research, Manchester Academic Health Science Centre, Division of Population Health, Health Services Research and Primary Care, University of Manchester, Manchester, UK. ${ }^{3}$ Leeds Institute of Health Sciences, University of Leeds, Leeds, UK

Contact address: Joanne E Butterworth, University of Exeter Collaboration for Academic Primary Care (APEx), University of Exeter Medical School, Smeall Building, St Luke's Campus, Exeter, Devon, EX1 2LU, UK. j.e.butterworth@exeter.ac.uk.

Editorial group: Cochrane Consumers and Communication Group

Publication status and date: New, published in Issue 10, 2019.

Citation: Butterworth JE, Hays R, McDonagh STJ, Richards SH, Bower P, Campbell J. Interventions for involving older patients with multi-morbidity in decision-making during primary care consultations. Cochrane Database of Systematic Reviews 2019, Issue 10. Art. No.: CD013124. DOI: 10.1002/14651858.CD013124.pub2.

Copyright (c) 2019 The Cochrane Collaboration. Published by John Wiley \& Sons, Ltd.

\section{A B S T R A C T}

\section{Background}

Older patients with multiple health problems (multi-morbidity) value being involved in decision-making about their health care. However, they are less frequently involved than younger patients. To maximise quality of life, day-to-day function, and patient safety, older patients require support to identify unmet healthcare needs and to prioritise treatment options.

\section{Objectives}

To assess the effects of interventions for older patients with multi-morbidity aiming to involve them in decision-making about their health care during primary care consultations.

\section{Search methods}

We searched the Cochrane Central Register of Controlled Trials (CENTRAL; all years to August 2018), in the Cochrane Library; MEDLINE (OvidSP) (1966 to August 2018); Embase (OvidSP) (1988 to August 2018); PsycINFO (OvidSP) (1806 to August 2018); the Cumulative Index to Nursing and Allied Health Literature (CINAHL) (Ovid) (1982 to September 2008), then in Ebsco (2009 to August 2018); Centre for Reviews and Dissemination Databases (Database of Abstracts and Reviews of Effects (DARE)) (all years to August 2018); the Health Technology Assessment (HTA) Database (all years to August 2018); the Ongoing Reviews Database (all years to August 2018); and Dissertation Abstracts International (1861 to August 2018).

\section{Selection criteria}

We sought randomised controlled trials (RCTs), cluster-RCTs, and quasi-RCTs of interventions to involve patients in decision-making about their health care versus usual care/control/another intervention, for patients aged 65 years and older with multi-morbidity in primary care.

\section{Data collection and analysis}

We used standard Cochrane methodological procedures. Meta-analysis was not possible; therefore we prepared a narrative synthesis.

\section{Main results}

We included three studies involving 1879 participants: two RCTs and one cluster-RCT. Interventions consisted of:

· patient workshop and individual coaching using behaviour change techniques; 
· individual patient coaching utilising cognitive-behavioural therapy and motivational interviewing; and

- holistic patient review, multi-disciplinary practitioner training, and organisational change.

No studies reported the primary outcome 'patient involvement in decision-making' or the primary adverse outcome 'less patient involvement as a result of the intervention'.

Comparing interventions (patient workshop and individual coaching, holistic patient review plus practitioner training, and organisational change) to usual care: we are uncertain whether interventions had any effect on patient reports of high self-rated health (risk ratio (RR) 1.40, 95\% confidence interval ( $\mathrm{Cl}$ ) 0.36 to 5.49; very low-certainty evidence) or on patient enablement (mean difference (MD) $0.60,95 \% \mathrm{Cl}-9.23$ to 10.43 ; very low-certainty evidence) compared with usual care. Interventions probably had no effect on health-related quality of life (adjusted difference in means $0.00,95 \% \mathrm{Cl}-0.02$ to 0.02 ; moderate-certainty evidence) or on medication adherence (MD 0.06 , $95 \% \mathrm{Cl}-0.05$ to 0.17 ; moderate-certainty evidence) but probably improved the number of patients discussing their priorities (adjusted odds ratio $1.85,95 \% \mathrm{Cl} 1.44$ to 2.38 ; moderate-certainty evidence) and probably increased the number of nurse consultations (incident rate ratio from adjusted multi-level Poisson model $1.37,95 \% \mathrm{Cl} 1.17$ to 1.61 ; moderate-certainty evidence) compared with usual care. Practitioner outcomes were not measured. Interventions were not reported to adversely affect rates of participant death or anxiety, emergency department attendance, or hospital admission compared with usual care.

Comparing interventions (patient workshop and coaching, individual patient coaching) to attention-control conditions: we are uncertain whether interventions affect patient-reported high self-rated health (RR $0.38,95 \% \mathrm{Cl} 0.15$ to 1.00 , favouring attention control, with very low-certainty evidence; RR $2.17,95 \% \mathrm{Cl} 0.85$ to 5.52, favouring the intervention, with very low-certainty evidence). We are uncertain whether interventions affect patient enablement and engagement by increasing either patient activation (MD 1.20, 95\% Cl -8.21 to 10.61 ; very low-certainty evidence) or self-efficacy ( $\mathrm{MD} 0.29,95 \% \mathrm{Cl}-0.21$ to 0.79 ; very low-certainty evidence); or whether interventions affect the number of general practice visits ( $\mathrm{MD} 0.51,95 \% \mathrm{Cl}-0.34$ to 1.36 ; very low-certainty evidence), compared to attention-control conditions. The intervention may however lead to more patient-reported changes in management of their health conditions ( $\mathrm{RR} 1.82,95 \% \mathrm{Cl} 1.35$ to 2.44; low-certainty evidence). Practitioner outcomes were not measured. Interventions were not reported to adversely affect emergency department attendance nor hospital admission when compared with attention control.

Comparing one form of intervention with another: not measured.

There was 'unclear' risk across studies for performance bias, detection bias, and reporting bias; however, no aspects were 'high' risk. Evidence was downgraded via GRADE, most often because of 'small sample size' and 'evidence from a single study'.

\section{Authors' conclusions}

Limited available evidence does not allow a robust conclusion regarding the objectives of this review. Whilst patient involvement in decision-making is seen as a key mechanism for improving care, it is rarely examined as an intervention and was not measured by included studies. Consistency in design, analysis, and evaluation of interventions would enable a greater likelihood of robust conclusions in future reviews.

\section{PLAIN LANGUAGE SUMMARY}

Interventions for involving older patients with more than one long-term health problem in decision-making during primary care consultations

\section{Background}

The number of older people with more than one long-term health problem is steadily increasing worldwide. Such individuals can have complicated healthcare needs. Although they frequently want to be involved in making decisions about their health care, they are less often involved than younger, healthier people. As a result, they may not be offered the same treatment options.

\section{Review question}

We reviewed available evidence about the effects of interventions intended to involve older people with more than one long-term health problem in decision-making about their health care during primary care consultations.

\section{Study characteristics}

We included research published up until August 2018. We found three relevant studies involving 1879 participants. These studies were reported from three countries. Participants were over 65 years of age with three or more long-term health problems on average. Interventions investigated included:

- patient workshops and individual patient coaching;

· patient coaching including cognitive-behavioural therapy; and 
- whole-person patient review, practitioner training, and organisational changes.

All studies were funded by national research bodies.

\section{Key results}

None of the studies reported the main outcome 'patient involvement in decision-making about their health care' nor whether there was less patient involvement as a result of the intervention. Interventions were not found to increase adverse outcomes such as death, anxiety, emergency department attendance, or hospital admissions..

We are uncertain whether interventions for involving older people with more than one long-term health problem in decision-making about their health care can improve their self-rated health or healthcare engagement, or make any difference in self-efficacy (one's belief in one's ability to succeed in specific situations) or in the overall number of general practice visits. We can report that these interventions probably make little or no difference in patients' quality of life but probably increase the number of patients discussing their priorities, and are associated with more patient consultations with nurses, when compared to usual care. Interventions may be associated with more changes in the management of health conditions when considered from the patient's perspective when compared with a control group.

The quality of the evidence was limited by small studies, and by studies choosing to measure different outcomes, resulting in lack of data that could be combined in analyses.

\section{Conclusions}

Further research in this developing area is required before firm conclusions can be drawn. 


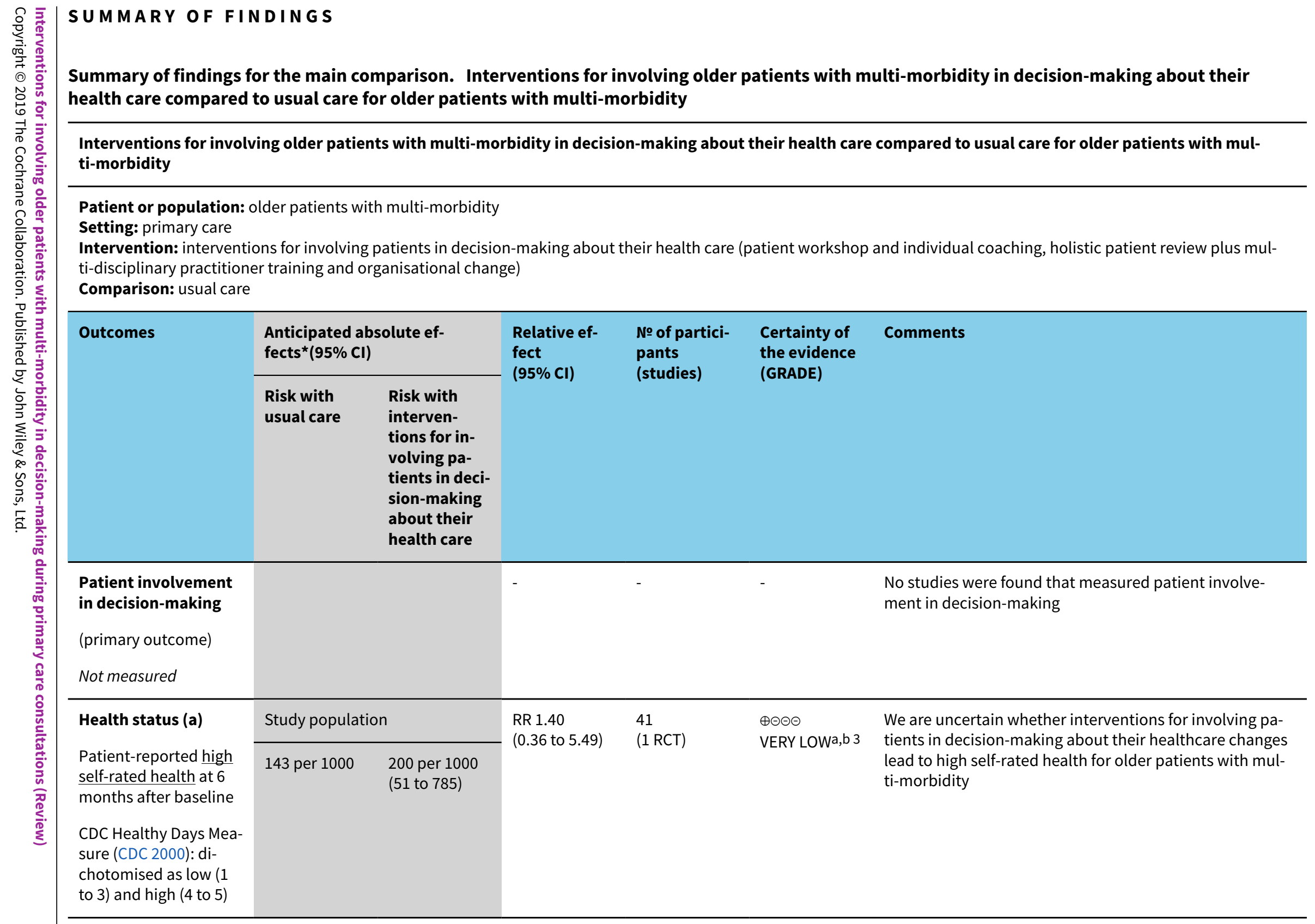

Intervention: interventions for involving patients in decision-making about their health care (patient workshop and individual coaching, holistic patient review plus multi-disciplinary practitioner training and organisational change) 


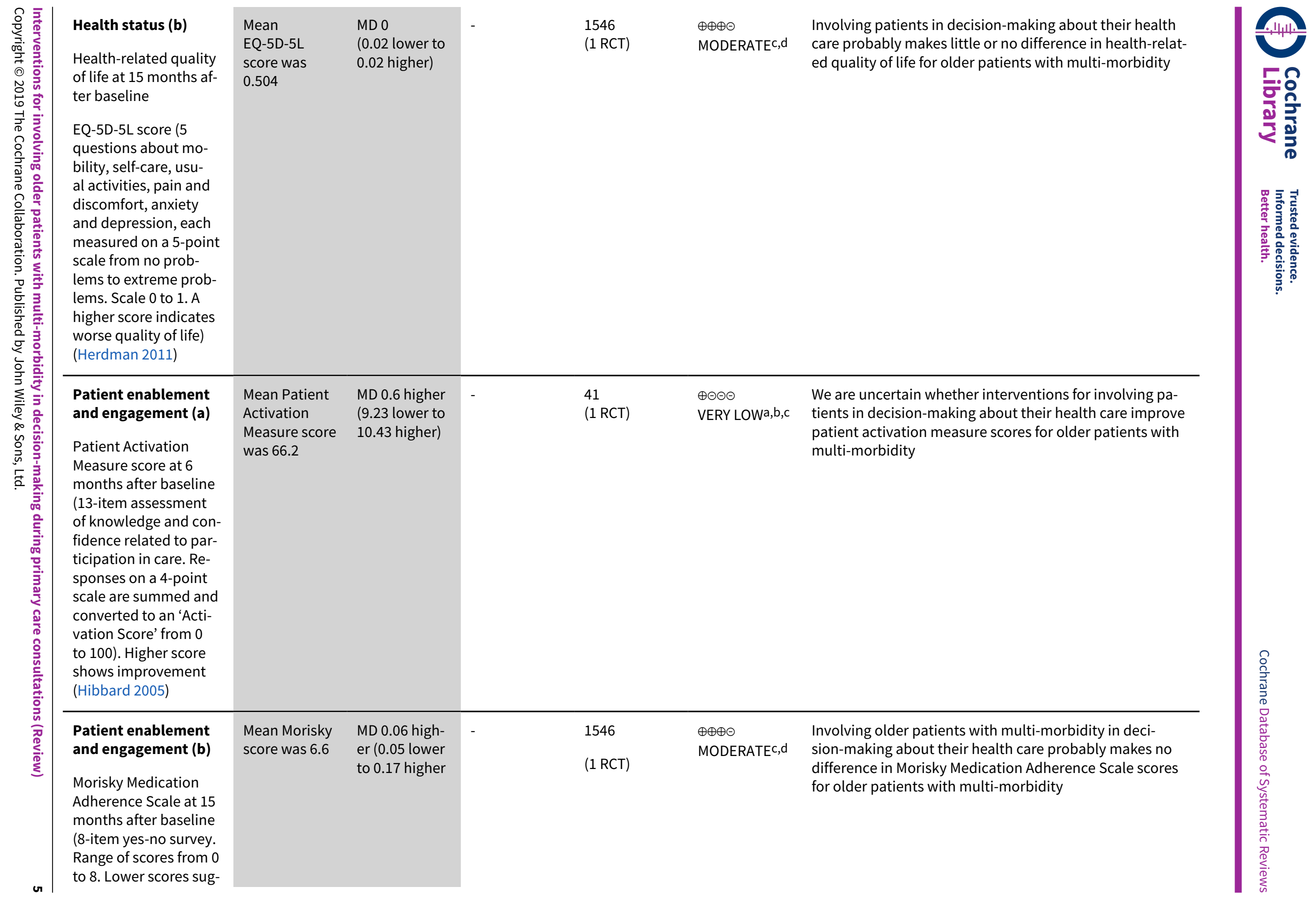




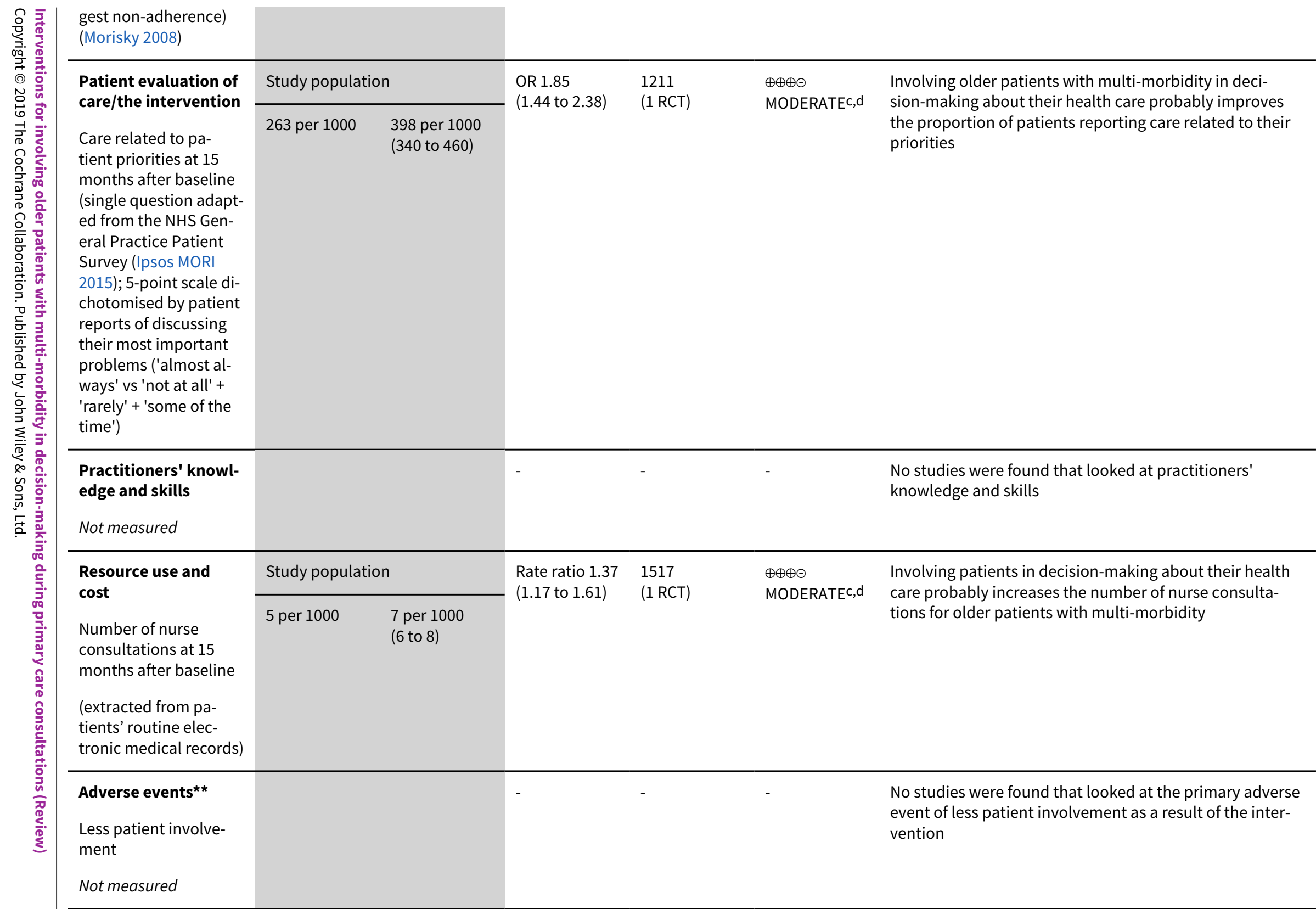

${ }^{\star}$ The risk in the intervention group (and its $95 \%$ confidence interval) is based on the assumed risk in the comparison group and the relative effect of the intervention (and its $95 \% \mathrm{Cl}$ ). The assumed risk in the comparison group is the mean, or median, risk (as reported in included studies) from the comparison groups. 
** Salisbury 2018 recorded full details of participant death and reported no differences between intervention and usual care groups and no association between death and the intervention. Salisbury 2018 reported no difference between intervention and usual care groups in rates of hospital admissions, in accident and emergency department visits, or in patient anxiety.

Cl: confidence interval; EQ-5D-5L: EuroQoL Group Quality of Life Questionnaire based on a five-level scale; NHS: National Health Service; OR: odds ratio; RCT: randomised controlled trial; RR: risk ratio.

\section{GRADE Working Group grades of evidence.}

High certainty: we are very confident that the true effect lies close to that of the estimate of the effect.

Moderate certainty: we are moderately confident in the effect estimate: the true effect is likely to be close to the estimate of the effect, but there is a possibility that it is substantially different.

Low certainty: our confidence in the effect estimate is limited: the true effect may be substantially different from the estimate of the effect.

Very low certainty: we have very little confidence in the effect estimate: the true effect is likely to be substantially different from the estimate of effect.

aUnclear performance bias, detection bias, and reporting bias have the potential to affect the outcome; however, not considered 'serious' risk (certainty not downgraded for risk of bias).

bSmall sample size (no. of events $<300)$ (certainty downgraded -2 for imprecision).

cAll results from the same study in a developing evidence base (certainty downgraded -1 for indirectness).

dUnclear performance bias and detection bias have the potential to affect the outcome; however, not considered 'serious' risk (certainty not downgraded for risk of bias).

\section{Summary of findings 2 . Interventions for involving patients in decision-making about their health care compared to attention-control conditions for} older patients with multi-morbidity

Interventions for involving patients in decision-making about their health care compared to attention-control conditions for older patients with multi-morbidity

Patient or population: older patients with multi-morbidity

Setting: primary care

Intervention: interventions for involving patients in decision-making about their health care (patient workshop and individual coaching, individual patient coaching) Comparison: attention-control conditions

\begin{tabular}{|c|c|c|c|c|c|c|}
\hline \multirow[t]{2}{*}{ Outcomes } & \multicolumn{2}{|c|}{ Anticipated absolute effects* $(95 \% \mathrm{CI})$} & \multirow{2}{*}{$\begin{array}{l}\text { Relative ef- } \\
\text { fect } \\
(95 \% \mathrm{CI})\end{array}$} & \multirow{2}{*}{$\begin{array}{l}\text { № of partici- } \\
\text { pants } \\
\text { (studies) }\end{array}$} & \multirow{2}{*}{$\begin{array}{l}\text { Certainty of } \\
\text { the evidence } \\
\text { (GRADE) }\end{array}$} & \multirow[t]{2}{*}{ Comments } \\
\hline & $\begin{array}{l}\text { Risk with atten- } \\
\text { tion-control con- } \\
\text { ditions }\end{array}$ & $\begin{array}{l}\text { Risk with inter- } \\
\text { ventions for in- } \\
\text { volving patients in } \\
\text { decision-making } \\
\text { about their health } \\
\text { care }\end{array}$ & & & & \\
\hline
\end{tabular}

Patient involvement in decision-making

No studies were found that measured patient

(primary outcome) 


\begin{tabular}{|c|c|c|c|c|c|c|}
\hline \multirow{4}{*}{ 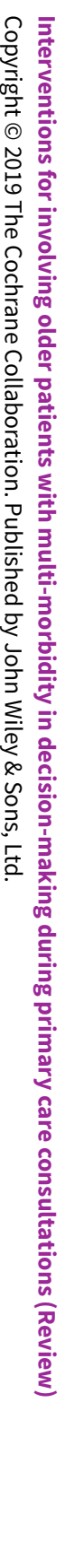 } & \multicolumn{6}{|l|}{ Not measured } \\
\hline & $\begin{array}{l}\text { Health status } \\
\text { Patient-reported high } \\
\text { self-rated health at } 6 \\
\text { months after baseline. } \\
\text { Hochhalter used CDC } \\
\text { Healthy Days Measure } \\
\text { (CDC 2000); Reed used } \\
\text { a similar 5-point Likert } \\
\text { scale developed by the } \\
\text { US National Health and } \\
\text { Nutrition Examination } \\
\text { Survey; each scale was } \\
\text { dichotomised as low (1 } \\
\text { to 3) and high (4 to 5) } \\
\text { Higher score shows im- } \\
\text { provement }\end{array}$ & \multicolumn{2}{|c|}{$\begin{array}{l}\text { Hochhalter } 2010 \text { reported fewer inter- } \\
\text { vention participants reported high self- } \\
\text { rated health when compared to atten- } \\
\text { tion-control participants at } 6 \text { months } \\
\text { (RR } 0.38,95 \% \mathrm{Cl} 0.15 \text { to } 1.00 ; \mathrm{P}=0.05 \text { ). } \\
\text { Conversely, Reed } 2018 \text { reported more } \\
\text { intervention participants reported high } \\
\text { self-rated health than attention-control } \\
\text { participants at } 6 \text { months (RR } 2.17,95 \% \\
\mathrm{Cl} 0.85 \text { to } 5.52 ; \mathrm{P}=0.11 \text { ) } \\
\text { Results were not pooled due to high het- } \\
\text { erogeneity between studies and opposite } \\
\text { directions of effect }\end{array}$} & $\begin{array}{l}297 \\
\text { (2 RCTs) }\end{array}$ & $\begin{array}{l}\oplus \ominus \odot \odot \\
\text { VERY } \\
\text { LOWa,b,c,d }\end{array}$ & $\begin{array}{l}\text { We are uncertain whether involving patients in } \\
\text { decision-making about their health care either } \\
\text { increases or decreases reports of high self-rat- } \\
\text { ed health for older patients with multi-morbid- } \\
\text { ity }\end{array}$ \\
\hline & $\begin{array}{l}\text { Patient enablement } \\
\text { and engagement (a) } \\
\text { Patient activation at } 6 \\
\text { months after baseline. } \\
\text { Patient Activation Mea- } \\
\text { sure score (13-item as- } \\
\text { sessment of } \\
\text { knowledge and confi- } \\
\text { dence related to partici- } \\
\text { pation in care. Respons- } \\
\text { es on a 4-point scale are } \\
\text { summed and converted } \\
\text { to an 'Activation Score' } \\
\text { from } 0 \text { to } 100 \text { ) (Hibbard } \\
2005) \\
\text { Higher score shows im- } \\
\text { provement }\end{array}$ & $\begin{array}{l}\text { Mean Patient Ac- } \\
\text { tivation Measure } \\
\text { score was } 65.6\end{array}$ & $\begin{array}{l}\text { MD } 1.2 \text { higher } \\
\text { (8.21 lower to } 10.61 \\
\text { higher) }\end{array}$ & $\begin{array}{l}43 \\
(1 \mathrm{RCT})\end{array}$ & $\begin{array}{l}\oplus \odot \ominus \odot \\
\text { VERY } \\
\text { LOWa,e,f,g }\end{array}$ & $\begin{array}{l}\text { We are uncertain whether interventions for in- } \\
\text { volving patients in decision-making about their } \\
\text { health care change Patient Activation Measure } \\
\text { scores for older patients with multi-morbidity }\end{array}$ \\
\hline & $\begin{array}{l}\text { Patient enablement } \\
\text { and engagement } \mathbf{( b )} \\
\text { Self-efficacy at } 6 \text { months } \\
\text { after baseline }\end{array}$ & $\begin{array}{l}\text { Mean self-efficacy } \\
\text { rating was } 6.26\end{array}$ & $\begin{array}{l}\text { MD } 0.29 \text { higher } \\
(0.21 \text { lower to } 0.79 \\
\text { higher) }\end{array}$ & $\begin{array}{l}254 \\
(1 \mathrm{RCT})\end{array}$ & $\begin{array}{l}\oplus \ominus \ominus \ominus \\
\text { VERY LOWe,f,g }\end{array}$ & $\begin{array}{l}\text { We are uncertain whether interventions for in- } \\
\text { volving patients in decision-making about their } \\
\text { health care either increase or decrease self-effi- } \\
\text { cacy for older patients with multi-morbidity }\end{array}$ \\
\hline
\end{tabular}




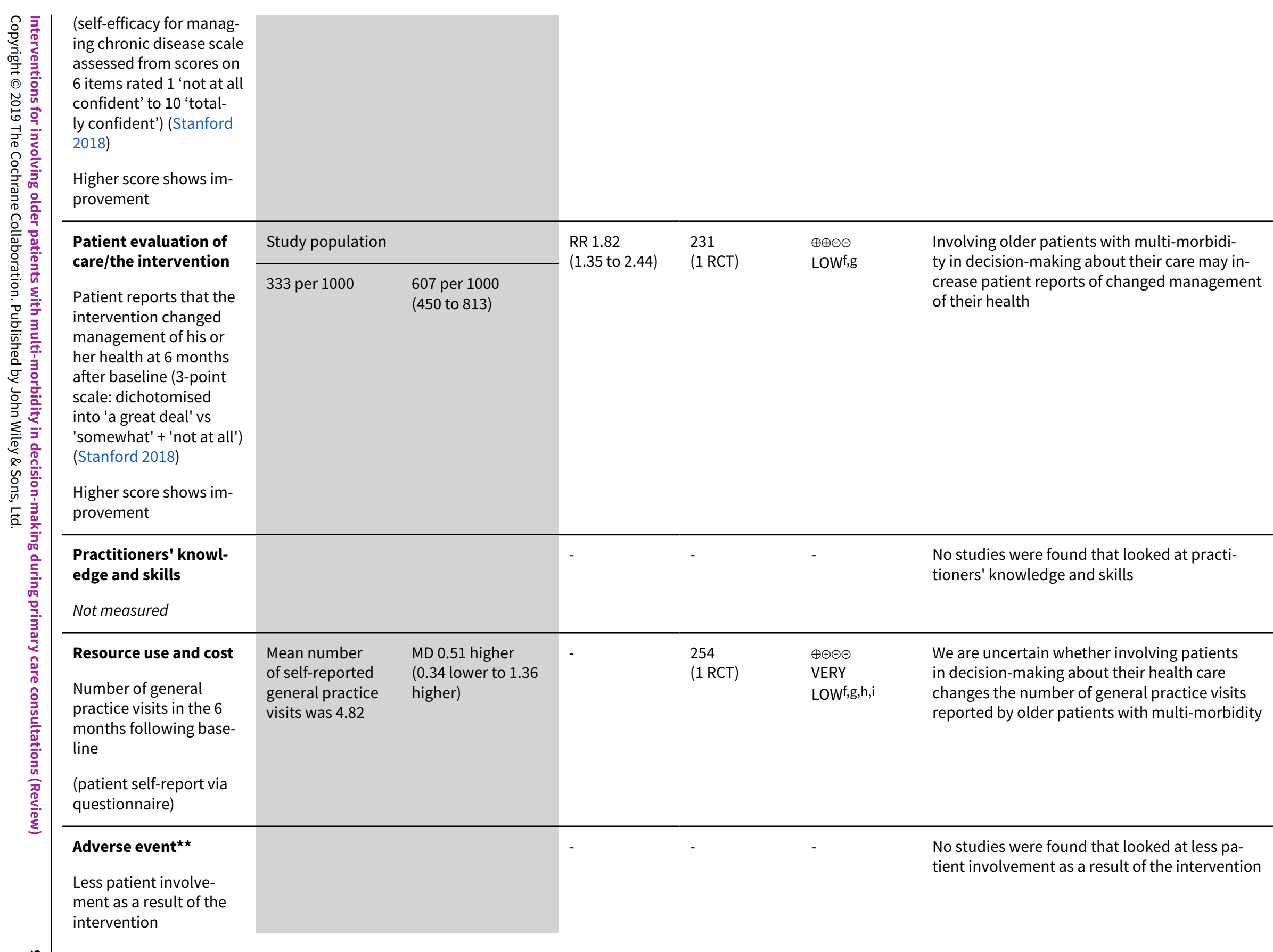


${ }^{\star}$ The risk in the intervention group (and its $95 \% \mathrm{Cl}$ ) is based on the assumed risk in the comparison group and the relative effect of the intervention (and its $95 \% \mathrm{Cl}$ ). The assumed risk in the comparison group is the mean risk from the comparison groups in included studies.

** Reed 2018 reported no difference between intervention and usual care groups in numbers of hospital admissions and in numbers of accident and emergency department visits.

CDC: Centers for Disease Control and Prevention; Cl: confidence interval; MD: mean difference; RCT: randomised controlled trial; RR: risk ratio.

\section{GRADE Working Group grades of evidence.}

High certainty: we are very confident that the true effect lies close to that of the estimate of the effect.

Moderate certainty: we are moderately confident in the effect estimate: the true effect is likely to be close to the estimate of the effect, but there is a possibility that it is substantially different.

Low certainty: our confidence in the effect estimate is limited: the true effect may be substantially different from the estimate of the effect.

Very low certainty: we have very little confidence in the effect estimate: the true effect is likely to be substantially different from the estimate of effect.

aUnclear performance bias, detection bias, and reporting bias have the potential to affect the outcome; however, not considered 'serious' risk (certainty not downgraded for risk of bias).

bHigh heterogeneity with effects in opposite directions (certainty downgraded -1 for inconsistency).

cSmall sample size, no. of events $<300$ (certainty downgraded -2 for imprecision).

$d$ Results from two small studies in a developing evidence base (certainty downgraded -1 for indirectness).

eAll results from the same small study in a developing evidence base (certainty downgraded -1 for indirectness).

fSmall sample size, no. of participants $<400$ (certainty downgraded -1 for imprecision).

g95\% confidence intervals include no effect and may cross the minimally important difference (certainty downgraded -1 for imprecision).

hPatient self-report as opposed to objective measure (certainty downgraded -1 for risk of bias (blinding)). 


\section{B A C K G R O U N D}

\section{Description of the condition}

Life expectancy is predicted to continue to rise globally (Oeppen 2002), and the prevalence of long-term conditions increases with age (Melzer 2015). The co-existence of two or more chronic (long-term) conditions is termed multi-morbidity (Academy of Medical Sciences 2018). Quality of care for older patients with multi-morbidity may be worsening when compared to management of patients with long-term conditions in general (Higashi 2007; Steel 2014). Consequences of multi-morbidity include functional decline, which is associated with poor quality of life, high healthcare utilisation and costs, reduced life expectancy, and a negative impact on the health of carers for patients with multi-morbidity (Academy of Medical Sciences 2018; Marengoni 2011).

Our previous work identified that older patients value being involved in decision-making about their health care (Butterworth 2014). However, they are less frequently involved in decision-making than younger patients (van den Brink-Muinen 2006). Evidence suggests associated health inequalities including discrepancies in rates of referral and requests for investigation among older people with multi-morbidity (Drennan 2007; McBride 2010; Tate 2010).

The importance of involving older patients with multi-morbidity in decision-making about their care when seeking to identify unmet healthcare needs has been acknowledged (Couët 2015; Department of Health and Social Care (UK) 2001; Homa 2015; Iliffe 2004; Noël 2007). Older patients need support in prioritising and rationalising treatment options to maximise quality of life and day-today function (Kiesler 2006; Peters 1994). Recent research suggests that supporting older patients with multi-morbidity in communicating their needs and concerns to healthcare providers could reduce risks to patient safety (Hays 2017).

'Old age' refers to nearing the end of the natural human life cycle. Whilst the widely accepted definition of an older person in westernised countries encompasses individuals aged 65 years and older, with the rise in life expectancy this age category is widening (Dong 2016; Oeppen 2002). Therefore, there may be differing healthcare requirements across the widening 'older' age group that must be considered by future research and, in particular, by intervention studies designed to support the needs of this patient group. Many currently available interventions appear outdated in their assessments of this population with regard to their wish for involvement in decision-making about their individual healthcare needs.

\section{Description of the intervention}

This Cochrane Review assesses the effects of interventions for older patients with multi-morbidity with the aim of involving them in decision-making about their health care during primary care consultations. We searched the literature for systematic reviews of interventions with a related aim, seeking to inform the description of interventions to be included in this review (Kinnersley 2008; Légaré 2018; Smith 2016; Wetzels 2007). Our description of the components of patient involvement in decision-making is also influenced by the components of patient-centred care as suggested by Wensing 2003.

Interventions may be delivered before or during a single consultation, or they may span multiple consultations. Studies may encom- pass one or any combination of three types of interventions centred around a consultation with a primary care practitioner.

- Patient-focused (e.g. written or online decision-support tools such as 'option grids' that can be completed with a practitioner during a consultation or completed by the patient outside of and before the consultation).

- Practitioner-focused (e.g. training in communication skills for use during a consultation).

- Related to organisational change (e.g. increased length of the consultation).

Interventions may be delivered, as well as received, by primary care practitioners, or they may be delivered by external clinicians or researchers or by administration staff. They may be facilitated by a patient's carer (a family member or friend, or a paid helper who regularly looks after the patient), who may or may not be present during a consultation.

We considered all interventions designed to facilitate involvement of patients with multi-morbidity in decision-making about their health care during primary care consultations.

\section{How the intervention might work}

Within the patient-practitioner consultation, patient involvement in decision-making refers to activities carried out by:

- a practitioner seeking to facilitate a patient's active engagement in decision-making within the consultation (including using 'shared decision-making'-related communication skills and/ or encouraging patient autonomy and empowering self-management and/or changing the way that information is delivered to meet patient preferences); and

- patients seeking to increase their own involvement in decision-making during the consultation (including expressing a preference for involvement, using written decision-making support tools, and taking ownership of patient-held records).

In addition, changes can be made to the organisation of care, so that healthcare services more comprehensively address patients' needs and preferences, potentially enabling patient involvement in decision-making about their health care. Therefore, a third approach to patient involvement in decision-making is directed towards improving the quality of healthcare delivery within the consultation, and might include longer consultations (to allow time for patient involvement in decision-making to take place, for example) or organisational change, with system improvements to facilitate continuity of care with an individual practitioner (Wensing 2003).

Shared decision-making has been defined as "an approach where clinicians and patients share the best available evidence when faced with the task of making decisions, and where patients are supported to consider options, to achieve informed preferences" (Elwyn 2010). Patient involvement in decision-making during healthcare consultations has long been identified and remains a priority feature of high-quality patient-centred care (Coulter 2011; WHO 1994; WHO 2018). Delivering such care is associated with improved outcomes for patients, doctors, and healthcare teams. These include patient adherence with treatment advice, satisfaction with health care, and trust in the doctor (Croker 2013; Flocke 2013; Loh 2007; Ommen 2011). 
The primary care practitioner's role in shared decision-making involves seeking the patient's implicit or explicit involvement in the decision-making process; exploring the patient's ideas, fears, and expectations about the problem and possible treatments; providing a balanced view in the discussion of healthcare options; conveying tailor-made healthcare information; checking the patient's understanding of the information and his or her reactions to it; asking about the patient's decision-making role preference; making, discussing, or deferring decisions with the patient; and arranging for appropriate follow-up (Elwyn 2000).

Elywyn's refined 'three-talk model' outlines conversational steps in which the practitioner provides support when introducing options, followed by strategies to compare and discuss trade-offs in the decision to be made before a process of deliberation takes place that is based on the patient's informed preferences (Elwyn 2017).

Whilst many studies have reported patients' positive views of the processes of involvement in decision-making about their health care, some have suggested that older patients may not value feeling involved in this way (Levinson 2005). Our previous work used qualitative methods to examine these apparent conflicts (Butterworth 2014). We found that, in general, older patients do value feeling involved in the decision-making process, but it is important to recognise that patient perceptions vary regarding what it means to be 'involved' (Berkelmans 2010; Kiesler 2006). For example, some participants did not report valuing every element of a shared decision-making approach identified in the literature as being of importance (Elwyn 2000). We therefore considered studies evaluating all interventions designed to facilitate involvement of patients with multi-morbidity in decision-making about their care, to understand the effects of these interventions for older patients living with multi-morbidity without solely focusing on a shared decision-making approach. We also considered studies of interventions designed to facilitate patient involvement in decision-making that were not designed for but were investigated in our population of interest.

Patients' perceptions of involvement in decision-making about their health care are considered important in predicting outcomes (Saba 2006). For example, there are positive associations between patients' trust in a general practitioner (GP) and their perceptions of having been involved in decision-making. The strength of this association increases with increasing patient age (Croker 2013). A brief review of the current literature suggests that it is difficult to draw firm conclusions regarding which types of interventions might most effectively facilitate the adoption of patient involvement in decision-making by primary care practitioners (Légaré 2018).

A 2007 Cochrane Review considered interventions to improve older patients' involvement in primary care consultations, including their involvement in decision-making about their health care (Wetzels 2007); however, it did not address the issue of multi-morbidity. At that time, the review authors reported on three intervention studies and concluded that available evidence was sparse. However, that review is now dated, and new research is available. This systematic review of new evidence aims to provide greater clarity regarding which interventions may best support the involvement of older patients with multi-morbidity in decision-making about their care, to achieve positive outcomes for patients, doctors, and healthcare teams, as outlined above.

\section{Why it is important to do this review}

There are concerns that current delivery of good-quality care is not meeting the needs of older patients, who often experience multi-morbidity (Salisbury 2012; Steel 2014). Older patients account for a large percentage of spending in primary care: $37 \%$ in UK (RCGP 2013). Such patients consult more frequently (Hobbs 2016), creating a substantial component of the primary care workload. The burden on primary care associated with this vulnerable patient group can be expected to increase as the prevalence of multi-morbidity in older age groups is predicted to rise (from $45.7 \%$ in 2015, to $52.8 \%$ in 2035, for people aged 65 to 74 years) (Kingston 2018). It is only recently that the benefits for older patients with multi-morbidity derived from participating in decision-making about their health care have been acknowledged.

The National Institute for Health and Care Excellence (NICE) in UK has published guidelines for the clinical assessment and management of patients with multi-morbidity (NICE 2016). These guidelines recommend that patients with multi-morbidity should be involved in decision-making about their health care. However, guideline authors have provided little instruction on how this should be achieved. Our review is warranted to provide evidence-based guidance to policy makers, researchers, and commissioners on how they can direct funding towards good-quality interventions targeting involvement of older patients in decision-making about their health care, and how they can provide practical guidance to clinicians who adopt these interventions.

We identified six previous reviews by conducting a brief literature search and by seeking the advice of content experts (Coulter 2015; Dawmena 2012; Kinnersley 2008; Légaré 2018; Rolfe 2014; Smith 2016). We discuss the similarities and differences between these reviews and our review by using the Donabedian structure/process/ outcomes model (Donabedian 1988); we also discuss why our review is needed to fill an important gap in the current literature (see Table 1).

Previous reviews have examined interventions specifically targeting shared decision-making, and largely focusing on other patient populations. However, we feel it is important to carry out a review of all interventions developed with the aim of facilitating the involvement of older patients with multi-morbidity in decision-making about their care. Therefore, our review will have a broader scope than past reviews in terms of the interventions, and a narrower scope in terms of the population.

We are not aware of any significant overlap with other Cochrane or non-Cochrane Reviews, either published or in progress.

Our review will inform the development of an intervention aimed at facilitating the involvement of older patients with multi-morbidity in decision-making about their health care when visiting a primary care physician. Feasibility testing will then inform the planning and design of a future definitive randomised controlled trial of the intervention. We hope that other researchers will use this review to similarly inform their work to support this growing and vulnerable patient population. 


\section{OB JECTIVES}

To assess the effects of interventions for older patients with multi-morbidity aiming to involve them in decision-making about their health care during primary care consultations.

\section{METHODS}

\section{Criteria for considering studies for this review}

\section{Types of studies}

We included individually randomised controlled trials (RCTs), cluster-RCTs, and quasi-RCTs (trials in which randomisation is attempted but is subject to potential manipulation, such as allocating participants by day of the week, date of birth, or sequence of entry into a trial). We anticipated that few high-quality RCTs would have been conducted on this topic, as many studies specifically exclude older patients or those with more than one health problem.

\section{Types of participants}

The patient population consisted of older patients (65 years of age and older) with multi-morbidity (more than one long-term health problem) and included their carers. However, we anticipated that searching for studies with such specific participant inclusion criteria might limit our findings. We included studies in which $100 \%$ of patients had multi-morbidity when we could determine this information from the trial report or from author contact, or when stratification of study findings enabled data on patients with multi-morbidity to be separately extracted and analysed. We planned to include studies in which $75 \%$ or more of the patient population was 65 years of age or older.

Like most researchers conducting studies in developed world countries, we have accepted the chronological age of 65 years and older as the definition of an older person. However, we recognise that, like many westernised concepts, this does not adapt well to circumstances in developing countries.

We included any study in which the study authors' definition of multi-morbidity incorporates our own. Our definition of 'more than one long-term health problem' therefore encompasses studies in which multi-morbidity is defined as 'three or more chronic conditions', for example.

We did not specify a minimum length of time for long-term conditions, examples of which include angina or heart problems; arthritis or joint problems; asthma or chest problems; blindness or severe visual impairment; cancer in the last five years; deafness or severe hearing impairment; diabetes; epilepsy; high blood pressure; kidney or liver disease; back problems; mental health problems; and neurological problems. We adapted this list from the English $\mathrm{Na}$ tional General Practice Patient Survey (GPPS) (Ipsos MORI 2015). When dyads of conditions occurred within the same category of the GPPS (e.g. anxiety, depression), we counted these as only one condition (e.g. mental health problems).

We excluded studies that did not measure specific long-term conditions but instead reported health 'domains' or 'problems'. We recognise that polypharmacy does not always equate to multi-morbidity, and therefore we did not consider a study population presenting with polypharmacy alone as sufficient for inclusion in the review.
We defined primary care as "first-contact, continuous, comprehensive, and coordinated care provided to populations undifferentiated by gender, disease, or organ system" (Starfield 1994). We included all interventions involving patients, their carers, primary care practitioners, and primary care administration staff (including receptionists) that were delivered within primary care with the aim of improving patient involvement within a primary care consultation. This included interventions delivered in the patient's home but initiated by the primary healthcare team. It also included interventions initiated by the research team but delivered in the context of primary care. We included patients in care or in nursing homes. We included carer participation because this is likely to be of relevance to consultations involving vulnerable, older patients with multi-morbidity. We recognised that interventions may have multiple components that it would be important to capture. Using administration staff to ensure organisational change within the practice may be one of these elements. We did not exclude patient participants based on whether they had public or private insurance.

We included studies involving interventions delivered by all types of practitioners working within primary care (e.g. doctors, nurses, physiotherapists, occupational therapists, mental health workers, pharmacists). We excluded dentists because our focus was around general medical practice. We included interventions delivered by non-clinical researchers or teachers/trainers to patients or practitioners, for example, training in communication skills.

Interventions could be directed at patients, primary care practitioners, or both. Interventions could be delivered to patients by primary care practitioners, and in some situations, practitioners could receive one element of an intervention (e.g. training in communication skills) and deliver another element (e.g. written support tool used during a consultation).

Alternatively, or additionally, interventions could involve organisational change within the practice, for example, longer consultation times.

We excluded interventions delivered by secondary care practitioners to their patients and interventions delivered to patients who had been recruited via secondary care because we consider the primary care setting to include healthcare practitioners and administrative staff working within the patient's general practice surgery; in the wider community, for example, community pharmacies and community support groups; and in the patient's home. We excluded consultations in acute care settings (e.g. accident and emergency department settings, out of hours services) because we are interested in first-contact, continuous, comprehensive, and co-ordinated care provided by a primary care practitioner, as described by Starfield 1994. We excluded studies in which only part of the intervention was delivered or facilitated via primary care, unless it was possible to differentiate findings according to intervention setting.

\section{Types of interventions}

There may be different types of interventions with the common aim of involving patients in decision-making about their health care. We expected to find face-to-face interventions for patients and/or practitioners, written or online information sheets with prompts for use before or during consultations, and some elements of organisational change within the primary care environment. 
As we are interested in all interventions that facilitate patient in volvement in decision-making about their health care, this is not limited to a shared decision-making approach. Therefore, we did not specify that the intervention needed to meet a certain number of shared decision-making elements (Elwyn 2000; Elwyn 2017). Equally, we recognise that shared decision-making usually requires shared equipoise informed by the preferences and values of the patient and the practitioner. With a motivational interviewing approach, the goals related to a decision have usually already been set by the practitioner. We did not exclude interventions whereby the goal had already been set by the practitioner unless the aim of the intervention was to persuade the patient to meet that goal. We also did not exclude interventions that utilised a predetermined patient goal.

Decisions around care at the end of life are important for this patient group, and studies were not excluded on the basis of this subject area when decisions were being made regarding immediate and specific management options. However, we did exclude interventions related to advanced directives, as planning for the future can often involve making hypothetical decisions. These sorts of decisions are different from those underpinned by a patient's current priorities and immediate healthcare needs. We planned to exclude studies in which decision-making about any type of hypothetical issues had taken place.

We included interventions if they addressed only a decision-making process surrounding a single long-term condition in a patient with multi-morbidity, as long as the aims of the study were to facilitate patient involvement in decision-making about their care. We included studies that investigated interventions with older patients with multi-morbidity, even if the intervention was not originally designed for this patient population.

We included both patient-focused and practitioner-focused interventions taking place before or during consultations. These could relate to single-patient encounters with a practitioner or may relate more broadly to patients' use of primary health care. Interventions could focus on using healthcare information resources, on preparing patients for patient-practitioner contacts, or on training practitioners in consultation skills.

Patient-focused interventions could include patient decision aids: pre-consultation mail-outs advising patients how to actively seek involvement in decision-making about their care during a consultation; 'option grids' and 'risk diagrams' delivered by practitioners to aid involvement in decision-making regarding treatments or regarding investigations during consultations; hand-held patient care plans with documentation of shared decisions made between patient and practitioner to aid in subsequent follow-up discussions about these decisions; conversation aids (Montori 2017); and patient agenda cards (Hamilton 2006).

Practitioner-focused interventions could involve training in patient-centred communication skills and in interventions that raise practitioner awareness of the potential benefits of involvement in decision-making for this patient group.

Studies of interventions encompassing organisational change could include longer consultations for older patients with multi-morbidity to allow time for effective involvement in decision-making, or allowing a third person (e.g. a carer) to be present within the consultation to act as a facilitator of the patient's in- volvement. Interventions focused solely on aspects of organisational change, for example, improving appointment availability, waiting lists, and consultation duration, were included only when the intervention explicitly aimed to facilitate the involvement of older patients with multi-morbidity in decision-making about their health care. Chrischilles 2014 is an example of a study examining an organisational change intervention (providing personal health records to patients) that does not explicitly involve patients in decision-making and so was judged as ineligible for this review.

Interventions delivered by clinician-researchers could include leaflets for patients or training for practitioners. Interventions delivered by practitioners to patients during consultations could be based on use of patient-centred communication skills. Interventions delivered by administration staff to patients could include mail-outs of information sheets and decision aids or distribution of consultation prompts in the waiting room.

We included studies that compared the intervention versus usual care or versus no intervention. We included studies with multiple arms evaluating the effectiveness of one form of intervention versus another, or evaluating the effectiveness of more than one intervention by comparing each with usual care.

We expected to identify studies assessing outcomes from patient and/or practitioner and/or observer perspectives.

We used the Template for Intervention Description and Replication (TIDieR) checklist to guide our description of intervention components (Hoffmann 2014).

\section{Types of outcome measures}

The main outcome categories for the 'Summary of findings' table were (1) evidence of patient involvement in decision-making; (2) health status; (3) patient engagement and enablement; (4) patient evaluation of care or of the intervention; (5) practitioners' knowledge and skills; (6) resource use and cost; and (7) primary adverse outcome (patient, practitioner, or observer perceptions of less patient involvement in decision-making than before the intervention).

We used the Institute for Health Care Improvement Triple Aim (improving the patient experience of care, improving the health of populations, and reducing the per capita cost of health care) to guide our selection of secondary outcomes (Berwick 2008).

\section{Primary outcomes}

Evidence of patient involvement in decision-making during the consultation from patient and/or practitioner and/or observer perspectives

Elwyn 2017 proposes that a sequence of skills should be demonstrated by the practitioner to involve the patient in the decision-making process. These skills can be measured by a variety of scales, including by an observer using the OPTION scale (Barr 2015), or by capturing patient perceptions of involvement (Barr 2014). Many measures of shared decision-making are available in the literature (Gärtner 2018).

Simple rating scales, such as those used in the General Practice Patient Survey (GPPS) in England (Ipsos MORI 2015), can be used to measure patient and practitioner perceptions, including whether 
patient involvement in decision-making about their health care took place during a primary care consultation.

\section{Secondary outcomes}

\section{Patient and carer outcomes}

- Health status: physical health status including clinical outcomes (physiological measures) and other patient-reported physical health outcomes (from patient-reported outcome measures); psychological and psychosocial health status including patient quality of life, social behaviour, and life satisfaction (from shortform health surveys such as the World Health Organization (WHO) quality of life instrument (WHO 2012))

- Treatment burden: medication burden (polypharmacy, co-ordinating medication, obtaining prescriptions, using devices), prescribed lifestyle changes (diet, exercise, smoking, alcohol), self-monitoring, impact on relationships (family/friends/carers), treatment burden associated with multi-morbidity

- Patient enablement and engagement: health behaviours including adherence to treatment plans (from practice databases and patient survey data), patient-initiated lifestyle changes (diet, exercise, smoking, alcohol), and knowledge and skills acquisition for patients including information access, knowledge about diseases/conditions, knowledge about treatments and risks, health beliefs, patient enablement for self-care (Howie 1998), symptom control skills, health-enhancing lifestyle measures

- Patient evaluation of care/the intervention: patient satisfaction with practitioners and care procedures; trust in the practitioner; perceptions of practitioner behaviours (knowledge, skills, empathy, attitudes regarding patient involvement); complaints. Tools could include the Patient Perceptions of Patient-Centredness (PPPC) instrument (Stewart 2000), as well as the General Practice Patient Survey (Croker 2013; Ipsos MORI 2015)

- Carer support: patient perceptions or ratings of carer support

- Carer evaluation of care: ratings of satisfaction with the encounter

\section{Practitioner outcomes}

- Knowledge and skills: knowledge of the potential benefits of patient involvement in the decision-making process; competence in patient-centred communication skills (e.g. shared decision-making skills) (as assessed by the OPTION scale (Barr 2015), or a similar tool)

- Attitudes (towards the intervention and compliance with it)

- Practitioner satisfaction with the intervention

\section{Health service use and related outcomes}

- Resource use and cost: length of consultation, frequency of attendance, types of appointments, cost implications of rates of referral and investigation, cost of care to the patient, accident and emergency department attendance, hospital admissions

- Quality of care: measured via condition- or drug-specific processes, or through patient-centred reports of experiences of care (Valderas 2019)

\section{Adverse outcomes}

- Patient, practitioner, or observer perceptions of less patient involvement in decision-making than before the intervention (primary adverse outcome); adverse effects of medications; inappropriate frequency of appointment attendance (in excess or did not attend); unwarranted treatments/procedures; increase in hospital admissions and accident and emergency department attendances; increased anxiety in patients due to the intervention process; stress among patients due to receiving information; increased practitioner anxiety/stress from the intervention; complaints

At the protocol stage, we were not able to predict every secondary outcome reported by included studies. However, we selected a primary outcome, a main adverse outcome, and pre-specified secondary outcome categories for use at the review stage. We applied the categorisation process to narrative synthesis of outcomes and to selection of outcomes for reporting in the 'Summary of findings' table.

Two review authors independently categorised the outcomes reported in each included study using the review's outcome categories. We planned to resolve any differences in categorisation by involving a third review author; however, this was not required. We found that in some cases, we assigned more than one outcome to each outcome category per study. In this scenario, we did the following.

- Selected the primary outcome as reported by study authors in published papers to date.

- When no primary outcome was identified, selected the outcome specified in the sample size calculation.

- If there were no sample size calculations, selected the outcome that appeared to relate most closely to the primary outcome of the review.

-When outcomes did not directly relate to the primary outcome, selected the patient-reported measure, or if there was no patient-reported measure, selected the measure most relevant to primary care.

- If all of the above were not appropriate, ranked the effect estimates and selected the outcome with the median effect estimate.

It was not appropriate to define, in advance, the timing of outcome assessment; however we defined this to include assessment at baseline (immediately after intervention delivery), at medium-term follow-up (e.g. months), or at long-term follow-up (e.g. years).

\section{Search methods for identification of studies}

\section{Electronic searches}

We searched the following electronic databases.

- Cochrane Central Register of Controlled Trials (CENTRAL; the latest issue), in the Cochrane Library (search date 01/08/2018).

- MEDLINE (OvidSP) (1966 to present) (search date 12/08/2018).

- Embase (OvidSP) (1988 to present) (search date 12/08/2018).

- PsycINFO (OvidSP) (1806 to present) (search date 12/08/2018).

- Cumulative Index to Nursing and Allied Health Literature (ClNAHL) (Ovid) (1982 to September 2008), then in Ebsco when no longer indexed by Ovid (2009 to present) (search date 12/08/2018).

- Centre for Reviews and Dissemination Databases (Database of Abstracts and Reviews of Effects (DARE)) (search date $12 / 08 / 2018)$ 
- Health Technology Assessment (HTA) Database (search date 12/08/2018).

- Ongoing Reviews Database (search date 12/08/2018).

- Dissertation Abstracts International (1861 to present) (search date 12/08/2018).

We present detailed search strategies in Appendix 1 through Appendix 6.

We applied no language or date restrictions.

\section{Searching other resources}

We sought additional studies by searching the reference lists of relevant trials and reviews identified. In addition, we examined our personal literature collections to identify relevant studies. We contacted experts in the field and authors of included studies for advice as to other known relevant studies. We also searched online trial registers (WHO International Clinical Trials Registry Platform (search date 13/08/2018); National Institutes of Health (search date 13/08/2018); ClinicalTrials.gov (search date 15/08/2018)) for ongoing and recently completed studies.

As this is an intervention review, we ran the Endnote Library of all references through the Cochrane RCT Classifier. Those that were as- sessed as having a 10 or higher probability out of 100 of being an RCT were screened first, followed by those of a lower probability.

\section{Data collection and analysis}

We followed the methods set out in our protocol and documented any discrepancies in the Differences between protocol and review section.

\section{Selection of studies}

Two review authors independently screened all titles and abstracts identified by searches to determine which met the inclusion criteria. We retrieved the full-text articles identified as potentially relevant by at least one review author. Two review authors independently screened full-text articles for inclusion or exclusion. We resolved discrepancies during title and abstract screening and during full-text screening by discussion, and by consultation with a third review author, if necessary, to reach consensus. We listed all potentially relevant papers excluded from the review at this stage as excluded studies, with reasons provided in the Characteristics of excluded studies table. We provided citation details and any available information about the single ongoing study identified. We planned to collate and report details of duplicate publications, so that each study (rather than each report) is the unit of interest in the review; however, this scenario did not arise. We reported the screening and selection process in a PRISMA flow chart (Figure 1) (Liberati 2009). 
Figure 1. PRISMA flow diagram.

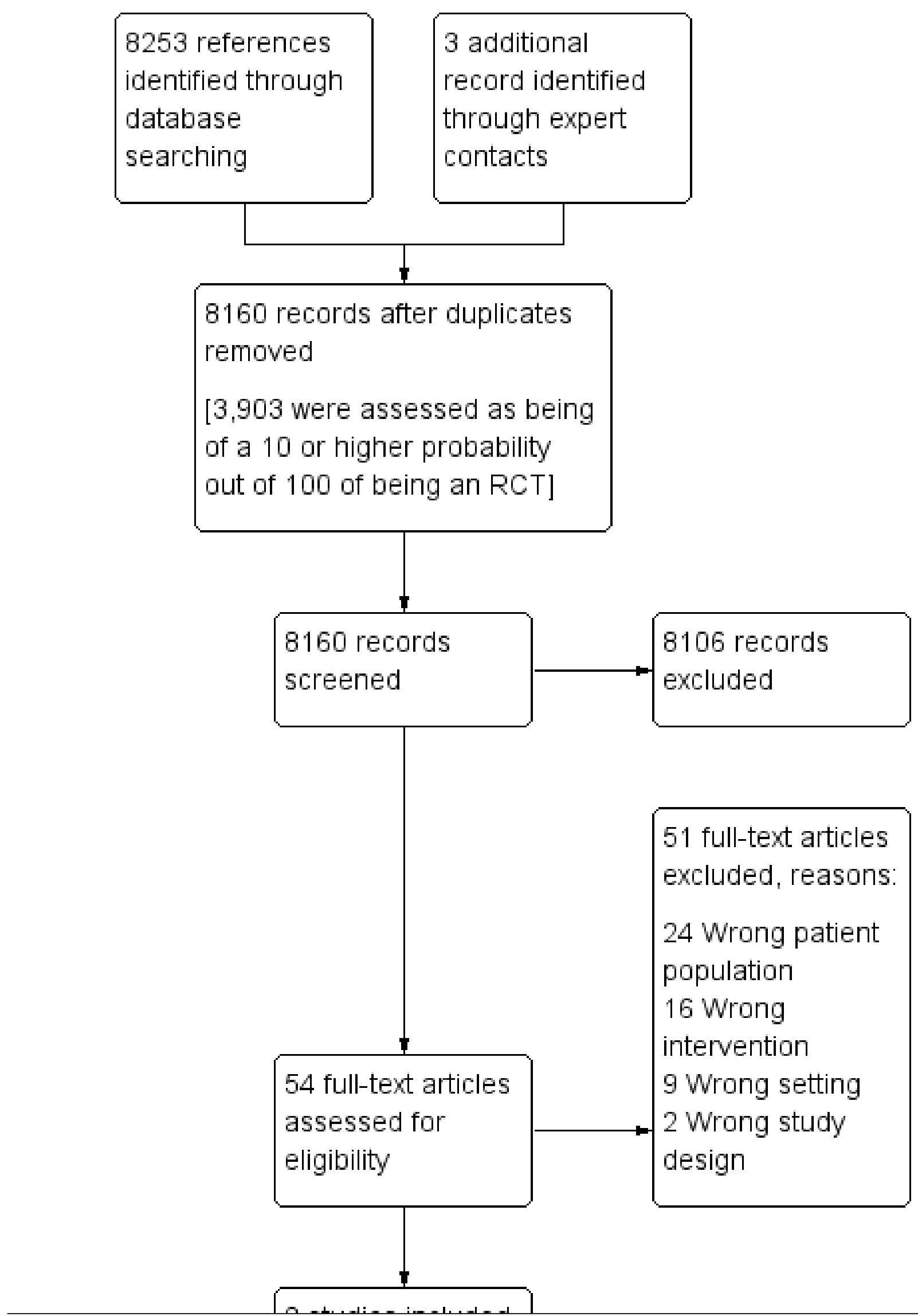

Interventions for involving older patients with multi-morbidity in decision-making during primary care consultations (Review) 


\section{Data extraction and management}

Two review authors began by independently extracting data from included studies using an agreed data extraction template. Any discrepancies were resolved by discussion until consensus was reached, or through consultation with a third review author when necessary. We developed and piloted a data extraction form using the Cochrane Consumers and Communication data extraction template.

We extracted data for the following items: study details (aim of intervention; study design, including type of intervention (practitioner/patient-focused), description of comparison group, recruitment and retention, randomisation, blinding), description of participants (country, setting, age, gender, ethnicity, socioeconomic status, number of long-term conditions, frailty, mobility, receipt of carer support, communication vulnerability (e.g. health literacy, sensory impairment, cognitive impairment, local language proficiency)), exclusions, definition of multi-morbidity used in the study (whether numbers of long-term health problems were listed and counted and types and numbers recorded), types of interventions (patient-/practitioner-/organisation-focused; timing of intervention delivery; whether the intervention involved a single episode of care vs multiple episodes), and outcomes (timing of outcome assessment, primary and secondary outcomes). We adapted the TIDieR checklist to describe the intervention components (Hoffmann 2014).

The Characteristics of included studies table provides more details of extracted data. Outcome data and results of studies were also extracted from included studies.

One review author entered all extracted data into Review Manager 5 (Review Manager 2014), and another review author, working independently, checked them for accuracy against the data extraction sheets.

\section{Assessment of risk of bias in included studies}

We assessed and reported on the methodological risk of bias of included studies in accordance with the Cochrane Handbook for Systematic Reviews of Interventions (Higgins 2011), as well as the guidelines of the Cochrane Consumers and Communication Review Group (Ryan 2013), which recommend explicit reporting of the following individual elements for RCTs: random sequence generation; allocation sequence concealment; blinding (participants, personnel); blinding (outcome assessment); completeness of outcome data; selective outcome reporting; and other sources of bias. Aside from 'selective recruitment of cluster participants' (assessed for cluster-RCTs only), we did not pre-specify any sources of bias for the 'other sources of bias' domain. Therefore, if no new sources of bias were identified, studies were rated at low risk for this domain. We considered blinding separately for different outcomes, as appropriate. We judged each item as being at high, low, or unclear risk of bias, as set out in the criteria provided by Higgins 2011; extracted a quote from the study report; and provided a justification for our judgement for each item in the 'Risk of bias' table.

Studies were deemed to be at highest risk of bias if they were scored as at high or unclear risk for the sequence generation or allocation concealment domain, based on growing empirical evidence that these factors are particularly important potential sources of bias (Higgins 2011).
In all cases, two review authors independently assessed the risk of bias of included studies, with any disagreements resolved by discussion to reach consensus. We contacted study authors for additional information about the included studies, or for clarification of study methods as required. We incorporated results of the 'Risk of bias' assessment into the review through standard tables, systematic narrative description, and commentary about each of the elements, leading to an overall assessment of the risk of bias of included studies and a judgement about the internal validity of review results.

We planned to assess and report quasi-RCTs as being at high risk of bias for the random sequence generation item of the 'Risk of bias' tool. We assessed and reported cluster-RCTs on the risk of bias associated with an additional domain: selective recruitment of cluster participants (described in Ryan 2013). We did not plan to restrict any meta-analysis to only low risk of bias studies but planned instead to explore the effects of risk of bias through sensitivity analysis.

\section{Measures of treatment effect}

For dichotomous outcomes, we analysed data based on the numbers of events and the numbers of people assessed in the intervention and comparison groups. We compared risks, odds and rates of events, reporting risk ratios, odds ratios, and rate ratios with $95 \%$ confidence intervals (Cls). For continuous measures, we analysed data based on mean, standard deviation (SD), and number of people assessed for both intervention and comparison groups to calculate mean difference (MD) and $95 \% \mathrm{Cl}$. We planned, when the MD was reported without individual group data, to use this to report study results. For the included cluster-RCT, data were skewed; therefore we presented data based on median and interquartile range as reported by study authors, and used the generic inverse variance method, with data adjusted to account for the intracluster correlation coefficient (ICC), to present the findings. If more than one study measured the same outcome using different tools, we had planned to calculate the standardised mean difference (SMD) and the $95 \% \mathrm{Cl}$ using the generic inverse variance method in Review Manager 5 (Review Manager 2014); however, this scenario did not occur.

\section{Unit of analysis issues}

We checked included cluster-RCTs for unit of analysis errors. If errors had been found, and sufficient information was available, we planned to re-analyse the data using the appropriate unit of analysis, by taking account of the ICC. We planned to obtain estimates of the ICC by contacting authors of included studies, or to impute them using estimates from external sources. When it was not possible to obtain sufficient information to re-analyse the data, we planned to report effect estimates and to annotate 'unit of analysis errors'. However we found no unit of analysis errors in the included cluster-RCT.

\section{Dealing with missing data}

We contacted study authors to request missing data (participant, outcome, or summary data). For participant data, when possible, we conducted analysis on an intention-to-treat (ITT) basis; otherwise we analysed data as reported. We reported on levels of loss to follow-up and assessed this as a source of potential bias. 
For missing outcome or summary data, we planned to impute missing data and to report any assumptions in the review; however, there were no instances when this was possible. We planned to investigate, through sensitivity analyses, the effects of any imputed data on pooled effect estimates; however, this was not possible due to the small number of included studies.

\section{Assessment of heterogeneity}

We considered whether studies were similar enough (by comparing similarities across interventions and patient populations) to allow pooling of data related to the one common outcome of interest across two studies, using meta-analysis. No statistical pooling was possible. We planned to assess the degree of heterogeneity by visually inspecting forest plots and by examining the $\mathrm{Chi}^{2}$ test for heterogeneity. We planned to quantify heterogeneity using the $I^{2}$ statistic. We planned to consider an $I^{2}$ value of $50 \%$ or more to represent substantial levels of heterogeneity, and we interpreted this value in light of the size and direction of effects and the strength of the evidence for heterogeneity, based on the $P$ value from the $\mathrm{Chi}^{2}$ test (Higgins 2011). When heterogeneity was found in pooled effect estimates, we planned to explore possible reasons for variability using narrative analysis.

We determined that studies were not similar enough to allow pooling of outcome data using meta-analysis due to clinical, methodological, and statistical heterogeneity and reporting of dissimilar outcome measures in relation to our outcome categories. We therefore did not report pooled results from meta-analysis but instead used a narrative approach to data synthesis. We attempted to explore possible clinical or methodological reasons for variation in the data by grouping studies that were similar in terms of populations, intervention features, or methodological features to explore differences in intervention effects.

\section{Assessment of reporting biases}

We assessed the likelihood of reporting bias qualitatively based on the characteristics of included studies (e.g. when only small studies that indicate positive findings were included in the review), and when information that we obtained by contacting experts and authors of studies suggested that there were relevant unpublished studies.

Insufficient studies were included in the review to allow construction of a funnel plot and formal testing of asymmetry, which may indicate publication bias. Should enough studies be included in future updates of the review, we will plan to undertake these analyses, with the choice of test based on advice in Higgins 2011.

\section{Data synthesis}

We decided whether to meta-analyse data based on whether the interventions in included trials were similar enough in terms of participants, settings, interventions, comparisons, and outcome measures to ensure meaningful conclusions from a statistically pooled result. Due to expected variability in the populations and interventions of our few included studies, we planned to use a random-effects model for meta-analysis. Random-effects models are particularly flawed when there are only a few studies, as there are not enough data points to calculate $\operatorname{tau}^{2}$ (the estimate of the variance of the distribution of effects between studies); therefore, the review authors decided that it was not appropriate to use meta-analysis for the only common outcome measure, which was reported by only two studies.

We were unable to consider pooling any other outcome data statistically using meta-analysis due to variability in terms of the outcome measures reported by included studies. We therefore conducted a narrative synthesis of results. We presented the major outcomes and results organised by pre-specified outcome categories within the main comparisons of the review.

- Intervention versus control.

- Intervention versus usual care.

- One form of intervention versus another form of intervention.

If studies compared more than one intervention, we had planned to compare each separately to no intervention/control, and to one another; however, no included studies compared more than one intervention.

Narrative synthesis was used to explore the relationships between study findings. A general framework was followed, as recommended by Popay 2006: review authors first considered the theory behind the included interventions (as reported by study authors) and compared the similarities and differences between the theory applied by included studies, using knowledge of the field to develop a conceptual model of the theory underlying the included interventions. Review authors then conducted a preliminary synthesis of study findings, explored relationships in the data and referred back to the theoretical model when interpreting these, and finally considered the robustness of the synthesis.

\section{Subgroup analysis and investigation of heterogeneity}

We anticipated that potential subgroups for analysis would include type of intervention (e.g. patient-focused vs practitioner-focused); timing of intervention delivery, either before or during a consultation; and whether the intervention involved a single episode of care versus multiple episodes (and whether these were with the same practitioner). We had planned to carry out subgroup analyses investigating intervention type and delivery, as these would be of most relevance to practitioners and policy makers looking to implement these types of interventions into practice, to inform them regarding the most effective approach. To reduce the chance of observing spurious results by undertaking too many subgroup analyses, we planned to limit subgroups to those of most relevance to this review. However, there were too few included studies to warrant any type of subgroup analyses, as only two studies were included per comparison for the review.

\section{Sensitivity analysis}

Too few studies, with dissimilar outcome measures, were included to allow for a thorough sensitivity analysis to assess the robustness of results, including the impact of notable assumptions, imputed data, and inclusion of studies at high risk of bias. We planned to remove lower-quality studies from the analysis to see how robust the results would be when based only on higher-quality studies; however, too few studies were included for this to be feasible. We instead classified studies to be at high, low, or uncertain risk using the Cochrane 'Risk of bias' tool (Higgins 2011), and we referred to these classifications during our narrative synthesis of results.

We had also planned to consider formally comparing 'Risk of bias' assessments using meta-regression; however, a minimum of 10 
studies is recommended for meta-regression for each variable included in the model (Thompson 2002). Therefore this also was not feasible.

\section{'Summary of findings' tables}

We prepared Summary of findings for the main comparison and Summary of findings 2 to present the results for each of the major primary outcomes, including the primary adverse outcome, as outlined in the Types of outcome measures section (with results presented narratively). We converted results into absolute effects when possible. Assumed risks cited in the tables were based on the mean or median risk (dependent on data reported by study authors) and on ranges of risks in the control groups of included studies. We used the GRADE criteria to rank the quality of the evidence based on the methods described in Chapter 11 of the Cochrane Handbook for Systematic Reviews of Interventions (Schünemann 2011).

We used GRADEpro software to prepare the tables (GRADEpro GDT 2015).

\section{Ensuring relevance to decisions in health care}

The protocol and the review received feedback from one consumer referee in addition to a content expert as part of the Cochrane Consumers and Communication Review Group's standard editorial process.

Using links with the patient involvement group from the National Institute for Health Research (NIHR) Collaboration for Leadership in Applied Health Research and Care, South West Peninsula (PenCLAHRC), we established a group of eight older members of the public who have varying degrees of morbidity and varying health service experiences. We arranged workshops to enable these $\mathrm{Pa}$ tient and Public Involvement group members to advise on the direction of the review and to ensure end-user relevance of the presentation of our results.

The lead author is a general practitioner (GP) and therefore has insight into the relevance of our review to primary health care. In addition, we sought the opinions of content experts, including primary healthcare practitioners with a special interest in older patients and experts on shared decision-making, regarding relevant evidence and theory, and asked for critical appraisal of our review methods and results. We discussed methods of delivering our results that are acceptable, engaging, and sustainable in context, giving consideration to resource allocation, recruitment issues, and the format of future evaluation.

\section{RES U L T S}

\section{Description of studies}

\section{Results of the search}

In total, we identified 8253 citations from electronic database searches and three additional records from expert contacts in the research area of interest (see PRISMA diagram in Figure 1). After removing duplicates, two review authors screened 8160 studies by title and abstract, excluding 8106 . A total of 54 remaining full-text articles appeared to be of relevance to the review. Of these, two review authors excluded 51 articles (see Characteristics of excluded studies table for reasons for exclusion). We did not identify any studies awaiting classification but found one ongoing study that was relevant to the review.

\section{Included studies}

The remaining three articles provided data on three studies that met our inclusion criteria. The three included studies, involving 1879 participants in total, provided results from three countries: USA $(n=1)$, Australia $(n=1)$, and UK $(n=1)$. Study details are summarised below, and an in-depth description is provided in the Characteristics of included studies table.

\section{Design}

All included studies were reported as RCTs (Hochhalter 2010; Reed 2018; Salisbury 2018). Hochhalter 2010 and Reed 2018 were parallel-group trials, randomised at patient level, each with a study duration of six months. Salisbury 2018 was cluster-randomised at the practice level with the trial carried out over 15 months.

The three studies differed in their approach to comparator groups: Hochhalter 2010 used three arms, comparing the intervention to an attention-control group as well as to usual care; Reed 2018 used two arms, comparing the intervention to an attention-control group; and Salisbury 2018 used a two-arm design to compare the intervention with usual care.

As expected by the review authors, studies differed in their definition of multi-morbidity; however, all three study definitions could be encompassed by the review's definition of 'more than one longterm health problem'.

\section{Sample size}

Total numbers of randomised participants per study were as follows: Hochhalter 2010 - $\mathrm{n}=79$; Reed 2018 - $\mathrm{n}=254$; and Salisbury $2018-\mathrm{n}=1546$ (33 practices: 16 intervention, 17 usual care).

\section{Setting}

The studies were conducted in three different countries. Whilst all studies were from developed countries and all fulfilled our prespecified criteria for a primary care setting, differences in primary health care delivery between USA, UK, and Australia are evident.

Both Hochhalter 2010 and Reed 2018 report that their intervention was delivered at patients' usual primary care clinics or at patients' homes; however, Reed 2018 reported that intervention providers were not members of patients' usual primary care teams, and the review authors assumed that this was also the case for Hochhalter 2010, although it was not explicitly reported. In contrast, Salisbury 2018 reported that the intervention was delivered by named responsible members of the primary care team, and that it was delivered at the patient's usual general practice.

\section{Participants}

Full details of participant characteristics are provided in the Characteristics of included studies table.

Only Hochhalter 2010 specified in its inclusion criteria that patients should be 65 years of age or older; however, it was possible to determine (as outlined in the review protocol) that for each study, $75 \%$ or more of the patient population was 65 years of age or older. The average number of long-term conditions per patient was greater than three in all studies. 
Each of the studies excluded some important patient groups of relevance to the review. Those with travel difficulties, receiving hospice care, or diagnosed with dementia were excluded by Hochhalter 2010, and information was insufficient to allow conclusions about other groups, including people with a disability. However, the mean Charlson Comorbidity Index at baseline for all groups in Hochhalter 2010 was low, suggesting that those with high risk of mortality from the combination of their chronic illnesses had not been included. Reed 2018 excluded those residing in a long-term care facility, those with terminal illness, those with cognitive impairment, those with hearing loss, and those who did not speak English. Salisbury 2018 reported that those with a life expectancy of less than 12 months and those 'unable to complete the questionnaire in English' were excluded.

Both Hochhalter 2010 and Salisbury 2018 participants were predominantly of white ethnicity; however, Reed 2018 did not provide information on ethnicity - only on country of birth.

\section{Interventions}

Detailed descriptions of the interventions are provided in the Characteristics of included studies table.

Both Hochhalter 2010's 'Making the Most of Your Healthcare' intervention and Reed 2018's 'Chronic Disease Self-Management Support (CDSMS)' programme were patient-focused interventions using theory- and evidence-based behaviour change techniques. Salisbury 2018's '3D' intervention was both patient- and practitioner-focused and addressed organisational change. The intervention was designed to encapsulate recent international guidance and strategies for management of patients with multi-morbidity.

Hochhalter 2010 used a workshop and individual 'coaching' phone calls, both delivered by the research team, with the aims of improving both patients' engagement during healthcare appointments with their usual clinicians and their health-related quality of life. Reed 2018 used individual coaching home visits and phone calls, during which a clinician from the research team used three standardised assessment and planning tools to "actively assist participants to achieve actions and goals" and to develop a care plan in collaboration. The intervention was delivered with the aim of improving patient skills and confidence in managing their long-term conditions. Salisbury 2018 replaced patients' usual disease-focused reviews of each health condition with one six-monthly comprehensive multi-disciplinary review (consisting of two appointments) with the patient's healthcare team. The intervention utilised an integrated electronic template and was delivered with the aim of improving "continuity, coordination and efficiency of care" for patients with multi-morbidity.

All three interventions featured content related to patient involvement in decision-making: Hochhalter 2010's workshop included content on 'making decisions with your doctor' and provided social support through group discussion about barriers to shared decision-making. Reed 2018's tools focused on facilitated goal-setting and active, collaborative decision-making (between patients and clinicians) and care plan development and review. Salisbury 2018 encouraged patients to "think about the health problems that bothered them the most" and trained clinicians to identify patient priorities and to agree and document a holistic, collaborative health plan, guided by the patient's priorities.
All three interventions had components that were tailored to the context of their patient participants' individual healthcare needs.

We provide a summary of the key components of the three interventions from the included studies below.

- Patient workshop and individual patient coaching: to provide tools and skills for preparation for consultations, communication with doctors, and follow-through with collaboratively made plans (using evidence-based behaviour change techniques) (Hochhalter 2010).

- Individual patient coaching: to increase patients' skills and confidence in managing their chronic diseases (utilising cognitive-behavioural therapy (CBT) and motivational interviewing (MI) techniques) (Reed 2018).

- Holistic patient review with practitioner training and organisational change: comprehensive multi-disciplinary patient review to improve continuity, co-ordination, and efficiency of care (Salisbury 2018).

\section{Outcomes}

None of the included studies reported the primary outcome of the review - 'evidence of patient involvement in decision-making'. However, all included studies provided data related to three or more of the secondary review outcomes, namely, health status; treatment burden; patient enablement and engagement; patient evaluation of care/the intervention; carer evaluation of care; resource use and cost; and quality of care. When studies reported more than one outcome per category, the highest-ranked outcome (as outlined in the methods section) is presented for each study in the Characteristics of included studies table. All secondary outcomes included in 'Summary of findings' tables were measured by studies, both at baseline and at the end of the trial.

None of the included studies reported the primary adverse outcome of less patient involvement as a result of the intervention. In respect to the other adverse outcomes of interest for this review, all studies measured accident and emergency department attendance and hospital admissions, although only two studies reported on these outcomes. These outcomes were extracted in the 'resource use and cost' category, and review authors planned to consider an increase in these outcomes as a result of the intervention as an adverse event. One study additionally reported on patient death and patient anxiety.

\section{Theory}

The aim of the Hochhalter 2010 intervention was to improve patient engagement and health-related quality of life through coaching workshops and telephone calls to stimulate behaviour change in older patients with multi-morbidity. Intervention components were developed according to the self-determination theory of motivation (Ryan 2000). This theory recognises three types of motivation for behaviour change in individuals: perceived 'competence' for a behaviour; perceived 'autonomy' (choice) of behaviour; and 'relatedness' of the behaviour to achieving personal goals. The review authors interpret that Hochhalter 2010's 'Making the Most of Your Health Care' intervention therefore provided information, offered tools, and taught skills with the aim of providing older patients with multi-morbidity with the ability and self-efficacy to become involved in decision-making about their health care: to choose to prepare for healthcare appointments; to choose to 
communicate effectively to gather information and support of relevance to their individual needs during healthcare appointments; and to choose to follow through on plans of care that were relevant to their own personal goals.

Reed 2018's 'Chronic Disease Self-Management Support' (CDSMS) intervention similarly aims to increase patients' "skills and confidence" but in relation to condition management, as compared to Hochhalter 2010's aim of improving patient engagement. Reed 2018 argues that motivation and information alone are not sufficient to empower older people with multi-morbidity to become involved in decision-making about their health care (Sevick 2007). Reed 2018 also considers the need for any behaviour change to be sustained (or habitual). Study authors report that these patients can often feel overwhelmed by complex health information and treatment regimens, and that these problems are amplified by the cognitive decline associated with multi-morbidity in older age. The review authors interpret that Reed 2018's CDSMS intervention was developed with the aim of providing older patients with the information and skills needed to identify problems and goals (in the hope that these behaviours become sustained/habitual), to reduce the burden of information-processing associated with self-management of multiple long-term conditions, and to enable patients to develop plans to address healthcare priorities with their clinician.

Like Reed 2018, Salisbury 2018 acknowledges the potential burden of care for patients with multi-morbidity, stating that "if each condition is considered in isolation, patients can be prescribed numerous drugs and lifestyle changes, and are expected to attend frequent health-care appointments". The patient-centred care model used in the ' $3 \mathrm{D}$ ' intervention is therefore designed to replace multiple reviews for a patient's individual chronic conditions with one multi-dimensional, multi-disciplinary, comprehensive review of the patient's multiple conditions. Study authors also report that intervention components focus on addressing patient priorities and on motivating and training clinicians to take a holistic approach when making decisions collaboratively with the patient.

All three studies highlight the importance of priority-setting for older patients with multi-morbidity and the challenges of patient-clinician agreement regarding healthcare priorities.
The theory underpinning the included interventions, as reported by study authors, can be considered in the context of the wider literature regarding behaviour change; however, it is beyond the scope of this review to perform a full analysis of the interventions in this respect. The Michie 2011 systematic review of frameworks of behaviour change interventions found three essential conditions that must all be present for behaviour change to occur: capability, opportunity, and motivation. Hochhalter 2010 addressed capability and motivation using individual coaching (to 'activate' patients for involvement in decision-making about their health care) and socially supportive group workshops (which included discussion of potential barriers for involvement). The review authors also perceive that, by acknowledging the patient's autonomy/choice to become involved in decision-making and by providing the communication support tools to facilitate patient involvement, Hochhalter 2010 addresses the opportunity for behaviour change. Reed 2018 similarly addressed the skills and motivation of patients by utilising cognitive-behavioural therapy and motivational interviewing techniques, and by working on patients' self-efficacy for involvement in decision-making. Reed's aim for sustained behaviour change, whereby patient identification of personal goals and priorities becomes habitual behaviour, would provide further motivation for patients' continued involvement in decision-making about their health care. The review authors interpret that Reed's intervention was also designed to provide opportunity for patient involvement by reducing the burden of information-processing for patients and thereby reducing the potential complexity of the decision-making process. Salisbury 2018's intervention addressed organisational factors including continuity and multi-disciplinary involvement to provide the opportunity for behaviour change; the skills and motivation needed for the desired behaviours were addressed by asking patients to consider their priorities and by training multi-disciplinary practitioners to holistically manage these priorities.

A conceptual model of the theory behind all three interventions, as described by the included studies, and set in the context of both the wider behaviour change literature and that of the outcomes of interest for this review, was developed by JB and is presented in Figure 2. 
Figure 2. A conceptual model of the theory underpinning the included interventions, in the context of the wider behaviour change literature and outcomes of interest for this review.

\begin{tabular}{|c|c|c|c|}
\hline & $\begin{array}{l}\text { Patient group workshop and } \\
\text { individual coaching }\end{array}$ & $\begin{array}{l}\text { Individual patient coaching } \\
\text { utilising cognitive behavioural } \\
\text { therapy and motivational } \\
\text { interviewing techniques }\end{array}$ & $\begin{array}{l}\text { Holistic patient review with } \\
\text { practitioner training and } \\
\text { organisational change }\end{array}$ \\
\hline \multirow{3}{*}{ 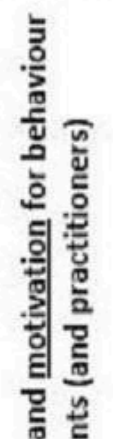 } & \multirow{2}{*}{\multicolumn{3}{|c|}{ Application of behaviour change theories }} \\
\hline & & & \\
\hline & & $\begin{array}{l}\text { Provide patients with the } \\
\text { information and skills for } \\
\text { involvement in decision-making } \\
\text { about their health care. }\end{array}$ & $\begin{array}{l}\text { Provide multidisciplinary practitioners } \\
\text { with the knowledge, skills and } \\
\text { attitudes to involve patients in } \\
\text { decision-making about their health } \\
\text { care. }\end{array}$ \\
\hline
\end{tabular}

Motivate and activate patients by addressing self-efficacy through coaching for involvement in decision-making prior to consultations with health care practitioners.

Relate patients' skills to their ability to achieve goals by reviewing any potential barriers to involvement in decision-making about their health care.

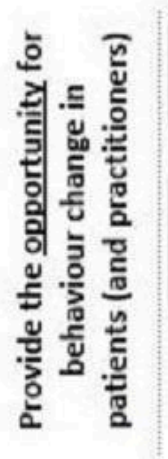

$\begin{aligned} & \text { Acknowledge the patient's } \\ & \text { autonomy/choice to be involved in } \\ & \text { decision-making about their care. }\end{aligned}$
$\begin{aligned} & \text { Reduce the burden of information processing for patients (associated with } \\ & \text { the management of multiple conditions). }\end{aligned}$
$\begin{aligned} & \text { Provide communication support tools } \\ & \begin{array}{l}\text { Provide continuity of care with } \\ \text { individual practitioners. }\end{array}\end{aligned}$
to facilitate patient involvement in decision-making about their health care.

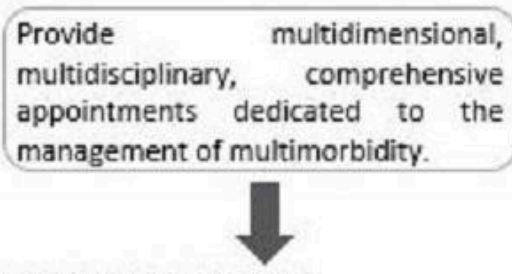

PATIENT INVOLVEMENT IN DECISION-MAKING ABOUT THEIR HEALTH CARE

Patients convey individualised health care goals and priorities to the health care practitioner.

Patients communicate effectively with the practitioner in order to gather information of relevance to their health care needs.

Practitioners carry out a
comprehensive review of multiple
conditions and take a holistic
approach when considering
management options.

Patients and clinicians collaboratively develop plans to achieve patients' health care goals and to address their priorities.
Patients follow through with collaboratively made health care plans.

\section{Achievement of other desirable outcomes}


All of the data reported in this review were obtained from published literature and through clarification by correspondence with the authors of two of the studies. The review authors did not have access to unpublished data. Correspondence with the authors of Hochhalter 2010 was not successful. For Reed 2018, correspondence with authors by email provided clarification that the questions related to participant feedback were collected by using participant self-report questionnaires. Answers to the review authors' queries regarding Salisbury 2018 were provided through access to the full trial report.

\section{Excluded studies}

We excluded 51 studies (see Characteristics of excluded studies). Reasons for exclusion were wrong patient population, wrong intervention, wrong setting, and wrong study design.

\section{Risk of bias in included studies}

Risk of bias in the included studies is illustrated in the risk of bias graph (Figure 3), as well as in the risk of bias summary (Figure 4). The review authors' ratings for each type of bias per study are presented, along with reasons, in the Characteristics of included studies table. None of the studies were rated at high risk of bias for any of the individual criteria assessed.

Figure 3. Risk of bias graph: review authors' judgements about each risk of bias item presented as percentages across all included studies.

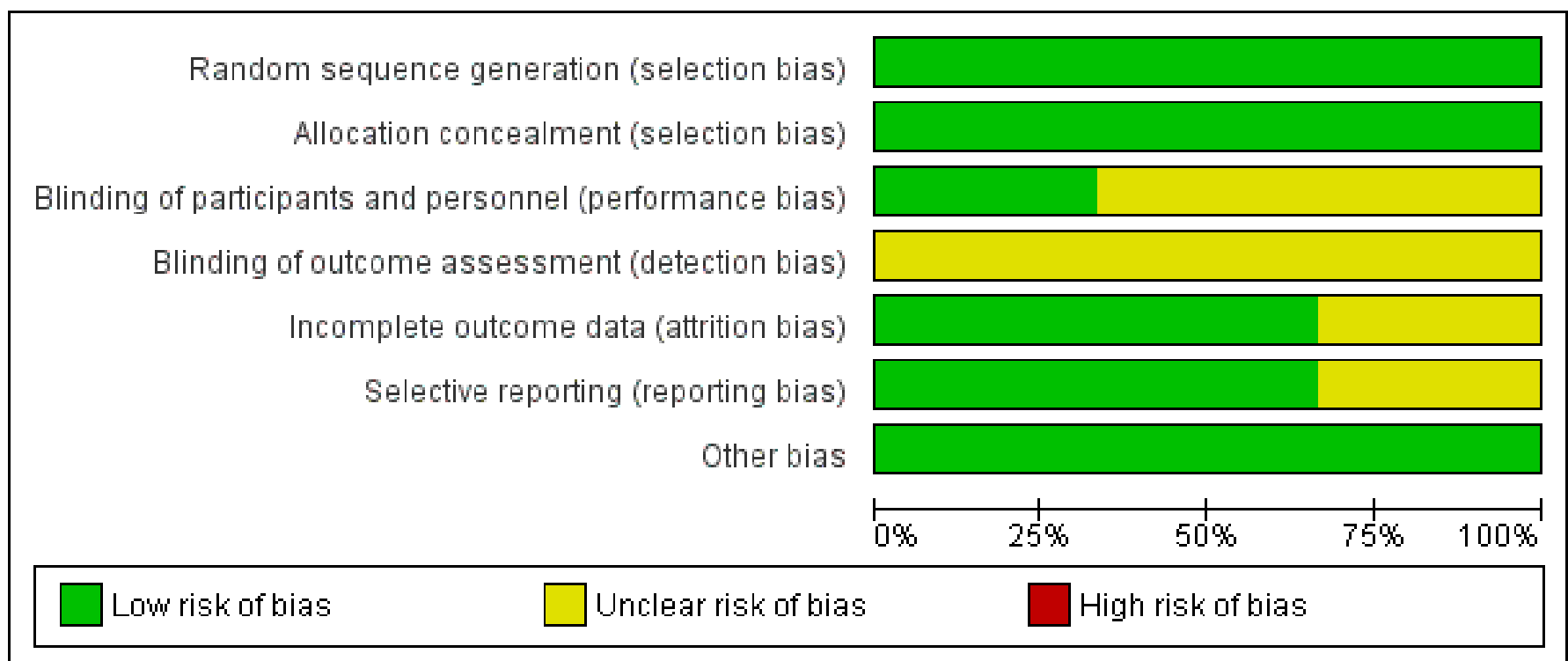


Figure 4. Risk of bias summary: review authors' judgements about each risk of bias item for each included study.

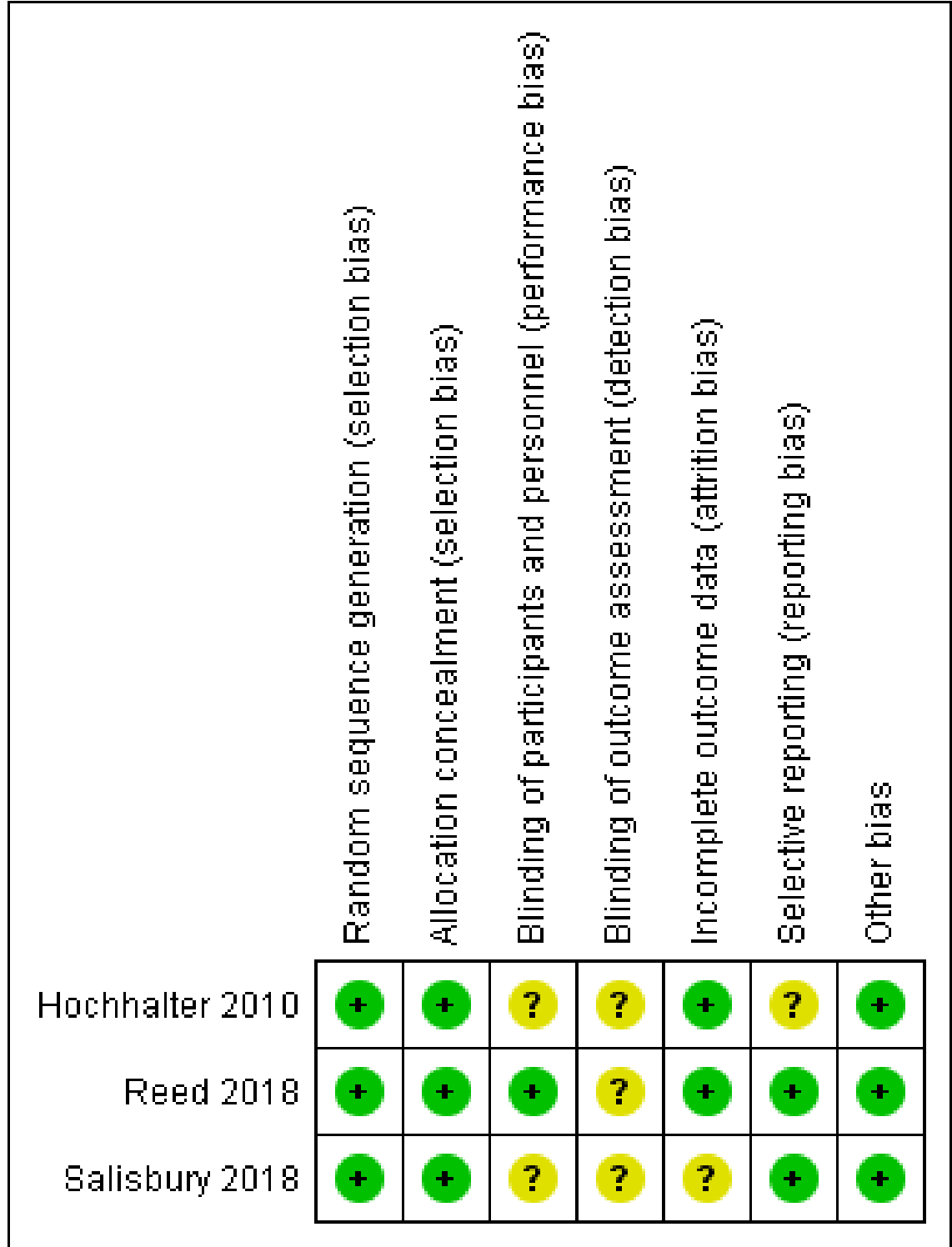

\section{Allocation}

All three studies were at low risk for selection bias. All studies used computer-generated randomisation sequences with central allocation, with randomisation taking place after enrolment.

\section{Blinding}

The review authors considered subjective and objective measures separately regarding performance and detection bias.

Reed 2018 reported incomplete blinding (of participants but not research personnel); however, review authors judged that all outcomes measured were not likely to have been influenced by this, and therefore rated Reed 2018 at low risk for performance bias. Review authors assumed that blinding of participants and personnel was not possible for Hochhalter 2010; however, the study was rated at unclear risk of bias, as review authors were unsure whether this could have affected reported outcomes. Salisbury 2018 was also rated as unclear for performance bias, as blinding of participants and personnel was not undertaken, and again, it is unclear whether this affected outcomes.

All three included studies were rated at unclear risk for detection bias: Hochhalter 2010 was rated as unclear overall, as outcomes of interest were assessed by patient self-report and patients were not blinded; additionally, the study authors did not report whether those extracting data from patients' electronic health records were blinded; Reed 2018 reported insufficient information to make the judgement; and Salisbury 2018 did not report blinding of outcome assessment for all outcomes.

\section{Incomplete outcome data}

Hochhalter 2010 was judged at low risk for attrition bias: the study authors used an intention-to-treat (ITT) analysis; there was some imbalance in participant numbers between groups, but review authors concluded that the imbalance was not enough to classify the study as high risk. Reed 2018 also conducted an ITT analysis, and attrition was balanced with the method of imputation clearly re- 
ported; this study was therefore judged to be at low risk for attrition bias. Salisbury 2018 conducted an ITT analysis. Data for some outcomes ('treatment burden' and 'proportion of patients who discussed the problems most important to them' at 15 months' follow-up) were lacking; however, the method of imputation was reported for the primary outcome of the study 'quality of life'. Review authors judged that information was insufficient to allow a clear judgement on attrition bias.

\section{Selective reporting}

Hochhalter 2010 reported that researchers had measured certain outcomes at baseline and at six months; however, some of these data were not reported, namely, 'number of outpatient/clinic visits'. Review authors were unable to find the protocol or trial registration for Hochhalter 2010 and received no response after attempting to contact the study authors; therefore, this study was judged to be at unclear risk for reporting bias. The protocol was available for Reed 2018, and all of the study's pre-specified outcomes had been reported in the pre-specified way. The protocol was available for Salisbury 2018, and all pre-specified outcomes were reported either in the paper or in the full report (Salisbury 2018); therefore this study was judged to be at low risk of reporting bias.

\section{Other potential sources of bias}

Salisbury 2018 was additionally assessed for selective recruitment of cluster participants. This study was judged to be at low risk, as cluster participants were recruited before group assignment and the same participants were followed up over time.

Salisbury reported that an intracluster coefficient (ICC) of 0.03 was assumed for clustering at the practice level based on a previous trial (Kennedy 2013).

Review authors noted no other obvious sources of bias in any of the three included studies.

\section{Effects of interventions}

See: Summary of findings for the main comparison Interventions for involving older patients with multi-morbidity in decision-making about their health care compared to usual care for older patients with multi-morbidity; Summary of findings 2 Interventions for involving patients in decision-making about their health care compared to attention-control conditions for older patients with multi-morbidity

Components of the three interventions were summarised in the Description of studies section as follows.

- Patient workshop and individual patient coaching using evidence-based behaviour change techniques (Hochhalter 2010).

- Individual patient coaching utilising cognitive-behavioural therapy and motivational interviewing (Reed 2018).

- Holistic patient review with multi-disciplinary practitioner training and organisational change (Salisbury 2018).

None of the studies reported the primary outcome of the review - evidence of patient involvement in decision-making about their health care. Also, no studies reported the primary adverse outcome of less patient involvement in decision-making as a result of the intervention.
Due to the small number of included studies and substantial clinical and methodological heterogeneity between studies, it was not possible to conduct a meta-analysis of findings. Therefore, the findings from a limited narrative synthesis are presented to explore the relationships between study findings related to the pre-specified secondary outcome categories. We planned to follow a general framework, as recommended by Popay 2006: review authors first considered the theory behind the study interventions (see Description of studies section), then conducted a synthesis of the findings of studies exploring relationships in the data, and finally assessed the robustness of the synthesis. (Considerations regarding the robustness of the synthesis are presented in the Discussion sections Quality of the evidence and Potential biases in the review process.)

Findings are presented below, and those ranked of greatest clinical relevance and importance to the review's readers are summarised in Summary of findings for the main comparison and Summary of findings 2 , by outcome category per comparison.

Two comparisons are presented.

- What are the effects of interventions to involve patients in decision-making about their health care versus usual care for older patients with multi-morbidity in primary care?

- What are the effects of interventions to involve patients in decision-making about their health care versus attention-control conditions for older patients with multi-morbidity in primary care?

No studies reported findings consistent with the third pre-specified comparison for the review: "What are the effects of an intervention to involve patients in decision-making about their health care versus an alternative intervention to involve patients in decision-making about their health care for older patients with multi-morbidity?"

As only Hochhalter 2010 compared the intervention to both usual care and attention-control conditions, findings from only two studies can be presented per comparison.

\section{What are the effects of interventions to involve patients in decision-making about their health care (patient workshop and individual coaching, holistic patient review plus multi- disciplinary practitioner training, and organisational change) versus usual care for older patients with multi-morbidity?}

Hochhalter 2010 and Salisbury 2018 compared intervention to usual care. Whilst both studies reported outcomes of relevance to common outcome categories for the review, these studies did not measure any of the same outcomes. We report their findings below by outcome category.

\section{Patient and carer outcomes - health status}

Hochhalter 2010 measured patient-reported 'self-rated health' using the 5-point Centers for Disease Control and Prevention (CDC) 'Healthy Days Measure' (CDC 2000). From these study findings, it is uncertain whether the 'Making the Most of Your Health Care' intervention affects participant reports of high self-rated health when compared to usual care at six months (risk ratio (RR) 1.40 , 95\% confidence interval $(\mathrm{Cl}) 0.36$ to $5.49 ; \mathrm{P}=0.63$; very low-certainty evidence (Analysis 1.1)). Certainty of evidence was downgraded for imprecision (small sample size), and because results were drawn from a single study in a developing evidence base. 
Salisbury 2018 measured health-related quality of life using patient-reported EuroQoL Group Quality of Life Questionnaire based on a five-level scale (EQ-5D-5L) scores (Herdman 2011). This study's primary analysis with missing data imputed suggests that there is probably no difference between study groups in health-related quality of life at 15 months (adjusted difference in means $0.00,95 \%$ $\mathrm{Cl}-0.02$ to $0.02 ; \mathrm{P}=1.00$; moderate-certainty evidence (Analysis 1.2)). Certainty of evidence was downgraded because all results were drawn from a single study in a developing evidence base. Also, performance bias and detection bias were unclear, which had the potential to affect the outcome; however, this was not considered a 'serious' risk.

Both measures of health status were considered clinically important by review authors; therefore, both are reported in Summary of findings for the main comparison.

\section{Patient and carer outcomes - treatment burden}

Salisbury 2018 measured treatment burden by asking patients to complete the Multi-morbidity Treatment Burden Questionnaire (MTBQ) (Duncan 2018). There is probably no difference in MTBQ score (mean (SD)) between intervention (12.9 (15.0)) and control $(15.0(17.1))$ at 15 months, based on an adjusted multi-level linear regression model (beta-coefficient $-0.46,95 \% \mathrm{Cl}-1.78$ to 0.86 ; $\mathrm{P}=$ 0.49 ; moderate-certainty evidence (Analysis 1.3 )). Certainty of evidence was downgraded because all results were drawn from a single study in a developing evidence base. Lack of clarity regarding performance bias and detection bias was not considered a 'serious' risk.

\section{Patient and carer outcomes - patient enablement and engagement}

Hochhalter 2010 used the Patient Activation Measure to assess patient enablement as a result of the study intervention (Hibbard 2005). It is uncertain whether there is a difference between intervention and usual care groups in Patient Activation Measure scores at six months (mean difference (MD) $0.60,95 \% \mathrm{Cl}-9.23$ to 10.43 ; $P$ $=0.9$; very low-certainty evidence (Analysis 1.4)). Certainty of evidence was downgraded for imprecision (small sample size), and because results were drawn from a single study in a developing evidence base. Lack of clarity regarding performance bias, detection bias, and reporting bias had the potential to affect the outcome; however, this was not considered a 'serious' risk.

Salisbury 2018 used the Morisky Medication Adherence Scale to measure medication adherence (Morisky 2008), which the review authors considered to be an aspect of patient engagement. Salisbury's findings suggest that there is probably no difference in score (mean (SD)) between intervention (6.7 (1.2)) and control (6.6 (1.3)) at 15 months based on an adjusted multi-level linear regression model (beta-coefficient $0.06,95 \% \mathrm{Cl}-0.05$ to 0.17 ; $\mathrm{P}=0.28$; moderate-certainty evidence (Analysis 1.5)). Certainty of evidence was downgraded because all results were drawn from a single study in a developing evidence base. Lack of clarity regarding performance bias and detection bias was not considered a 'serious' risk.

\section{Patient and carer outcomes - patient evaluation of care/the intervention}

Salisbury 2018 reported on aspects of patient evaluation of the care received. Study authors used a single question adapted from the National Health Service (NHS) General Practice Patient Survey and dichotomised the 5-point scale by patient reports of discussing their most important problems ('almost always' vs 'not at all' + 'rarely' + 'some of the time') (Ipsos MORI 2015). Study findings suggest that there were probably greater numbers of intervention participants $(42 \%)$ than control participants $(26 \%)$ reporting that they 'almost always discuss the problems most important to them in managing their own health' at 15 months. Salisbury 2018 reported findings from multi-level ordinal logistic regression (adjusted odds ratio $1.85,95 \% \mathrm{Cl} 1.44$ to $2.38 ; \mathrm{P}<0.00001$; moderate-certainty evidence (Analysis 1.6)). Certainty of evidence was downgraded because all results were drawn from a single study in a developing evidence base. Lack of clarity regarding performance bias and detection bias was not considered a 'serious' risk.

\section{Patient and carer outcomes - patient perceptions or ratings of carer support}

None of the included studies measured patient perceptions or ratings of carer support.

\section{Patient and carer outcomes - carer evaluation of care}

Salisbury 2018 was the only study that reported any carer outcomes (data taken from the full trial report). Study authors used a six-item carer experience questionnaire, with responses transformed to a profile measure value between 0 and 100 (Al-Janabi 2011). It is uncertain whether there is evidence of improved carer experience in the intervention arm at 15 months when compared with usual care (adjusted difference in means $6.51,95 \% \mathrm{Cl} 0.25$ to $12.77 ; \mathrm{P}=0.042$; very low-certainty evidence; (Analysis 1.7)). Certainty of evidence was downgraded for imprecision (small sample size), and because all results were drawn from a single study in a developing evidence base. Lack of clarity regarding performance bias and detection bias was not considered a 'serious' risk.

\section{Practitioner outcomes}

The included studies did not measure the review's pre-specified practitioner outcomes: practitioner knowledge and skills; practitioner attitudes (towards the intervention and compliance with it); and practitioner satisfaction with the intervention.

\section{Health service outcomes - resource use and cost}

Resource use was measured in terms of numbers of consultations. Findings for the numbers of outpatient/clinic visits were reported to have been measured but were not published by Hochhalter 2010, and review authors received no response from study authors to their request for these data.

Salisbury 2018 reviewed routine medical records. Findings suggest that patients in the intervention group probably attended more nurse consultations at 15 months when compared with the usual care group (incident rate ratio from adjusted multi-level Poisson model $1.37,95 \% \mathrm{Cl} 1.17$ to $1.61 ; \mathrm{P}=0.0001$; moderate-certainty evidence (Analysis 1.8)). Certainty of evidence was downgraded because all results were drawn from a single study in a developing evidence base. Lack of clarity regarding performance bias and detection bias was not considered a 'serious' risk.

\section{Health service outcomes - quality of care}

Salisbury 2018 looked at indicators of high-risk prescribing as a measure of quality of care by reviewing patients' electronic health records and using an approach developed for a previous trial (Dreis- 
chulte 2016). Study findings suggest that there is probably no difference between intervention and usual care in the number of indicators of high-risk prescribing at 15 months (incident rate ratio from adjusted multi-level Poisson model $1.04,95 \% \mathrm{Cl} 0.87$ to 1.25 ; $\mathrm{P}=0.65$; moderate-certainty evidence (Analysis 1.9)). Certainty of evidence was downgraded because all results were drawn from a single study in a developing evidence base. Lack of clarity regarding performance bias and detection bias was not considered a 'serious' risk.

\section{Adverse outcomes}

The review's primary adverse outcome of less patient involvement in decision-making than before the intervention was not measured by the included studies.

Salisbury 2018 recorded full details of participant death and reported no differences between intervention and usual care groups and no association between death and the intervention. These investigators also reported no difference in participant anxiety between intervention and usual care groups. Increases in accident and emergency attendances or hospital admissions were also prespecified adverse outcomes for the review. Emergency department visits and hospital admissions were measured by both Hochhalter 2010 and Salisbury 2018; however, these findings were not reported by Hochhalter 2010, and review authors' attempts to correspond with these study authors were unsuccessful. Salisbury 2018 found no difference between intervention and usual care groups with respect to these outcomes.

\section{What are the effects of interventions to involve patients in decision-making about their health care (patient workshop and individual coaching, individual patient coaching) versus attention-control conditions for older patients with multi- morbidity?}

Hochhalter 2010 and Reed 2018 compared intervention to attention-control conditions.

\section{Patient and carer outcomes - health status}

Hochhalter 2010 dichotomised participants' 5-point scores on the CDC 2000 scale for self-reported health and reported low scores ( 1 to 3 ) and high scores (4 to 5). It is uncertain whether more attention-control participants reported high self-rated health when compared to intervention participants at six months (RR 0.38, 95\% $\mathrm{Cl} 0.15$ to $1.00 ; \mathrm{P}=0.05$; very low-certainty evidence (Analysis 2.1)). Certainty of evidence was downgraded for imprecision (small sample size), and because results were drawn from a single study in a developing evidence base.

Conversely, Reed 2018 used a similar 5-point scale initially developed for the US National Health and Nutrition Examination Survey. Review authors converted the 5-point Likert scores reported by Reed 2018 to low scores (1 to 3 ) and high scores (4 to 5 ) to draw comparisons with the findings reported by Hochhalter 2010. From the Reed 2018 data, it is uncertain whether more intervention participants than attention-control participants have high self-rated health scores at six months (RR 2.17, $95 \% \mathrm{Cl} 0.85$ to 5.52; $\mathrm{P}=0.11$; very low-certainty evidence (Analysis 2.1)). Certainty of evidence was downgraded for imprecision (small sample size), and because results were drawn from a single study in a developing evidence base.
Due to high heterogeneity between studies $\left(\mathrm{I}^{2}=85 \%\right.$ on testing a random-effects model for meta-analysis), the results from Hochhalter 2010 and Reed 2018 were not pooled. Findings for both studies are illustrated on a non-pooled forest plot (Analysis 2.1), where the opposite directions of effect can be clearly visualised.

\section{Patient and carer outcomes - treatment burden}

Neither study reported on this outcome.

\section{Patient and carer outcomes - patient enablement and engagement}

Hochhalter 2010 reported Patient Activation Measure scores at six months for attention-control and intervention groups (Hibbard 2005). It is not certain whether there is a difference in Patient Activation Measure score at six months between intervention and attention-control groups (MD 1.20, $95 \% \mathrm{Cl}-8.21$ to $10.61 ; \mathrm{P}=0.8$; very low-certainty evidence (Analysis 2.2)). Certainty of evidence was downgraded for imprecision (small sample size), and because results were drawn from a single study in a developing evidence base. Additionally, 95\% confidence intervals showed no effect.

Reed 2018 measured patient self-efficacy using the 'self-efficacy for managing chronic disease scale' (Stanford 2018). It is not certain whether there is a difference in mean scores between intervention and attention-control groups at six months (MD 0.29, 95\% Cl -0.21 to $0.79 ; \mathrm{P}=0.26$; very low-certainty evidence (Analysis 2.3)). Certainty of evidence was downgraded for imprecision (small sample size), and because results were drawn from a single study in a developing evidence base. Additionally, 95\% confidence intervals showed no effect.

Both of these measures of patient enablement and engagement were considered clinically important by review authors; therefore, both are reported in Summary of findings 2.

\section{Patient and carer outcomes - patient evaluation of care/the intervention}

Reed 2018 measured patient evaluation of care received using the patient self-report to determine whether patients regarded the programme as having changed the management of their health care (correspondence with study authors confirmed that self-report occurred via patient questionnaire, not via interview, as incorrectly stated in the paper). Researchers used a three-point scale, dichotomised for analysis into 'a great deal' versus 'somewhat' + 'not at all'. The intervention may increase the number of participants regarding the programme as 'having changed management' of their health conditions (RR 1.82, 95\% Cl 1.35 to 2.44; $\mathrm{P}<0.0001$; lowcertainty evidence (Analysis 2.4)). Certainty of evidence was downgraded for imprecision (small sample size), and because results were drawn from a single study in a developing evidence base.

\section{Practitioner outcomes}

The included studies did not measure the review's pre-specified practitioner outcomes: practitioner knowledge and skills; practitioner attitudes (towards the intervention and compliance with it); and practitioner satisfaction with the intervention.

\section{Health service outcomes - resource use and cost}

Findings for the numbers of outpatient/clinic visits were not reported by Hochhalter 2010, and the review authors received no correspondence from study authors in response to a request for 
these data. The review authors believe that these data would have contributed to any certain evidence of effect, however, based on GRADE assessments for all other outcomes reported by Hochhalter 2010 alone.

Reed 2018 reported absolute numbers of general practice visits reported by participants. However, it is not certain whether intervention participants reported more general practice visits during the study when compared to attention-control participants at the end of the six-month trial (MD $0.51,95 \% \mathrm{Cl}-0.34$ to 1.36 ; $\mathrm{P}=0.24$; very low-certainty evidence (Analysis 2.5)). Certainty of evidence was downgraded for imprecision (small sample size), and because results were drawn from a single study in a developing evidence base. Additionally, this outcome was measured by patient self-report as opposed to using an objective measure.

\section{Health service outcomes - quality of care}

Neither study reported on this outcome.

\section{Adverse outcomes}

The review's primary adverse outcome of less patient involvement in decision-making than before the intervention was not measured by the included studies.

Emergency department visits and hospital admissions were measured by both Hochhalter 2010 and Reed 2018; however, these findings were not reported by Hochhalter 2010, and attempts to correspond with the study authors were unsuccessful. Reed 2018 reported no difference between intervention and attention-control groups, and therefore no adverse effects of the intervention on either of these outcomes.

\section{DISCUSSION}

\section{Summary of main results}

The results of greatest clinical importance and relevance to the review are summarised in the summary of findings tables based on the pre-specified priority outcome categories (Summary of findings for the main comparison; Summary of findings 2). No studies that measured the primary outcome 'patient involvement in decision-making' were found, and no studies looked at the primary adverse outcome 'evidence of less patient involvement as a result of the intervention'.

From the original 8256 studies identified, three studies were included in the review, with only two studies of relevance per comparison. Some aspects of risk of bias were unclear across studies, particularly in relation to performance bias, detection bias, and reporting bias; however, no studies were rated at high risk for any of the aspects of bias that were assessed.

All but one of the secondary outcomes (namely, health status, treatment burden, patient enablement and engagement, patient evaluation of care/the intervention, carer evaluation of care, resource use and cost, and quality of care) were reported by a single study. Two out of three included studies had small participant numbers; this is the main reason for uncertainty in the review findings.

We are uncertain as to whether interventions for involving patients in decision-making about their health care can improve reports of self-rated health or patient activation for older patients with multi-morbidity when compared with usual care. We are uncertain as to whether interventions for involving patients in decision-making about their health care improve reports of self-rated health, patient activation, or self-efficacy, or alter the number of general practice visits for older patients with multi-morbidity when compared with attention-control conditions.

We can report, with moderate certainty, that compared with usual care, involving patients in decision-making about their health care probably makes little or no difference in patient-reported healthrelated quality of life, or in enablement as assessed via medication adherence, for older patients with multi-morbidity.

However, involving older patients with multi-morbidity in decision-making about their health care probably increases patients' perceptions that the care received is related to their priorities when compared to usual care (moderate-certainty evidence); is probably associated with an increase in the number of nurse consultations when compared to usual care (moderate-certainty evidence); and may increase patient perceptions of changes in the management of their health when compared to attention-control conditions (lowcertainty evidence).

Whilst the primary adverse outcome for this review was not reported, two out of the three included studies reported on hospital admissions and accident and emergency attendances. Studies reported no increase in either of these outcomes as a result of the intervention, when compared with usual care or with attention-control. Therefore, these 'resource use and cost' outcomes were not reported to have been adversely affected by the intervention; however, they have been included in this category of the summary of findings tables for transparency of reporting. The largest included study additionally reported that the intervention had no effect on participant death nor anxiety when compared with usual care.

\section{Overall completeness and applicability of evidence}

Identified studies were not sufficient to address all of the objectives of the review. Whilst the pre-specified primary outcome of the review 'evidence of patient involvement in decision-making' was not the endpoint of the included trials (and therefore was not explicitly measured by any of the included studies), it is apparent in the theoretical underpinning of each of the interventions evaluated by the included trials.

The population investigated in each of the included studies was the participant population pre-specified for the review, and interventions were consistent with those pre-specified. However, only one study had intervention components that focused on practitioners and organisational change, in addition to the focus on patients, which was common to all included studies.

The review authors systematically mapped the outcomes reported in the included studies against the secondary outcome categories identified as of importance in the review protocol. The included studies' outcomes covered nearly all of our pre-specified categories, including patient and carer outcomes of 'health status', 'treatment burden', 'patient enablement and engagement', 'patient evaluation of care/the intervention', 'carer evaluation of care', and the health service outcome of 'resource use and cost'. These studies did not cover any of our pre-specified practitioner outcomes, although one of the studies evaluated an intervention that was partially practitioner-focused. Despite the breadth of coverage of pre-specified outcome categories, due to the small num- 
ber of included studies, there was little overlap in the actual outcome measures used, and this limited the comparability of the specific outcomes reported.

The only findings with any certainty of evidence (of effect or of no effect) were related to the review's outcomes of interest when intervention was compared with usual care. These findings were from Salisbury 2018, which evaluated a complex intervention that involved holistic patient review, multi-disciplinary practitioner training, and organisational change (with moderate-certainty evidence).

Salisbury 2018 found no evidence of a difference between groups in patient-reported health-related quality of life; however, study authors found that larger numbers of 3D intervention participants reported that the care received related to their own priorities. The odds ratio for the latter, of 1.85 , could be clinically meaningful, and the approach used in the 3D intervention resulting in these two outcomes could be generalisable to similar populations from countries other than UK.

Salisbury 2018's finding that, during the trial period, there were more nurse consultations in the intervention group than in the usual care group had an odds ratio of 1.37 and could be interpreted as clinically relevant. This finding may be less applicable in primary care settings where usual practice is not based on nurse-led review of long-term conditions, as it is in UK. However, this finding is interesting, given that the aim of the intervention was to reduce the number of individual disease-focused nurse reviews and to replace them with one multi-disciplinary six-monthly review. Study authors did not report any conclusions regarding this; however, only $49 \%$ of intervention participants had two 3D reviews in 15 months as intended. All intervention and usual care participants had a mean of three long-term conditions from a list of seven, suggesting that usual care participants should have attended at least three annual reviews - one review per condition. Therefore, the intervention may have increased the number of nurse consultations for other reasons, not only for routine review of long-term conditions, and this outcome measure is likely to be vulnerable to confounding. However, without further studies against which to draw comparisons, it is beyond the scope of this review to comment on reasons for these findings without speculation.

When intervention and attention control were compared, the only findings with positive and significant effects were reported by Reed 2018, which assessed the effects of individual patient coaching (with low-certainty evidence). These researchers found that a higher proportion of patient participants receiving the Chronic Disease Self-Management Support (CDSMS) programme felt that the care received had changed management of their health when compared to reports from the attention-control group. The risk ratio of 1.82 suggests that this finding could be clinically meaningful. When older patients are provided with the skills to identify problems and goals, to reduce the burden of information-processing associated with self-management of multiple long-term conditions, and to enable them to address healthcare priorities with their clinician, they perceive greater changes in the management of their health care. This concept could be transferable to other countries, to both primary and secondary care settings, and to any scenario in which changes to the patient's health care are required.

The only outcome that was reported by more than one study was patient 'self-reported health', measured similarly on 5-point scales by both Hochhalter 2010 and Reed 2018 when comparing interventions with attention controls. This was also the only outcome for which Hochhalter 2010 findings came close to showing evidence of effect $(P=0.05)$, but with very low-certainty evidence. Reed 2018 and Hochhalter 2010 reported different directions of effect, however, with Hochhalter 2010 reporting higher self-rated health in the attention-control group, and Reed 2018 favouring the intervention. Hochhalter was a much smaller study than Reed and therefore should carry less weight in the interpretation of these findings; however, when findings from Reed 2018 were dichotomised for comparison with findings from Hochhalter 2010, there was no longer evidence of effect in the Reed 2018 findings and evidence was of low certainty. There were some similarities in the theory underpinning the interventions delivered by both Hochhalter 2010 and Reed 2018, with Reed 2018 additionally aiming to reduce the burden of information-processing for intervention group participants. Although carried out in different countries, intervention delivery was comparable between the two studies, as both used members of the research team to deliver a combination of face-toface components and at-a-distance phone calls; however, Hochhalter 2010 provided a group workshop and Reed 2018 additionally used one-on-one home visits (see Characteristics of included studies). Reed 2018 had greater intensity of intervention delivery, using three home visits and four follow-up phone calls, compared to Hochhalter 2010's one workshop and two phone calls approach. It is difficult to draw comparisons between the two study populations due to lack of, or inconsistency in, reported data. It is tentatively proposed that greater intensity of intervention delivery, when seeking to involve patients in decision-making about their care, might be expected to yield greater improvements in patient self-reported health when compared to less intensive delivery. However, this remains to be tested in robust trials.

In consideration of the comparison groups used by included studies, details provided by study authors were insufficient to enable the review authors to compare the 'usual care' groups used by Hochhalter 2010 and Salisbury 2018. However, the review authors are aware that with these types of complex interventions, the size of the difference between intervention and usual care arm components can often vary greatly between trials. This can lead to heterogeneity in effects. Both of the attention-control groups used by Hochhalter 2010 and Reed 2018 were patient-centred and were given the aim of controlling for the potential positive benefits of receiving attention from a health professional. The provision of 'positive attention' to control participants may explain why there were small, if any, differences between intervention and attention-control groups, however.

\section{Quality of the evidence}

Despite the overall good quality of included studies, the body of evidence identified does not allow for a robust conclusion regarding review objectives. The synthesis was limited due to only three included studies with 1879 participants in total.

Hochhalter 2010 was limited by a small sample size $(n=79)$; the study was therefore likely to lack precision in estimates of effects on secondary outcomes of interest in this review (see Summary of findings for the main comparison; Summary of findings 2). As Hochhalter 2010 was the only study common to both of our comparisons, it is difficult to draw any meaningful conclusions regarding relationships between data provided by the included studies. 
All studies excluded from the trial some potentially important subgroups of the population of interest. Patients excluded by at least one study were those with travel difficulties, those with a terminal illness or receiving hospice care, those with cognitive impairment or diagnosed with dementia, those residing in a long-term care facility, those with hearing loss, and those who do not speak English. Such restrictions may limit applicability of the findings of these studies, even when considered for this highly focused population group.

Only one outcome was commonly measured across studies: 'selfrated health', as measured by Hochhalter 2010 and Reed 2018. However, there was inconsistency in the direction of effect and no strong evidence of effect reported by either study with respect to this outcome, and the certainty of evidence was very low.

The included studies assessed outcomes typically at 6 months and at 15 months, and there was no apparent pattern in these findings in relation to outcome time points. Long-term follow-up of outcomes is important in trials of interventions; however, it may be unrealistic to expect such sustained effects on the outcomes sought by this review for interventions of this type.

Two review authors independently rated the quality of included evidence for the outcomes of interest using the GRADE method and compared assessments (Schünemann 2011). There were no discrepancies in GRADE assessments between review authors. The GRADE assessments for certainty of evidence ranged from very low to moderate across all outcomes. Only some findings from Salisbury 2018, comparing intervention to usual care, were rated with moderate certainty (downgraded from high certainty on the basis that all results were from the same study in a developing evidence base). Therefore, conclusions were drawn regarding probable evidence of effect for those outcomes. The certainty of evidence for each outcome when intervention was compared to attention control was assessed as 'low' or 'very low' (downgraded largely on the basis of small sample size, with all results coming from the same study, and for the one common outcome, because effects were in opposite directions); therefore, all findings for this comparison were interpreted with caution when the narrative synthesis was prepared, and when conclusions for the review were decided. As a result of the low or very low certainty of evidence for many outcome measures, future research is likely to change the findings of this review.

\section{Potential biases in the review process}

The inclusion criteria stated that only randomised controlled trials (RCTs), cluster-RCTs, and quasi-RCTs were to be included in the review. It may be that more relevant studies would have been found by widening the search to include greater methodological heterogeneity. This might allow for a thorough narrative synthesis of findings for translation into clinical practice.

Correspondence with study authors was successful for two of the three included studies, and all queries regarding relevant data were answered satisfactorily by responses, with no assumptions required for interpretation of findings for Reed 2018 or Salisbury 2018. The review authors were unable to obtain data from study authors for Hochhalter 2010 related to the reportedly measured outcome of 'numbers of outpatient/clinic visits'; however, all data were available for the priority outcomes as presented in the summary of findings tables. It was not possible to clarify the background and qualifications of health "coaches" delivering the Hochhalter 2010 intervention (assumed to have been part of the research team), or to obtain further detail regarding the "recruitment area" for the Hochhalter 2010 study. This would have assisted interpretation of the context and transferability of the intervention in practice. In addition, Hochhalter 2010 was assumed to be a parallel trial, although this was not made explicit by the study authors.

Bias was minimised in searching, study selection, and data collection by two review authors carrying out each aspect of the work independently. Any discrepancies were resolved by discussion. Two review authors ranked and selected outcomes of clinical importance/relevance using the methods outlined, to reduce the potential for bias from subjective judgements. With regard to adverse events, in some cases, the review's pre-specified adverse events related to worsening of the outcomes that were extracted under the 'resource use and cost' outcome category (e.g. hospital admissions, accident and emergency attendance). Interventions were not reported to have adversely affected (increased) these outcomes in the included studies; however, for transparency, these potential adverse outcomes have been mentioned in Summary of findings for the main comparison and Summary of findings 2 .

It was not possible to conduct pooled analysis of outcomes due to heterogeneity across studies, and because included trials used dissimilar secondary outcome measures. Pooling of the one common measure 'high self-rated health' and meta-analysis of these results were ruled out on the basis of heterogeneity $\left(\mathrm{I}^{2}=85 \%\right)$ and effects in opposite directions. However, the review authors used guidance on the narrative synthesis to structure their exploration and presentation of the limited findings to allow transparency in interpretation of results (Popay 2006).

\section{Agreements and disagreements with other studies or reviews}

As described in the methods section, the review authors were very specific about the way in which the term 'multi-morbidity' was operationalised with respect to our screening and selection criteria to maintain a focus on the right population for the review, while looking broadly at the effects of relevant interventions. For example, studies were excluded that did not measure specific long-term conditions but instead reported health 'domains' or 'problems'; studies were excluded if less than $100 \%$ of participants (rather than a majority) had multi-morbidity; and the review authors did not consider polypharmacy to always equate to multi-morbidity; therefore, polypharmacy was not used as an eligibility criterion. With respect to the included interventions, those with decision goals that had been pre-specified by a practitioner, whereby the aim was to persuade the patient to meet those goals, and those related to hypothetical decisions and advanced directives, were excluded. Additionally, all interventions focusing on organisational change were included only if they were 'aiming to facilitate the involvement of older patients with multi-morbidity in decision-making about their health care'. We considered the role of our eligibility criteria in the context of any agreements and disagreements with other reviews presented below.

The Wetzels 2007 Cochrane systematic review of interventions for improving older patients' involvement in primary care episodes found very little available data. Although our review was more focused than that of Wetzels, limiting the patient population to those with multi-morbidity, we too found only three included studies. The 
review authors nevertheless expected to find more relevant studies due to the perception that this is a topical and expanding field of research.

The Smith 2016 Cochrane systematic review did not design its search strategy to find studies of interventions to facilitate involvement of older patients with multi-morbidity in decision-making about their care (see Table 1), and review authors excluded the outcomes of attitude and knowledge when reporting studies that we felt to be very important for this review. Therefore, the studies included by Smith 2016 did not fulfil the criteria for inclusion in this review. Additionally, Smith 2016 did not include Hochhalter 2010; both Salisbury 2018 and Reed 2018 were published after completion of the Smith review, and therefore could not have been in cluded. However, Smith 2016 identified 18 trials of interventions to improve outcomes for people with multi-morbidity and common comorbidities in primary care and community settings. These review authors found considerable heterogeneity between studies and similarly concluded that there were remaining uncertainties about the effectiveness of interventions for people with multi-morbidity in general.

Bunn 2018 conducted a realist synthesis of a broader evidence base, supporting shared decision-making for older people with multiple health and social care needs (as opposed to multiple longterm health problems). Of 88 review items selected for screening, 46 primary research studies were included, of which five were RCTs. However, these RCTs did not fulfil the inclusion criteria for this review. Bunn 2018's patient population of interest was nevertheless similar to ours. Bunn 2018 concluded that programmes and interventions likely to be successful in promoting shared decision-making are 'those that allow older people to feel that they are respected and understood, and that engender confidence to engage in shared decision-making'. This concept fits with the theory underpinning our included studies, and previous research using expert advisory groups has identified 'patient priority-directed care' as a feasible and sustainable approach for older patients with multi-morbidities (Tinetti 2016).

Coulter 2015 conducted a systematic review to assess the effects of personalised care planning for adults with long-term health conditions. This review did not focus on older people with multi-morbidity; however, these review authors were interested in interventions in which active involvement of patients in treatment and management decisions was a key component, and all of their included studies had interventions designed to support behaviour change among patients with respect to this - a common theme in our included studies. Coulter 2015 concluded that personalised care planning leads to improvement in certain indicators of physical and psychological health status and in people's capability to self-manage their condition when compared to usual care.

There are additional barriers and facilitators to patient involvement in decision-making about their health care (Butterworth 2014), some of which relate to system factors (including access to healthcare appointments, continuity of care, and consultation duration) that were not directly addressed by our review, despite Salisbury 2018's organisational change approach. Legare 2008 explored barriers to shared decision-making in that systematic review, focusing on practitioner perspectives, and found that the most frequently reported barrier was time constraints.

\section{AUTHORS' CONCLUSIONS}

\section{Implications for practice}

The current evidence base on effects of interventions for involving older patients with multi-morbidities in decision-making about their health care is simply too limited to interpret with any certainty.

Current interventions to involve older patients with multi-morbidities in decision-making about their health care appear, probably, to make little or no difference in health-related quality of life as perceived by patients. It may be, however, that current interventions lack potency, and that a much larger effect on patient involvement in decision-making is required to affect clinical outcomes, although Salisbury 2018 highlights, from a systematic review of interventions for multi-morbidities (see the Appendix), that very little has been shown to improve quality of life in patients with multi-morbidities.

Interventions to involve older patients with multi-morbidities in decision-making about their health care appear, probably, to increase patient perceptions that the care they receive relates to their priorities. This type of intervention may also increase patient perceptions of changes made to management of their health. Implications for practice regarding these findings depend on the perceived weighting and importance of these outcomes for older patients with multi-morbidities and their practitioners in the context of primary care. Currently, evidence is insufficient to identify definitive implications.

\section{Implications for research}

Whilst patient involvement in decision-making is seen as a key mechanism for improving care in almost all recent guidelines and frameworks on the topic of multi-morbidity (American Geriatric Society Expert Panel 2012; Muth 2014; NICE 2016; Palmer 2018), this is rarely tested as an intervention and was not measured for older patients with multi-morbidity in primary care settings by our included studies. The review authors conclude that very few RCTs have evaluated the effectiveness of interventions to facilitate involvement of older patients with multi-morbidity in decision-making about their primary health care. Therefore, there is currently a large gap between the substantial amount of guidance recommending improved patient involvement in decision-making and an evidence base to support implementation of this guidance, particularly for older patients with multi-morbidity in primary care settings.

More research is required to provide clinicians, researchers, and policy makers with the best evidence to provide good-quality care for older patients with multiple health problems. The consensus view, from a 2018 symposium involving experts in the field of multi-morbidity research, is that there is 'a need for a truly patient-centred care that takes into account the individual patient from a comprehensive and multi-dimensional perspective and acknowledges the complexity and dynamics of older adults' health' (CalderónLarrañaga 2019).

Researchers should seek ways to include important and vulnerable populations that are frequently excluded from trials, including those receiving end-of-life care, those with cognitive decline, those residing in long-term care facilities, and those with potential language barriers. 
Studies, in assessing this patient group, should also consider the increasingly diverse nature of the 'older' age category caused by increasing life expectancy. Additionally, the implications of this review are relevant to younger populations with increasing prevalence of multi-morbidity, including socially deprived populations, for example.

Consistency in intervention design (including transparency in the theory underpinning the design), analysis, and evaluation would enable greater likelihood of comparable findings across studies in future systematic reviews. As the underlying themes in the theory underpinning our included studies can be related to behaviour change (Michie 2011), future intervention development and evaluation might usefully take account of 'capability/skills', 'motivation', and 'opportunity' for both patients and practitioners in the context of patient involvement in decision-making about their health care. Other potential sources of theory might also come from the wider decision theory literature (Hansson 2005), for example. Future interventions and new models of care should be described with the aid of transparent tools and frameworks (e.g. the 'TIDier' checklist (Hoffmann 2014), 'the Foundations Framework for Developing and Reporting New Models of Care for Multimorbidity' (Stokes 2017)) to allow comparisons to be drawn between studies and to gauge generalisability and transferability of findings. A new model for clinical decision-making in patients with multi-morbidity is currently under development (Jack 2018), and a full, definitive RCT to determine the effectiveness of goal-setting for patients with multi-morbidity to improve outcomes in primary care is anticipated (Steel 2016).

Several validated measures of shared decision-making are currently available (Gärtner 2018), and it is possible to measure outcomes from patient, practitioner, and external observer perspectives. However, measures of shared decision-making are yet to be utilised in trials involving older patients with multi-morbidity consulting in primary care. Application of such measures would encourage reporting of coherent outcomes with standardised intervals across trials to benefit future systematic reviews of these findings.

Measuring patient preferences for and experiences of care will be crucial to the development of interventions that provide high-quality care directed towards older patients with multi-morbidity (Butterworth 2014; Valderas 2019).

Potential secondary outcome measures should also be validated and could include measures specifically designed for use in older populations such as those measuring potentially inappropriate prescribing (Campanelli 2012; O'Mahony 2015). The Primary Care Outcomes Questionnaire (PCOQ) was recently developed to specifically measure primary care-oriented outcomes (Murphy 2018). Future studies could usefully report practitioner outcomes in terms of knowledge and skills gained, attitudes towards the intervention, and compliance with the intervention (Légaré 2018). Additionally, recommendations were recently provided for a Core Outcome Set for Multimorbidity Research (COSmm) (Smith 2018).

Duration of follow-up will need to be carefully considered when intervention implementation is planned, to assess the longer-term effectiveness of new interventions for involving older patients with multi-morbidity in decision-making when consulting in primary care.

\section{ACKN OWLEDGEMENTS}

We thank the Cochrane Consumers and Communication editors and staff, particularly our managing editor, Bronwen Merner, and our search co-ordinator, Anne Parkhill. 


\section{R E F E R E N C E S}

\section{References to studies included in this review}

Hochhalter 2010 \{published data only\}

Hochhalter, AK, Song J, Rush J, Sklar L, Stevens A. Making the Most of Your Healthcare intervention for older adults with multiple chronic illnesses. Patient Education and Counseling 2018;81(2):207-13.

\section{Reed 2018 \{published data only\}}

Reed RL, Roeger L, Howard S, Oliver-Baxter JM, Battersby MW, Bond $\mathrm{M}$, et al. A self-management support program for older Australians with multiple chronic conditions: a randomised controlled trial. Medical Journal of Australia 2018;208:69-74.

\section{Salisbury 2018 \{published data only\}}

Salisbury C, Man M-S, Bower P, Guthrie B, Chaplin K, Gaunt DM, et al. Management of multimorbidity using a patient-centred care model: a pragmatic cluster-randomised trial of the 3D approach. The Lancet 2018;392(10141):41-50.

Salisbury C, Man MS, Chaplin K, Mann C, Bower P, Brookes S, et al. A patient-centred intervention to improve the management of multimorbidity in general practice: the 3D RCT. Health Services and Delivery Research 2019;7(5):2050-4349. [DOI: 10.3310/hsdr07050]

\section{References to studies excluded from this review}

\section{Alkema 2007 \{published data only\}}

Alkema GE, Wilber KH, Shannon GR, Allen D. Reduced mortality: the unexpected impact of a telephone-based care management intervention for older adults in managed care. Health Services Research 2007:42:1632-50.

\section{Beck 2013 \{published data only\}}

Beck A, Scott J, Williams P, Robertson B, Jackson D, Gade G, et al. A randomized trial of group outpatient visits for chronically ill older HMO members: the cooperative health care clinic. Journal of the American Geriatrics Society 2013;45:543-9.

\section{Berglund 2013 \{published data only\}}

Berglund $\mathrm{H}$, Wilhelmson K, Blomberg S, Dunér A, Kjellgren K, Hasson $\mathrm{H}$. Older people's views of quality of care: a randomised controlled study of continuum of care. Journal of Clinical Nursing 2013;22:2934-44. [DOI: 10.1111/jocn.12276]

\section{Berglund 2015 \{published data only\}}

Berglund $\mathrm{H}$, Hasson $\mathrm{H}$, Kjellgren $\mathrm{K}$, Wilhelmson $\mathrm{K}$. Effects of a continuum of care intervention on frail older persons' life satisfaction: a randomized controlled study. Journal of Clinical Nursing 2015;24:1079-90.

\section{Bernabei 1998 \{published data only\}}

Bernabei R, Landi F, Gambassi G, Sgadari A, Zuccala G, Mor V, et al. Randomised trial of impact of model of integrated care and case management for older people living in the community. British Medical Journal 1998;316:1348-51.
Bielaszka-DuVernay 2011 \{published data only\}

Bielaszka-DuVernay C. Innovation profile: the 'GRACE' model: in-home assessments lead to better care for dual eligibles. Health Affairs 2011;30:431-4.

Blom 2016 \{published data only\}

Blom J, den Elzen W, van Houwelingen AH, Heijmans M, Stijnen T, Van den Hout W, et al. Effectiveness and costeffectiveness of a proactive, goal-oriented, integrated care model in general practice for older people. A cluster randomised controlled trial: Integrated Systematic Care for older People - the ISCOPE study. Age and Ageing 2016;45(1):30-41.

Bosma 2011 \{published data only\}

Bosma H, Lamers F, Jonkers CC, van Eijk JT. Disparities by education level in outcomes of a self-management intervention: the DELTA trial in The Netherlands. Psychiatric Services 2011;62(7):793-5.

\section{Boult 2008 \{published data only\}}

Boult C, Reider L, Frey K, Leff B, Boyd CM, Wolff JL, et al. Early effects of 'Guided Care' on the quality of health care for multimorbid older persons: a cluster-randomized controlled trial. Journals of Gerontology Series A: Biological Sciences \& Medical Sciences 2008;63:321-7.

Boult 2011a \{published data only\}

Boult, C. Guided care model of health care for older patients with multiple chronic conditions. Annals of the Academy of Medicine Singapore 2011;1:S2-S3.

\section{Boult 2011b \{published data only\}}

Boult C, Reider L, Leff B, Frick KD, Boyd CM, Wolff JL, et al. The effect of guided care teams on the use of health services: results from a cluster-randomized controlled trial. Archives of Internal Medicine 2011;171:460-6.

\section{Boult 2013 \{published data only\}}

Boult C, Leff B, Boyd CM, Wolff JL, Marsteller JA, Frick KD, et al. A matched-pair cluster-randomized trial of guided care for high-risk older patients. Journal of General Internal Medicine 2013;28:612-21.

Boyd 2007 \{published data only\}

Boyd CM, Boult C, Shadmi E, Leff B, Brager R, Dunbar L, et al. Guided care for multimorbid older adults. Gerontologist 2007;47:697-704.

\section{Boyd 2008 \{published data only\}}

Boyd CM, Shadmi E, Conwell LJ, Griswold M, Leff B, Brager R, et al. A pilot test of the effect of guided care on the quality of primary care experiences for multimorbid older adults. Journal of General Internal Medicine 2008;23:536-42.

Caughey 2017 \{published data only\}

Caughey GE, Huynh E, Shakib S, Rose JM, Swait J. Influence of medication risks and benefits on patient and clinician preferences for treatment in multimorbidity: a discrete- 
choice experiment. Pharmacoepidemiology and Drug Safety 2017;26(S2):447.

\section{Cheema 2017 \{published data only\}}

Cheema R, Kwolek S, Frias J, Mangin D, Moore A, Masrur M. Measurement of medication discrepancies and use of medication wallet cards to increase patient self-efficacy. Canadian Family Physician 2017;63(2;S1):S108.

\section{Cheng 2018 \{published data only\}}

Cheng WL. The effects of mutual goal-setting practice in older adults with chronic illness. Geriatric Nursing 2018;39:143-50.

\section{Chi-Jane 2013 \{published data only\}}

Chi-Jane W, Fetzer SJ, Yi-Ching Y, Jing-Jy W. The Impacts of using community health volunteers to coach medication safety behaviors among rural elders with chronic illnesses. Geriatric Nursing 2013;34:138-45.

\section{Chow 2014 \{published data only\}}

Chow SK, Wong FK. A randomized controlled trial of a nurseled case management programme for hospital-discharged older adults with co-morbidities. Journal of Advanced Nursing 2014;70:2257-71.

\section{Coburn 2012 \{published data only\}}

Coburn KD, Marcantonio S, Lazansky R, Keller M, Davis N. Effect of a community-based nursing intervention on mortality in chronically ill older adults: a randomized controlled trial. PLOS Medicine 2012;9(7):e1001265.

\section{Dorr 2008 \{published data only\}}

Dorr DA, Wilcox AB, Brunker CP, Burdon RE, Donnelly SM. The effect of technology-supported, multidisease care management on the mortality and hospitalization of seniors. Journal of the American Geriatrics Society 2008;56:2195-202.

\section{Dowrick 2018 \{published data only\}}

Dowrick C. Patient-centred care for multimorbidity: an end in itself?. Lancet 2018;392(10141):4-5.

\section{Dye 2018 \{published data only\}}

Dye C, Willoughby D, Aybar-Damali B, Grady C, Oran R, Knudson A. Improving chronic disease self-management by older home health patients through community health coaching. International Journal of Environmental Research and Public Health 2018;15(4):e660.

\section{Elzen 2007 \{published data only\}}

Elzen H, Slaets JP, Snijders TA, Steverink N. Evaluation of the chronic disease self-management program (CDSMP) among chronically ill older people in the Netherlands. Social Science \& Medicine 2007;64:1832-41.

\section{Engelhardt 2009 \{published data only\}}

Engelhardt JB, Rizzo VM, Penna RDD, Feigenbaum PA, Kirkland KA, Nicholson JS, et al. Effectiveness of care coordination and health counseling in advancing illness. American Journal of Managed Care 2009;15:817-25.

\section{Fortin 2016 \{published data only\}}

Fortin M, Chouinard MC, Dubois MF, Belanger M, Almirall J, Bouhali $\mathrm{T}$, et al. Integration of chronic disease prevention and management services into primary care: a pragmatic randomized controlled trial (PR1MaC). Canadian Medical Association Journal Open 2016;4:e588-98.

Freund 2011 \{published data only\}

Freund T, Peters-Klimm F, Rochon J, Mahler C, Gensichen J, Erler A. Primary care practice-based care management for chronically ill patients (PraCMan): study protocol for a cluster randomized controlled trial [ISRCTN56104508]. Trials [Electronic Resource] 2011;12:163.

Fried 2017 \{published data only\}

Fried TR, Niehoff KM, Street RL, Charpentier PA, Rajeevan N, Miller PL, et al. Effect of the tool to reduce inappropriate medications on medication communication and deprescribing. Journal of the American Geriatrics Society 2017;65:2265-71.

Ganz 2010 \{published data only\}

Ganz DA, Koretz BK, McCreath HE, Wenger NS, Roth CP, Bail JK, et al. Nurse practitioner comanagement for patients in an academic geriatric practice. Journal of the American Geriatrics Society 2010;16(12):e343-55.

\section{Glaser 2017 \{published data only\}}

Glaser E, Richard C, Lussier MT. The impact of a patient web communication intervention on reaching treatment suggested guidelines for chronic diseases: a randomized controlled trial. Patient Education \& Counseling 2017;100:2062-70.

\section{Hanlon 1996 \{published data only\}}

Hanlon JT, Weinberger M, Samsa GP, Schmader KE, Uttech KM, Lewis IK, et al. A randomized, controlled trial of a clinical pharmacist intervention to improve inappropriate prescribing in elderly outpatients with polypharmacy. American Journal of Medicine 1996;100:428-37.

\section{Harrison 2012 \{published data only\}}

Harrison M, Reeves D, Harkness E, Valderas J, Kennedy A, Rogers A, et al. A secondary analysis of the moderating effects of depression and multimorbidity on the effectiveness of a chronic disease self-management programme. Patient Education \& Counseling 2012;87:67-73.

\section{Ivey 2018 \{published data only\}}

Ivey SL, Shortell SM, Rodriguez HP, Wang Y. Patient engagement in ACO practices and patient-reported outcomes among adults with co-occurring chronic disease and mental health conditions. Medical Care 2018;56:551-6.

\section{Jerant 2009 \{published data only\}}

Jerant A, Moore-Hill M, Franks P. Home-based, peer-led chronic illness self-management training: findings from a 1year randomized controlled trial. Annals of Family Medicine 2009;7:319-27. 
Joos 1996 \{published data only\}

Joos SK, Hickam DH, Gordon GH, Baker LH. Effects of a physician communication intervention on patient care outcomes. Journal of General Internal Medicine 1996;11:147-55.

\section{Junius-Walker 2012 \{published data only\}}

Junius-Walker U, Wrede J, Voigt I, Hofmann W, Wiese B, Hummers-Pradier E, et al. Impact of a priority-setting consultation on doctor-patient agreement after a geriatric assessment: cluster randomised controlled trial in German general practices. Quality in Primary Care 2012;20(5):321-34.

\section{Kangovi 2017 \{published data only\}}

Kangovi S, Mitra N, Smith RA, Kulkarni R, Turr L, Huo H, et al. Decision-making and goal-setting in chronic disease management: baseline findings of a randomized controlled trial. Patient Education and Counseling 2017;100(3):449-55.

\section{Kennedy 2013 \{published data only\}}

Kennedy A, Bower P, Reeves D, Blakeman T, Bowen R, ChewGraham C, et al. Implementation of self management support for long term conditions in routine primary care settings: cluster randomised controlled trial. British Medical Journal 2013;346:f2882.

\section{Kim 2017 \{published data only\}}

Kim H, Park Y, Jung Y, Choi H, Lee S, Kim G, et al. Evaluation of a technology-enhanced integrated care model for frail older persons: protocol of the SPEC study, a stepped-wedge cluster randomized trial in nursing homes. BMC Geriatrics 2017;17(1):88.

\section{Légaré 2015 \{published data only\}}

Légaré F, Briere N, Stacey D, Bourassa H, Desroches S, Dumont S, et al. Improving Decision making On Location of Care with the frail Elderly and their caregivers (the DOLCE study): study protocol for a cluster randomized controlled trial. Trials 2015;16(50):PMC4337186. [DOI: 10.1186/s13063-015-0567-7]

\section{Lin 2012 \{published data only\}}

Lin EH, Von Korff M, Ciechanowski P, Peterson D, Ludman EJ, Rutter CM, et al. Treatment adjustment and medication adherence for complex patients with diabetes, heart disease, and depression: a randomized controlled trial. Annals of Family Medicine 2012;10:6-14.

\section{LudmanEvette 2013 \{published data only\}}

Ludman EJ, Peterson D, Katon WJ, Lin EH, Von Korff M, Ciechanowski P, et al. Improving confidence for self care in patients with depression and chronic illnesses. Behavioral Medicine 2013;39(1):1-6.

\section{Markle-Reid 2018 \{published data only\}}

Markle-Reid M, Ploeg J, Fraser KD, Fisher KA, Bartholomew A, Griffith LE, et al. Community program improves quality of life and self-management in older adults with diabetes mellitus and comorbidity. Journal of the American Geriatrics Society 2018:66:263-73.

\section{Panagioti 2018 \{published data only\}}

Panagioti M, Reeves D, Meacock R, Parkinson B, Lovell K, Hann M, et al. Is telephone health coaching a useful population health strategy for supporting older people with multimorbidity? An evaluation of reach, effectiveness and cost-effectiveness using a 'trial within a cohort'. BMC Medicine 2018;16(1):80.

\section{Sudore 2017 \{published data only\}}

Sudore Rl, Boscardin J, Feuz MA, McMahan RD, Katen MT, Barnes DE. Effect of the PREPARE website vs an easy-to-read advance directive on advance care planning documentation and engagement among veterans: a randomized clinical trial. JAMA Internal Medicine 2017;117(8):1102-9.

\section{Valdivieso 2018 \{published data only\}}

Valdivieso B, Garcia-Sempere A, Sanfelix-Gimeno G, Faubel R, Librero J, Soriano E, et al. The effect of telehealth, telephone support or usual care on quality of life, mortality and healthcare utilization in elderly high-risk patients with multiple chronic conditions. A prospective study. Medicina Clinica 2018;151(8):308-14.

\section{Von 2011 \{published data only\}}

Von Korff M, Katon WJ, Lin EH, Ciechanowski P, Peterson D, Ludman EJ, et al. Functional outcomes of multi-condition collaborative care and successful ageing: results of randomised trial. British Medical Journal (Online) 2011;343:1083.

\section{Wetzels 2005 \{published data only\}}

Wetzels R, Wensing M, van Weel C, Grol R. A consultation leaflet to improve an older patient's involvement in general practice care: a randomized trial. Health Expectations 2005;8(4):286-94.

\section{Willeboordse 2017 \{published data only\}}

Willeboordse F, Schellevis FG, Chau SH, Hugtenburg JG, Elders PJM. The effectiveness of optimised clinical medication reviews for geriatric patients: Opti-Med, a cluster randomised controlled trial. Family Practice 2017;34(4):437-45.

\section{Wissow 2004 \{published data only\}}

Wissow LS, Belote A, Kramer W, Compton-Phillips A, Kritzler R, Weiner JP. Promoting advance directives among elderly primary care patients. Journal of General Internal Medicine 2004;19:944-51.

\section{Wrede 2013 \{published data only\}}

Wrede J, Voigt I, Bleidorn J, Hummers-Pradier E, Dierks ML, Junius-Walker U. Complex health care decisions with older patients in general practice: patient-centeredness and prioritization in consultations following a geriatric assessment Patient Education and Counseling 2013;90(1):54-60.

\section{References to ongoing studies}

\section{Steel 2016 \{published data only\}}

* Steel N, Clark A, Ford J, et al. Goal plan study. University of East Anglia; http://www.uea.ac.uk/medicine/research/primarycareand-epidemiology/goalplan (accessed 31 July 2019). 


\section{Additional references}

\section{Academy of Medical Sciences 2018}

Academy of Medical Sciences. Multimorbidity: a priority for global health research. April 2018. acmedsci.ac.uk/filedownload/99630838 (accessed 11 June 2018).

\section{Al-Janabi 2011}

Al-Janabi H, Flynn TN, Coast J. Estimation of a preference-based carer experience scale. Medical Decision Making 2011;31:458-68.

\section{American Geriatric Society Expert Panel 2012}

American Geriatrics Society Expert Panel on the Care of Older Adults With Multimorbidity. Patient-centered care for older adults with multiple chronic conditions: a stepwise approach from the American Geriatrics Society: American Geriatrics Society Expert Panel on the Care of Older Adults With Multimorbidity. Journal of the American Geriatric Society 2012;60(10):1957-68.

\section{Barr 2014}

Barr PJ, Thompson R, Walsh T, Grande SW, Ozanne EM, Elwyn G. The psychometric properties of CollaboRATE: a fast and frugal patient-reported measure of the shared decision-making process. Journal of Medical Internet Research 2014;16(1):e2.

\section{Barr 2015}

Barr PJ, O'Malley AJ, Tsulukidze M, Gionfriddo MR, Montori V, Elwyn G. The psychometric properties of Observer OPTION(5), an observer measure of shared decision making. Patient Education and Counseling 2015;98(8):970-6.

\section{Berkelmans 2010}

Berkelmans PG, Berendsen AJ, Verhaak PFM, van der Meer K. Characteristics of general practice care: what do senior citizens value? A qualitative study. BMC Geriatrics 2010;10:80. [DOI: 10.1186/1471-2318-10-80]

\section{Berwick 2008}

Berwick DM, Nolan TW, Whittington J. The triple aim: care, health, and cost. Health Affairs 2008;27(3):759-69.

\section{Bunn 2018}

Bunn F, Goodman C, Russell B, Wilson P, Manthorpe J, Rait G, et al. Supporting shared decision making for older people with multiple health and social care needs: a realist synthesis. BMC Geriatrics 2018;18(1):165.

\section{Butterworth 2014}

Butterworth JE, Campbell JL. Older patients and their GPs: shared decision making in enhancing trust. British Journal of General Practice 2014;64(628):e709-18.

\section{Calderón-Larrañaga 2019}

Calderón-Larrañaga A, Fratiglioni L. Mulitmorbidity research at the crossroads: developing the scientific evidence for clinical practice and health policy. Association for Publication of the Journal of Internal Medicine 2019;285:251-4.

\section{Campanelli 2012}

Campanelli CM. American Geriatrics Society updated Beers criteria for potentially inappropriate medication use in older adults. Journal of the American Geriatric Society 2012;60:616-31.

\section{CCCG 2013}

Cochrane Consumers and Communication Group. Standard protocol text and additional guidance for review authors (2013). cccrg.cochrane.org/author-resources (accessed before 31 July 2018).

\section{CDC 2000}

Centers for Disease Control and Prevention. Measuring healthy days: population assessment of health-related quality of life (2000). https://www.cdc.gov/hrqol/pdfs/mhd.pdf (accessed 20 March 2019). Atlanta, Georgia: CDC.

\section{Chrischilles 2014}

Chrischilles EA, Hourcade JP, Doucette W, Eichmann D, Gryzlak B, Lorentzen R, et al. Personal health records: a randomized trial of effects on elder medication safety. Journal of the American Medical Informatics Association 2014;21(4):679-86

\section{Coulter 2011}

Coulter A, Collins A. Making shared decision making a reality: No decision about me, without me. Making Shared DecisionMaking a Reality. No Decision About Me, Without Me. London: The King's Fund, 2011. [ISBN 9781857176247]

\section{Coulter 2015}

Coulter A, Entwistle VA, Eccles A, Ryan S, Shepperd S, Perera R. Personalised care planning for adults with chronic or long-term health conditions. Cochrane Database of Systematic Reviews 2015, Issue 3. [DOI: 10.1002/14651858.CD010523.pub2]

\section{Couët 2015}

Couët N, Desroches S, Robitaille H, Vaillancourt H, Leblanc A, Turcotte $\mathrm{S}$, et al. Assessments as to the extent to which healthcare providers involve patients in decision-making: a systematic review of studies using the OPTION instrument. Health Expectations 2015;18(4):542-61.

\section{Croker 2013}

Croker JE, Swancutt DR, Roberts MJ, Abel GA, Roland M, Campbell JL. Factors affecting patients' trust and confidence in GPs: evidence from the English national GP patient survey. British Medical Journal Open 2013;3(5):e002762. [DOI: 10.1136/ bmjopen-2013-002762]

\section{Dawmena 2012}

Dwamena F, Holmes-Rovner M, Gaulden CM, Jorgensen S, Sadigh G, Sikorskii A, et al. Interventions for providers to promote a patient-centred approach in clinical consultations. Cochrane Database of Systematic Reviews 2012, Issue 12. [DOI: 10.1002/14651858.CD003267.pub2]

\section{Department of Health and Social Care (UK) 2001}

Department of Health and Social Care (UK). National service framework: older people (2001). www.gov.uk/government/ 
publications/quality-standards-for-care-services-older-people (accessed before 31 July 2018).

\section{Donabedian 1988}

Donabedian A. The quality of care: how can it be assessed? Journal of the American Medical Association 1988;260(12):17438.

\section{Dong 2016}

Dong X, Milholland B, Vijg J. Evidence for a limit to human lifespan. Nature 2016;538(7624):257-9. [DOI: 10.1038/ nature19793]

\section{Dreischulte 2016}

Dreischulte T, Donnan P, Grant A, Hapca A, McCowan C, Guthrie B. Safer prescribing - a trial of education, informatics, and financial incentives. New England Journal of Medicine 2016;374:1053-64.

\section{Drennan 2007}

Drennan V, Walters K, Lenihan P, Cohen S, Myerson S, Iliffe S. Priorities in identifying unmet need in older people attending general practice: a nominal group technique study. Family Practice 2007;24(5):454-60.

\section{Duncan 2018}

Duncan P, Murphy M, Man MS, Chaplin K, Gaunt D, Salisbury C. Development and validation of the Multimorbidity Treatment Burden Questionnaire (MTBQ). British Medical Journal Open 2018;8:e019413.

\section{Elwyn 2000}

Elwyn G, Edwards A, Kinnersley P, Grol R. Shared decisionmaking and the concept of equipoise: the competences of involving patients in healthcare choices. British Journal of General Practice 2000;50(460):892-9.

\section{Elwyn 2010}

Elwyn G, Laitner S, Coulter A, Walker E, Watson P, Thomson R. Implementing shared decision making in the NHS. British Medical Journal 2010;341:c5146. [DOI: 10.1136/bmj.c5146]

\section{Elwyn 2017}

Elwyn G, Durand MA, Song J, Aarts J, Barr PJ, Berger Z, et al. A three-talk model for shared decision making: multistage consultation process. British Medical Journal 2017;359:j4891.

\section{Flocke 2013}

Flocke SA, Miller WL, Crabtree BF. Relationships between physician practice style, patient satisfaction, and attributes of primary care. Family Practice 2013;51(10):835-40.

\section{GRADEpro GDT 2015 [Computer program]}

McMaster University (developed by Evidence Prime). GRADEpro GDT. Version accessed before 31 July 2018. Hamilton (ON): McMaster University (developed by Evidence Prime), 2015.

\section{Gärtner 2018}

Gärtner FR, Bomhof-Roordink H, Smith IP, Scholl I, Stiggelbout AM, Pieterse AH. The quality of instruments to assess the process of shared decision making: a systematic review. PLoS One 2018;15(13(2)):e0191747.

\section{Hamilton 2006}

Hamilton W, Britten N. Patient agendas in primary care: perhaps the main benefit is to encourage patients to voice embarrassing problems. British Medical Journal 2006;332(7552):1225-6.

\section{Hansson 2005}

Hansson, S. Decision Theory: A Brief Introduction. Stockholm: Royal Institute of Technology (KTH), 2005:https://people.kth.se/ 乞soh/decisiontheory.pdf (accessed 8 August 2019).

\section{Hays 2017}

Hays R, Daker-White G, Esmail A, Barlow W, Minor B, Brown B, et al. Threats to patient safety in primary care reported by older people with multimorbidity: baseline findings from a longitudinal qualitative study and implications for intervention. BMC Health Services Research 2017;17(1):754. [DOI: 10.1186/ s12913-017-2727-9]

\section{Herdman 2011}

Herdman M, Gudex C, Lloyd A, et al. Development and preliminary testing of the new five-level version of EQ-5D (EQ-5D-5L). Quality of Life Research 2011;20:1727-36.

\section{Hibbard 2005}

Hibbard JH, Mahoney ER, Stockard J, Tusler M. Development and testing of a short form of the patient activation measure. Health Services Research 2005;40:1918-30.

\section{Higashi 2007}

Higashi T, Wenger N, Adams J, Fung C, Roland M, McGlynn E, et al. Relationship between number of medical conditions and quality of care. New England Journal of Medicine 2007;356(24):2496-504.

\section{Higgins 2011}

Higgins JPT, Green S, editor(s). Cochrane Handbook for Systematic Reviews of Interventions Version 5.1.0 (updated March 2011). The Cochrane Collaboration, 2011. Available from handbook.cochrane.org.

\section{Hobbs 2016}

Hobbs FDR, Bankhead C, Mukhtar T, Stevens S, PereraSalazar R, Holt T, et al. Clinical workload in UK primary care: a retrospective analysis of 100 million consultations in England, 2007-14. Lancet 2016;387(10035):2323-30.

\section{Hoffmann 2014}

Hoffmann T, Glasziou PP, Boutron I, Milne R, Perera R, Moher D, et al. Better reporting of interventions: template for intervention description and replication (TIDieR) checklist and guide. BMJ 2014;348:g1687. [DOI: 10.1136/bmj.g1687]

\section{Homa 2015}

Homa L, Rose J, Hovmand PS, Cherng ST, Riolo RL, Kraus A, et al. A participatory model of the paradox of primary care. Annals of Family Medicine 2015;13(5):456-65. 


\section{Howie 1998}

Howie JG, Heaney DJ, Maxwell M, Walker JJ. A comparison of a Patient Enablement Instrument (PEI) against two established satisfaction scales as an outcome measure of primary care consultation. Family Practice 1998;15(2):165-71.

\section{Iliffe 2004}

Iliffe S, Lenihan P, Orrell M, Walters K, Drennan V, Tai SS. The development of a short instrument to identify common unmet needs in older people in general practice. British Journal of General Practice 2004;54(509):914-8.

\section{Ipsos MORI 2015}

Ipsos MORI Social Research Institute. GP patient survey technical annex. 2014-15 annual report. Ipsos MORI; London, 2015.

\section{Jack 2018}

Jack E, Maskrey N, Byng R. SHERPA: a new model for clinical decision making in patients with multimorbidity. The Lancet 2018;392:1397-9.

\section{Kiesler 2006}

Kiesler DJ, Auerbach SM. Optimal matches of patient preferences for information, decision-making and interpersonal behavior: evidence, models and interventions. Patient Education and Counseling 2006;61(3):319-41.

\section{Kingston 2018}

Kingston A, Robinson L, Booth $\mathrm{H}$, Knapp M, Jagger C. Projections of multi-morbidity in the older population in England to 2035: estimates from the Population Ageing and Care Simulation (PACSim) model. Age and Ageing 2018;47(3):374-80.

\section{Kinnersley 2008}

Kinnersley P, Edwards A, Hood K, Ryan R, Prout H, Cadbury N, et al. Interventions before consultations to help patients address their information needs by encouraging question asking: systematic review. BMJ 2008;337:a485. [DOI: 10.1136/bmj.a485]

\section{Legare 2008}

Légaré F, Ratté S, Gravel K, Graham ID. Barriers and facilitators to implementing shared decision-making in clinical practice: update of a systematic review of health professionals' perceptions. Patient Education and Counseling 2008;73(3):526-35

\section{Levinson 2005}

Levinson W, Kao A, Kuby A, Thisted RA. Not all patients want to participate in decision-making. A national study of public preferences. Journal of General Internal Medicine 2005;20(6):531-5.

\section{Liberati 2009}

Liberati A, Altman DG, Tetzlaff J, Mulrow C, Gøtzsche PC, Ioannidis JP, et al. The PRISMA statement for reporting systematic reviews and meta-analyses of studies that evaluate health care interventions: explanation and elaboration. PLOS Medicine 2009;6(7):e1000100.

\section{Loh 2007}

Loh A, Leonhart R, Wills CE, Simon D, Harter M. The impact of patient participation on adherence and clinical outcome in primary care of depression. Patient Education and Counseling 2007;65(1):69-78.

\section{Légaré 2018}

Légaré F, Adekpedjou R, Stacey D, Turcotte S, Kryworuchko J, Graham ID, et al. Interventions for increasing the use of shared decision making by healthcare professionals. Cochrane Database of Systematic Reviews 2018, Issue 7. [DOI: 10.1002/14651858.CD006732.pub4]

\section{Marengoni 2011}

Marengoni A, Angleman S, Melis R, Mangialasche F, Karp A, Garmen A, et al. Aging with multimorbidity: a systematic review of the literature. Ageing Research Reviews 2011;10(4):430-9.

\section{McBride 2010}

McBride D, Hardoon S, Walters K, Gilmour S, Raine R. Explaining variation in referral from primary to secondary care: cohort study. British Medical Journal 2010;341:c6267. [DOI: 10.1136/ bmj.c6267]

\section{Melzer 2015}

Melzer D, Tavakoly B, Winder RE, Masoli JAH, Henley WE, Ble A, et al. Much more medicine for the oldest old: trends in UK electronic clinical records. Age and Ageing 2015;44(1):46-53. [DOI: 10.1093/ageing/afu113]

\section{Michie 2011}

Michie S, van Stralen MM, West R. The behaviour change wheel: a new method for characterising and designing behaviour change interventions. Implementation Science 2011;6(42):doi: 10.1186/1748-5908-6-42.

\section{Montori 2017}

Montori VM, Kunneman M, Brito JP. Shared decision making and improving health care: the answer is not in. Journal of the American Medical Association 2017;318(7):617-8.

\section{Morisky 2008}

Morisky DE, Ang A, Krousel-Wood M, Ward P. Predictive validity of a medication adherence measure in an outpatient setting. Journal of Clinical Hypertension 2008;8:348-54.

\section{Murphy 2018}

Murphy M, Hollinghurst S, Cowlishaw S, Salisbury C. Primary care outcomes questionnaire: psychometric testing of a new instrument. British Journal of General Practice 2018;68:e433e40.

\section{Muth 2014}

Muth C, van den Akker M, Blom JW, Mallen CD, Rochon J, Schellevis FG, et al. The Ariadne principles: how to handle multimorbidity in primary care consultations. BMC Medicine 2014;12(1):223. [DOI: 10.1186/s12916-014-0223-1]

\section{NICE 2016}

National Institute for Health and Care Excellence (NICE). Multimorbidity: clinical assessment and management. 
Multimorbidity: assessment, prioritisation and management of care for people with commonly occurring multimorbidity. NICE guideline NG56 (2016). www.nice.org.uk/guidance/ng56/ evidence/full-guideline-2615543103 (accessed before 31 July 2018).

\section{Noël 2007}

Noël PH, Parchman ML, Williams JW Jr, Cornell JE, Shuko L, Zeber JE, et al. The challenges of multimorbidity from the patient perspective. Journal of General Internal Medicine 2007;22(Suppl 3):419-24.

\section{Oeppen 2002}

Oeppen J, Vaupel JW. Broken limits to life expectancy. Science 2002;296(5570):1029-31.

\section{Ommen 2011}

Ommen $\mathrm{O}$, Thuem S, Pfaff H, Janssen C. The relationship between social support, shared decision-making and patient's trust in doctors: a cross-sectional survey of 2,197 inpatients using the Cologne Patient Questionnaire. International Journal of Public Health 2011;56(3):319-27.

\section{O'Mahony 2015}

O'Mahony D, O'Sullivan D, Byrne S, O'Connor MN, Ryan C, Gallagher P. STOPP/START criteria for potentially inappropriate prescribing in older people: version 2. Age Ageing 2015;44:21318.

\section{Palmer 2018}

Palmer K, Marengoni A, Forjaz MJ, Jureviciene E, Laatikainen T, Mammarella F, et al. Multimorbidity care model: recommendations from the consensus meeting of the Joint Action on Chronic Diseases and Promoting Healthy Ageing Across the Life Cycle (JA-CHRODIS). Health Policy 2018;122:4-11.

\section{Peters 1994}

Peters RM. Matching physician practice style to patient information issues and decision-making preferences. An approach to patient autonomy and medical paternalism issues in clinical practice. Archives of Family Medicine 1994;3(9):760-3.

\section{Popay 2006}

Popay J, Roberts H, Sowden A, Petticrew M, Arai L, Rodgers M, et al. 2006. Guidance on the Conduct of Narrative Synthesis in Systematic Reviews: A Product From the ESRC Methods Programme. http://citeseerx.ist.psu.edu/viewdoc/download? doi=10.1.1.178.3100\&rep=rep1\&type=pdf (accessed 5 January 2019). [DOI: 10.13140/2.1.1018.4643]

\section{RCGP 2013}

Royal College of General Practitioners. The 2022 GP compendium of evidence (2013). www.rcgp.org.uk/ /media/ Files/Policy/A-Z-policy/The-2022-GP-Compendium-ofEvidence.ashx (accessed before 31 July 2018).

\section{Review Manager 2014 [Computer program]}

Nordic Cochrane Centre, The Cochrane Collaboration. Review Manager 5 (RevMan 5). Version 5.3. Copenhagen: Nordic Cochrane Centre, The Cochrane Collaboration, 2014.

\section{Rolfe 2014}

Rolfe A, Cash-Gibson L, Car J, Sheikh A, McKinstry B. Interventions for improving patients' trust in doctors and groups of doctors. Cochrane Database of Systematic Reviews 2014, Issue 3. [DOI: 10.1002/14651858.CD004134.pub3]

\section{Ryan 2000}

Ryan RM, Deci EL. Self-determination theory and the facilitation of intrinsic motivation, social development, and well-being. American Psychologist 2000;55:68-78.

\section{Ryan 2013}

Ryan R, Hill S, Prictor M, McKenzie J. Study quality guide (2013). cccrg.cochrane.org/authorresources (accessed 16 February 2017).

\section{Saba 2006}

Saba GW, Wong ST, Schillinger D, Fernandez A, Somkin CP, Wilson CC, et al. Shared decision-making and the experience of partnership in primary care. Annals of Family Medicine 2006;4(1):54-62.

\section{Salisbury 2012}

Salisbury C. Multimorbidity: redesigning health care for people who use it. The Lancet 2012;380(9836):7-9.

\section{Schünemann 2011}

Schünemann HJ, Oxman AD, Higgins JPT, Vist GE, Glasziou P, Guyatt GH. Chapter 11. Presenting results and 'Summary of findings' tables. In: Higgins JP, Green S, editor(s). Cochrane Handbook for Systematic Reviews of Interventions Version 5.1.0 (updated March 2011). The Cochrane Collaboration, 2011. Available from handbook.cochrane.org.

\section{Sevick 2007}

Sevick MA, Trauth JM, Ling BS, Anderson RT, Piatt GA, Kilbourne AM, et al. Patients with complex chronic diseases: perspectives on supporting self-management. Journal of General Internal Medicine 2007;22:438-44.

\section{Smith 2016}

Smith SM, Wallace E, O'Dowd T, Fortin M. Interventions for improving outcomes in patients with multimorbidity in primary care and community settings. Cochrane Database of Systematic Reviews 2016, Issue 3. [DOI: 10.1002/14651858.CD006560.pub3]

\section{Smith 2018}

Smith SM, Wallace E, Salisbury C, Sasseville M, Bayliss E, Fortin M. A Core Outcome Set for multimorbidity research (COSmm). Annals of Family Medicine 2018;16:132-8.

\section{Stanford 2018}

Stanford Self Management Resource Centre. Self-Efficacy for Managing Chronic Disease 6-item Scale. Online 2018. [https:// www.selfmanagementresource.com/resources/evaluationtools/english-evaluation-tools (accessed 20 March 2019)]

\section{Starfield 1994}

Starfield B. Is primary care essential?. The Lancet 1994;344(8930):1129-33. 


\section{Steel 2014}

Steel N, Hardcastle AC, Clark A, Mounce LT, Bachmann MO, Richards SH, et al. Self-reported quality of care for older adults from 2004 to 2011: a cohort study. Age and Ageing 2014;43(5):716-20.

\section{Stewart 2000}

Stewart M, Belle Brown J, Conner A, McWhinney IR, Oates J, Weston WW, et al. The impact of patient-centered care on outcomes. Journal of Family Practice 2000;49(9):796-804.

\section{Stokes 2017}

Stokes J, Man MS, Guthrie B, Mercer SW, Salisbury C, Bower P. The foundations framework for developing and reporting new models of care for multimorbidity. Annals of Family Medicine 2017;15(6):570-7.

\section{Tate $\mathbf{2 0 1 0}$}

Tate AR, Nicholson A, Cassell JA. Are GPs under-investigating older patients presenting with symptoms of ovarian cancer? Observational study using General Practice Research Database. British Journal of Cancer 2010;102(6):947-51.

\section{Thompson 2002}

Thompson SG, Higgins JPT. How should meta-regression analyses be undertaken and interpreted?. Statistics in Medicine 2002;21(11):1559-73.

\section{Tinetti 2016}

Tinetti ME, Esterson J, Ferris R, Posner P, Blaum CS. Patient priority-directed decision making and care for older adults with multiple chronic conditions. Clinics in Geriatric Medicine 2016;32(2):261-75.

\section{Valderas 2019}

Valderas JM, Gangannagaripalli J, Nolte E, Boyd M, Roland M, Sarria-Santamera A, et al. Quality of care assessment for people with multimorbidity. Association for Publication of the Journal of Internal Medicine 2019;285:289-300.

\section{van den Brink-Muinen 2006}

van den Brink-Muinen A, van Dulmen SM, de Haes HC, Visser AP, Schellevis FG, Bensing JM. Has patients' involvement in primary care decision-making process changed over time?. Health Expectations 2006;9(4):333-42.

\section{Wensing 2003}

Wensing M, Baker R. Patient involvement in general practice care. European Journal of General Practice 2003;9(2):62-5.

\section{Wetzels 2007}

Wetzels R, Harmsen M, Van Wheel C, Grol R, Wensing M. Interventions for improving older patients' involvement in primary care episodes. Cochrane Database of Systematic Reviews 2007, Issue 1. [DOI: 10.1002/14651858.CD004273.pub2]

\section{WHO 1994}

World Health Organization. A declaration on the promotion of patients' rights in Europe (1994). www.who.int/genomics/ public/eu_declaration1994.pdf (accessed before 31 July 2018).

\section{WHO 2012}

World Health Organization. WHOQoL HIV instrument (2012). apps.who.int/iris/bitstream/10665/77774/1/ WHO_MSD_MER_Rev.2012.01_eng.pdf?ua=1 (accessed before 31 July 2018)

\section{WHO 2018}

World Health Organization. Declaration of Astana. Global Conference on Primary Healthcare 2018;1:https://www.who.int/ docs/default-source/primary-health/declaration/gcphcdeclaration.pdf (accessed 25 March 2019).

\section{References to other published versions of this review \\ Butterworth 2018}

Butterworth JE, Hays R, Richards SH, Bower P, Campbell J. Interventions for involving older patients with multimorbidity in decision-making during primary care consultations. Cochrane Database of Systematic Reviews 2018, Issue 9. [DOI: 10.1002/14651858.CD013124]

* Indicates the major publication for the study

\section{CHARACTERISTICS OF STUDIES}

Characteristics of included studies [ordered by study ID]

\section{Hochhalter 2010}

Methods Study design: randomised controlled trial; assumed parallel-group design; 3 arms: 'Making the Most of Your Health Care' intervention; 'Safety' group (attention control); usual care Definition of multi-morbidity: at least 2 of 7 qualifying chronic illnesses as defined by International Classification of Diseases (ICD-9) codes Study duration: study dates not reported; 6-month follow-up period

Participants

Description: patients 65 years or older with multi-morbidity $(26$ intervention +27 attention control +26 usual care)

Geographic location: study carried out in collaboration with the Scott \& White Center for Diagnostic Medicine, Temple, Texas, USA 
Setting: usual primary care clinic; patients' homes. However, staff delivering the intervention and attention-based control were unlikely to be the usual care providers

Age, mean (SD): intervention group 76 (7); safety group 73 (6); usual care group 73 (5)

Number of long-term conditions, mean (SD): intervention group 3.6 (0.9); safety group 3.3 (1.0); usual care group $3.8(1.2)$

Gender: $65.8 \%$ female

Ethnicity: 98\% non-Hispanic/Latino, 92.4\% white

Language: not reported (however, all included participants required to communicate in English)

Socioeconomic status: $60.6 \%$ had an annual household income of $\$ 50,000$ or more

Work status: not reported

IMD for practices: not reported

Place of residence: not reported

Education: $84.6 \%$ had received at least some college education

Frailty: Charlson Commorbidity Index, mean (SD): intervention group 1.5 (1.6); safety group 1.1 (0.9); control group 1.9 (1.6)

Mobility/functional ability: not reported (however, included participants were able to travel to the clinic for a workshop)

Receipt of carer support: not reported

Communication vulnerability: not reported

Intervention type: patient-focused; patient group workshop and individual coaching intervention, using evidence-based behaviour change techniques

Aims and rationale: to improve patient engagement and health-related quality of life using evidence-based behaviour change techniques. Intervention components were developed using the SelfDetermination Theory of motivation. The intervention provided information, offered tools, and taught skills to patients to prepare for healthcare appointments; communicate effectively and gather information and support during healthcare appointments; and follow through on plans of care

Materials: participants received print copies of 'A Guide for Older People: Talking with Your Doctor, Bound for Your Good Health'* and a list of local community resources upon arrival to the workshop. During the workshop, content from 'A Guide for Older People: Talking with Your Doctor'* was discussed including worksheets on "changes to discuss", "concerns", and "medications"^. Coaches utilised electronic health records. Coaching calls adhered to the 'Five As framework for behavioural counselling (assess, advise, agree, assist, arrange)'

Procedures: a 2-hour workshop led by a "coach" and 2 telephone calls tailored to the patient's pre- and post-healthcare appointment needs. The workshop covered introduction and breaking the ice; giving information and getting ready for appointments; getting information at appointments; and following through after appointments. The workshop involved group discussion, visual presentation, role-play of interactions with doctors, and individual practice. Coaches monitored participants' upcoming healthcare appointments using electronic records and provided a brief coaching phone call within a week before a scheduled appointment and another call within a week after that appointment. Phone calls were used to discuss the workshop content in the context of each participant's unique circumstances

Elements related specifically to patient involvement in decision-making: the workshop topic 'Getting Information at Appointments' included content on 'making decisions with your doctor', based on guidance from the National Institute on Ageing. Groups discussed examples of barriers to shared decision-making 
Mode of delivery: face-to-face group workshops; at-a-distance phone calls with individuals

Who delivered the intervention?

Health "coaches" delivered workshops and telephone calls. No further details were provided on the background or qualifications of the health coaches - assumed members of the research team

Where was the intervention provided?

Workshops were delivered at the patient's usual primary care clinic (a large internal medicine clinic). Assumed patients contacted on personal telephones for coaching calls, presumably in own homes, although not explicitly stated

When and how often or how much of the intervention was provided?

Three contacts: 1 workshop and 2 coaching telephone calls. Appointments were tracked for up to 3 months after baseline. Within 5 days before (pre-appointment call) and 5 days after (follow-up call), coaches contacted participants by telephone for sessions that lasted approximately 15 minutes. Workshops were offered at convenient times

Was the intervention tailored?

Coaching phone calls were tailored to the context of each participant's unique circumstances

Was the intervention modified or adapted?

No modifications or adaptations were reported

Outcomes

High self-rated health

Tool: the 'Healthy Days Measure' (CDC 2000) 5-point scale; higher scores = higher self-rated health

Review category: health status

Timing of measurement: baseline and at 6 months

Patient activation

Tool: patient self-report using the Patient Activation Measure (Hibbard 2005); scale 0 to 100; higher score $=$ greater patient activation

Review category: patient enablement and engagement

Timing of measurement: baseline and at 6 months

Number of outpatient/clinic visits

Tool/measure not reported

Review category: resource use and cost

Timing of measurement: baseline and at 6 months

Control or usual care Usual care: primary care within a large internal medicine clinic

Control: attention-control condition (safety group): patient-focused; employed the same types and numbers of contacts as the intervention. The topic of the safety contacts was "general safety for older adults", and content included arranging the home environment to avoid falls and fire risks, identifying theft, and discussing caregiver stress

Funding source and poten- Funding: the study was supported by a grant from the Scott \& White Healthcare Research Foundation tial conflicts of interest Potential conflicts of interest: insufficient information reported

Notes

*National Institute on Aging publications

Other outcomes, considered of less relevance to the review:

Communication with physicians scale

Total unhealthy days 
Hochhalter 2010 (Continued)

\author{
Unhealthy mental days \\ Unhealthy physical days \\ Self-efficacy for managing chronic disease measure \\ Number of emergency department visits \\ Number of hospitalisations \\ Nights spent in the hospital \\ Number of chronic illness diagnoses \\ Charlston Comorbidity Index
}

\title{
Risk of bias
}

\begin{tabular}{lll}
\hline Bias & Authors' judgement & Support for judgement \\
\hline $\begin{array}{ll}\text { Random sequence genera- } \\
\text { tion (selection bias) }\end{array}$ & Low risk & Randomisation using computer software \\
& & $\begin{array}{l}\text { "The randomization schedule was generated using SAS version } 9.1 .2 \text { (SAS In- } \\
\text { stitute Inc., Cary, NC) with an equal proportion assigned to each of the three } \\
\text { groups in the master list" }\end{array}$ \\
\hline
\end{tabular}

\begin{tabular}{ll}
\hline $\begin{array}{l}\text { Allocation concealment } \\
\text { (selection bias) }\end{array}$ & Randomisation occurred after enrolment; central allocation was used \\
& "Following baseline, a study coordinator who also served as a coach requested \\
& group assignment from the biostatistics office for each participant"
\end{tabular}

\begin{tabular}{|c|c|c|}
\hline $\begin{array}{l}\text { Blinding of participants } \\
\text { and personnel (perfor- }\end{array}$ & Unclear risk & $\begin{array}{l}\text { Assumed blinding was not possible in all cases due to the nature of the inter- } \\
\text { vention; however, it is unclear whether this could have affected outcomes }\end{array}$ \\
\hline
\end{tabular}
vention; however, it is unclear whether this could have affected outcomes mance bias)

All outcomes

\begin{tabular}{|c|c|c|}
\hline $\begin{array}{l}\text { Blinding of outcome as- } \\
\text { sessment (detection bias) } \\
\text { All outcomes }\end{array}$ & Unclear risk & $\begin{array}{l}\text { Telephone interviewers were blinded, but it is not stated whether or not ex- } \\
\text { tracting data from EHRs involved "telephone interviews [were] conducted by a } \\
\text { research assistant who was blinded to group assignment" }\end{array}$ \\
\hline $\begin{array}{l}\text { Incomplete outcome data } \\
\text { (attrition bias) } \\
\text { All outcomes }\end{array}$ & Low risk & $\begin{array}{l}\text { Some imbalance between groups but not enough to class as high-risk. ITT } \\
\text { analysis }\end{array}$ \\
\hline $\begin{array}{l}\text { Selective reporting (re- } \\
\text { porting bias) }\end{array}$ & Unclear risk & Unable to find the protocol or trial registration \\
\hline Other bias & Low risk & No other obvious sources of bias \\
\hline
\end{tabular}

Reed 2018

$\begin{array}{ll}\text { Methods } & \text { Study design: randomised controlled trial; parallel-group design; } 2 \text { arms: 'chronic disease self-manage- } \\ \text { ment support' (CDSMS) intervention; 'positive attention' control } \\ \text { Definition of multi-morbidity: } 2 \text { or more of } 8 \text { types of chronic conditions identified as Australian Nation- } \\ \text { al Health priority areas but with the addition of several chronic conditions that are frequently managed } \\ \text { in Australian general practice } \\ \text { Study duration: September } 2009 \text { to June 2010; 6-month follow-up period }\end{array}$

Participants Description: patients at least 60 years old with multi-morbidity $(127+127)$


Setting: general practice, patient's home. Research set up with no direct contact between providers and participants' usual GPs or other healthcare providers

Age: CDSMS group: $48 \%$ aged 60 to $75,36 \%$ aged 76 to $85,16 \%$ aged $>85$; control group: $46 \%$ aged 60 to $75,40 \%$ aged 76 to $85,14 \%$ aged $>85$

Number of long-term conditions (S): CDSMS group 4.4 (0.11); control group 4.5 (0.12)

Gender: CDSMS group 59\% women; control group 61\% women

Country of birth: CDSMS group: Australia 76\%, Ireland or United Kingdom 14\%, Europe 9\%, Other 1\%; control group: Australia 76\%, Ireland or United Kingdom 13\%, Europe 8\%, Other 2\%

Language: not reported; however, all eligible participants spoke English

Socioeconomic status: household income CDSMS group: $\$ 0$ to $20,00029 \%, \$ 20,001$ to $40,00044 \%$, > $\$ 40,00022 \%$; missing data: $6 \%$; household income control group: $\$ 0$ to $20,00031 \%, \$ 20,001$ to 40,000 $47 \%$, > \$40,000 17\%; missing data: $6 \%$

Work status: CDSMS group: $85 \%$ retired from employment, $9 \%$ home duties, $6 \%$ other; control group: $85 \%$ retired from employment, $10 \%$ home duties, $5 \%$ other

\section{IMD for practices: not reported}

Place of residence: not explicitly reported but those residing in a long-term care facility were excluded

Education: CDSMS group: $39 \%$ left school age 15 or earlier, $61 \%$ left school after age 15; control group: $49 \%$ left school age 15 or earlier, $51 \%$ left school after age 15

Frailty: not reported

Mobility/functional ability: not reported

Receipt of carer support: not reported

Communication vulnerability: not reported

Intervention type: patient-focused; an individual patient coaching intervention, utilising cognitive-behavioural therapy (CBT) and motivational interviewing (MI)

Aims and rationale: based on the Flinders Chronic Condition Management Programme (Battersby 2007), the CDSMS programme is designed to be a structured intervention based on cognitive-behavioural therapy and motivational interviewing, with the aim of achieving sustained behaviour change for patients by increasing patients' skills and confidence in managing their chronic diseases. Theoretical reasons for utilising CDSMS for older people with multi-morbidity are reported: (1) complexity of information and treatment regimens, and (2) need for priority setting

Materials: 3 standardised assessment and planning tools, designed to actively assist participants to achieve actions and goals and to develop and review a care plan: 'Partners in Health Scale'; 'Cue and Response Interview'; 'Problems and Goals Assessment'

Procedures: a structured process to enable clinicians and patients to collaboratively assess self-management behaviour, identify problems, set goals, and develop individual care plans that address selfcare, medical, psychosocial, and carer problems. The health professional's role is to facilitate goal-setting and to act as coach and advisor. The participant's role is in active decision-making in collaboration with the health professional. The 'Partners in Health Scale' is used first, the 'Cue and Response Interview' is then used to collaboratively identify problems and motivate behaviour change, and the 'Problems and Goals Assessment' is then used to identify goals; finally, a care plan is written 
Reed 2018 (Continued)

Elements related specifically to patient involvement in decision-making: facilitated goal-setting; active decision-making in collaboration and care plan development and review between patient and health professional

Mode of delivery: a combination of paper-based, face-to-face, and over-the-phone delivery

Who delivered the intervention?

Clinical staff, with qualifications in nursing or psychology and associated with the research team, delivered the intervention. There was no direct contact between these staff and participants' GPs or other healthcare providers. Ongoing mentoring from accredited trainers was available to clinicians delivering the CDSMS and control programmes. Participants continued taking routine medications and visiting their usual primary care physician throughout the study

Where was the intervention provided?

Patients' homes, metropolitan Adelaide, South Australia

When and how often or how much of the intervention was provided?

Participants in each programme received 3 home visits and 4 follow-up phone calls over a 6 -month period

Was the intervention tailored?

Care plans were individualised

Was the intervention modified or adapted?

No modifications or adaptations were reported

\section{Outcomes}

\section{Self-rated health}

Tool: 5-point scale initially developed for the US National Health and Nutrition Examination Survey; higher scores $=$ higher self-rated health

Review category: health status

Timing of measurement: baseline and at 6 months

Self-efficacy

Tool: Patient self-report using the self-efficacy for managing chronic disease scale (Stanford 2018); higher scores $=$ higher self-efficacy

Review category: patient enablement and engagement

Timing of measurement: baseline and at 6 months

(Review authors have calculated the SD from the SE for this outcome)

Patient reports of whether the programme changed management of their health conditions Tool: patient self-report via questionnaire using a 3-point scale; higher score = higher perception of changed management

Review category: patient evaluation of care/the intervention

Timing of measurement: baseline and at 6 months

Numbers of general practice visits during the preceding 6 months

Tool: patient self-report via questionnaire

Review category: resource use and cost

Timing of measurement: baseline and at 6 months

(Review authors have calculated the SD from the SE for this outcome)
Control: attention-control condition: patient-focused.

The comparator group was chosen to control for the positive benefits of receiving attention from a health professional. The semi-structured approach, delivered by clinical staff associated with the re- 
Reed 2018 (Continued)

search team, provided health information, non-directive counselling, and supportive listening. The approach used no assessment or self-management tools; however, personalised health information was provided to facilitate health-related conversations. The clinician's role was to provide positive attention. The participant's role was to passively receive health information and to participate in informal conversations

Provided in patients' homes, metropolitan Adelaide, South Australia

Participants in each programme received 3 home visits and 4 follow-up phone calls over a 6-month period

Funding source and potential conflicts of interest
Funding: Australian Department of Health and Ageing (DoHA) under the Sharing Health Care Initiative Innovations in Chronic Disease Self-Management Research Grants programme

Potential conflicts of interest:

Richard Osborne was supported in part by a National Health and Medical Research Council Population Health Research Fellowship (Career Development Award)

Malcolm Battersby is the developer of the Flinders Program but declares no financial interest

\begin{tabular}{l} 
Other outcomes, considered of less relevance to the review: \\
Health status: fatigue \\
Health status: pain \\
Health status: health distress \\
Health status: energy \\
Health status: depression \\
Health status: illness intrusiveness \\
Health behaviours: exercise \\
Health behaviours: medication adherence \\
Numbers of emergency department visits \\
Numbers of hospital admissions \\
Rating of usefulness of the programme \\
Whether the program improved patients' relationship with their GP \\
Whether patients would recommend the programme to other patients \\
Perceived usefulness of the programme in improving patients' health \\
\hline
\end{tabular}

\section{Risk of bias}

\begin{tabular}{lll}
\hline Bias & Authors' judgement & Support for judgement \\
\hline $\begin{array}{l}\text { Random sequence genera- } \\
\text { tion (selection bias) }\end{array}$ & Low risk & Computer-generated randomisation sequence \\
\hline $\begin{array}{l}\text { Allocation concealment } \\
\text { (selection bias) }\end{array}$ & Low risk & $\begin{array}{l}\text { Central allocation after baseline } \\
\text { "A printed record of the allocation sequence was retained by an independent, } \\
\text { centrally located hospital pharmacy ... carried out after the baseline inter- } \\
\text { view" }\end{array}$ \\
\hline
\end{tabular}


Reed 2018 (Continued)

Blinding of participants Low risk Incomplete blinding (participants but not research personnel), but the review and personnel (perforauthors judge that the outcome is not likely to be influenced by lack of blindmance bias)

All outcomes ing

"Participants provided written, informed consent for participation; they were blinded to their allocation, but the investigators were not"

Blinding of outcome as- Unclear risk Insufficient information to permit judgement of 'low risk' or 'high risk'

sessment (detection bias)

All outcomes

Incomplete outcome data Low risk

(attrition bias)

Attrition was balanced. ITT analysis; method of imputation reported

All outcomes

"The analyses were intention-to-treat analyses; missing data were imputed according to the baseline-value-carried-forward method"

Selective reporting (re- Low risk

porting bias)

The study protocol is available, and all of the study's pre-specified (primary and secondary) outcomes that are of interest in the review have been reported in the pre-specified way

Other bias Low risk No other obvious sources of bias

Salisbury 2018

Methods $\quad$ Study design: cluster-randomised controlled trial; 2 arms: '3D' intervention; usual care. Clusters at practice level. Allocations were made in blocks of 2 per area, with an intervention and a control practice allocated simultaneously

Definition of multi-morbidity: at least 3 types of chronic conditions from a list of 11 compiled by grouping the 17 chronic conditions included in the UK Quality and Outcomes Framework (QOF) pay-for-performance programme into types of conditions with similar management considerations Study duration: March 2014 to September 2017; 15-month follow-up period

Participants

Description: patients with multi-morbidity $(797+749)$ from 33 practices: 16 intervention practices, 17 usual care practices

Geographical location: Bristol and Greater Manchester in England, and Ayrshire in Scotland

Setting: GP surgeries providing National Health Service (NHS) primary medical care. Patients' usual general practice and usual primary care providers

Age, mean (SD): intervention group 71.0 (11.6), control group 70.7 (11.4)

Number of long-term conditions (SD): $3.2(0.5)$

Gender: intervention group female 51\%; control group female $50 \%$

Ethnicity: intervention group: white 99\%; other or unknown 1\%; control group: white 99\%; other or unknown $1 \%$

Language: no English language was an exclusion criterion; no further details provided

Socioeconomic status: intervention group fully retired from work $71 \%$; control group fully retired from work $69 \%$

IMD for practices: intervention group: English 15.6 (9.6), $\mathrm{n}=11$, Scottish 24.2 (20.0), $\mathrm{n}=5$; control group: English 15.8 (12.2), $n=12$, Scottish 26.4 (18.3), $n=5$

Place of residence: not reported

Education: not reported 


\section{Frailty: not reported}

Mobility/functional ability: not explicitly reported; however, some aspects captured in 'health-related quality of life' measure

\section{Receipt of carer support: not reported}

Communication vulnerability: some likely to have been excluded by eligibility criteria; however, $1 \%$ of both groups had a learning disability and $4 \%$ of both groups had dementia

Intervention type: patient-focused, practitioner-focused, and related to organisational change; a comprehensive, holistic intervention, utilising multi-disciplinary practitioner training and organisational change with the aim to maximise continuity, co-ordination, and efficiency of care

Aims and rationale: a patient-centred care model, encapsulating strategies recommended in recent international guidelines (ref), replacing disease-focused review of each health condition with one 6monthly comprehensive multi-disciplinary review. The 3D intervention has the aim of improving continuity, co-ordination, and efficiency of care for patients with multi-morbidity. Using the 3D review, study authors seek to address the burden of treatment for patients with multi-morbidity. Study authors report that if each condition is considered in isolation, patients can be prescribed numerous drugs and lifestyle changes, and are expected to attend frequent healthcare appointments

Materials: an electronic template integrated within the EMIS electronic medical records system reinforces the patient-centred approach and is interactive, with prompts for clinicians that change depending on the patient's combination of chronic conditions. In addition, an appointment letter asked the patient to think about the health problems that bother them most, and patients were provided with a 3D wallet card, naming their responsible doctor

Procedures: each 3D review consists of 2 appointments (a nurse appointment and a named responsible physician appointment) and a records-based medication review by a pharmacist. "The nurse focuses on identifying the health problems most important to the patient; asking about pain, function, and quality of life; screening for depression and dementia; and then addressing the disease-specific care the patient requires. Findings are printed as a patient-held agenda to inform the subsequent consultation with the doctor. The pharmacist uses the patient's electronic medical records to review medication, and makes recommendations about simplifying and optimising treatment. The physician considers the nurse and pharmacist reviews, discusses treatment adherence, and agrees on a collaborative health plan with the patient. The patient is given a printed copy of the plan, which specifies how the patient and clinicians will address the agreed goals over the next 6 months through routine consultations" (Procedures, pp 43-44)

Elements related specifically to patient involvement in decision-making: training sessions with clinicians included how to identify patients' priorities and agree on a health plan with patients that was 'SMART' (Specific; Measurable; Achievable; Realistic; Time-bound). The 3D review seeks to identify the health problems of most importance to the patient, along with additional problems from the clinician's point of view. All problems are shared with the patient after the first consultation in an 'agenda' document, to encourage collaboration. During a subsequent GP consultation, a holistic, collaborative plan is made to address the agenda, guided by the patient's top 4 priorities for action. This health plan is documented and printed as the result of an agreed, negotiated discussion

Mode of delivery: assumed patients sent appointment letter by post. Location of patient appointments not recorded but assumed face-to-face. Medication reviews records-based and not appearing to involve patients directly

Who delivered the intervention?

Each practice identified a local champion to support implementation. At practice level, changes were made to flag patients with multi-morbidity in electronic medical records systems; promote continuity of care; provide a 3D wallet card for patients, naming the responsible doctor; encourage patients to ask for longer appointments when needed; train clinicians and receptionists; replace separate disease-focused reviews with one 6-monthly whole-person 3D review; and implement an interactive 3D electronic data entry template. Each patient was allocated a usual responsible GP and nurse, who would conduct 
the $3 \mathrm{D}$ reviews. All practice clinical staff involved in delivering the intervention received 2 half-days of training. Administrative staff were trained in a separate meeting

Where was the intervention provided?

The intervention was delivered at the patient's usual GP practice

When and how often or how much of the intervention was provided?

The intention was for patients to receive $23 \mathrm{D}$ reviews within a 12-month period, with reviews carried out every 6 months

Was the intervention tailored?

Disease-specific questions and prompts (presented to clinicians via the electronic template) varied depending on the patient's combination of conditions

Was the intervention modified or adapted?

The intervention was not modified nor adapted

Outcomes

Health-related quality of life

Tool: patient self-report using the EQ-5D-5L measure (Herdman 2011); higher scores = higher perceived quality of life

Review category: health status

Timing of measurement: baseline, at 9 months (data not extracted), and at 15 months

(Results have been recalculated for analysis using data as presented in the trial report)

Treatment burden

Tool: patient self-report using the Multi-morbidity Treatment Burden Questionnaire (MTBQ) (Duncan

2018); higher score = higher perceived burden

Review category: treatment burden

Timing of measurement: baseline, at 9 months (data not extracted), and at 15 months

(Results have been recalculated for analysis using data as presented in the trial report)

Medication adherence

Tool: patient self-report using the Morisky Medication Adherence Scale (Morisky 2008); higher score = greater adherence

Review category: patient enablement and engagement

Timing of measurement: baseline and at 15 months

(Results have been recalculated for analysis using data as presented in the trial report) Patient-centred care: proportion who discussed the problems most important to them

Tool: patient self-report using a single question and a 5-point scale, adapted from the General Practice

Patient Survey (Ipsos MORI 2015); higher score = higher perception of discussing priorities

Review category: patient evaluation of care/the intervention

Timing of measurement: baseline, at 9 months (data not extracted), and at 15 months

(Results have been recalculated for analysis using data as presented in the trial report)

\section{Carer experience}

Tool: carer self-report using a 6-item carer experience questionnaire (Al-Janabi 2011); score 0 to 100; higher scores $=$ better experience with the health care provided

Review category: patient and carer outcomes

Timing of measurement: baseline and at 15 months 
Salisbury 2018 (Continued)

(Results have been recalculated for analysis using data as presented in the trial report)

Number of consultations in primary care: nurse

Tool: routine review of medical records by the research team

Review category: resource use and cost

Timing of measurement: baseline and at 15 months

(Results have been recalculated for analysis using data as presented in the trial report) Number of indicators of high-risk prescribing

Tool: review of routine electronic health records using an approach developed for a previous trial

(Dreischulte 2016)

Review category: quality of care

Timing of measurement: at 15 months

(Results have been recalculated for analysis using data as presented in the trial report)

Control or usual care

Funding source and potential conflicts of interest
Usual care. In UK, mainly consists of: nurse-led disease-specific chronic disease reviews focused on meeting the outcomes of the UK Quality and Outcomes Framework pay-for-performance scheme

Funding: National Institute for Health Research, Health Services and Delivery Research programme, project number $12 / 130 / 15$

Potential conflicts of interest:

One study author is a member of the NIHR Health Services and Delivery Research Board

Another study author chairs the Guideline Development Group of the National Institute for Health and

Clinical Excellence (NICE) Multimorbidity Clinical Guideline NG56 and was a member of the NIHR Health

Services and Delivery Research researcher-led panel

All other study authors declared no competing interests

Notes

Other outcomes, considered of less relevance to the review:

Burden of illness: self-rated health

Burden of illness: how much illness affects the individual's life

Burden of illness: anxiety

Burden of illness: depression

Polypharmacy: number of different drugs prescribed in last 3 months

Patient-centred care: doctor

Patient-centred care: nurse

Patient-centred care: proportion experiencing care as joined up

Patient-centred care: proportion having written a care plan, health plan, or treatment plan

Satisfaction with care

Continuity of care: Continuity of Care Index

Discontinuity of care: Visit Entropy measure

Number of consultations in primary care: physician

Number of consultations and secondary care: hospital admissions

Number of consultations and secondary care: outpatient attendance

Additional cost-effectiveness data

Quality of disease management: proportion of applicable QOF chronic disease targets met 


\section{Risk of bias}

Bias Authors' judgement Support for judgement

Random sequence genera- Low risk tion (selection bias)

Sequence generation appears sufficient to ensure random assignment of participants

"The randomisation system was run from the Bristol Randomised Trials Collaboration by the trial statistician, who was masked to practice identifiers. Allocations were done in blocks of two in each area, with an intervention and a control practice allocated simultaneously"

\begin{tabular}{ll}
\hline $\begin{array}{l}\text { Allocation concealment } \\
\text { (selection bias) }\end{array}$ & Randomisation carried out after practice recruitment \\
& "Patients were assessed for eligibility and invited to participate before prac- \\
& tice allocation, and were not informed of their practice's allocation until they \\
& had given consent and completed baseline measures... The randomisation \\
& system was run from the Bristol Randomised Trials Collaboration by the trial \\
& statistician, who was masked to practice identifiers. Allocations were done in \\
blocks of two in each area, with an intervention and a control practice allocat- & ed simultaneously so that concealment of allo cation was maintained"
\end{tabular}

$\begin{array}{lll}\begin{array}{l}\text { Blinding of participants } \\ \text { and personnel (perfor- }\end{array} & \text { Unclear risk } & \begin{array}{l}\text { Not done. Some potential for this to influence outcomes but not clear if this } \\ \text { occurred }\end{array}\end{array}$

"Because of the nature of the intervention, practices and participants were

mance bias)

All outcomes aware of their treatment allocation"

\begin{tabular}{|c|c|c|}
\hline Blinding of outcome as- & Unclear risk & Some blinding/automation but not for all outcomes \\
\hline All outcomes & & $\begin{array}{l}\text { "Outcome data were selfreported or based on automated extraction of data } \\
\text { from the electronic medical records, except for details of hospital use, which } \\
\text { were collected manually by researchers who were aware of practice alloca- } \\
\text { tion. Analysis was done by the trial statistician (DG), who was masked to allo- } \\
\text { cation, except for details of healthcare use, for which masking could not be } \\
\text { maintained" }\end{array}$ \\
\hline
\end{tabular}

Incomplete outcome data Unclear risk (attrition bias)

All outcomes
Intention-to-treat analysis; attrition not reported; lack of data for some items and some imbalance between groups but not enough to be classed as high risk; method of imputation reported (for the primary outcome)

"We used multiple imputation by chain equations including baseline, 9month, 15 month, and EQ5D5L data as available, intervention group, stratification and minimisation variables, and other covariates that were informative of missingness"

$\begin{array}{ll}\begin{array}{l}\text { Selective reporting (re- } \\ \text { porting bias) }\end{array} & \text { Low risk } \\ & \begin{array}{l}\text { Protocol available. All pre-specified outcomes reported either in the paper or } \\ \text { in the full report }\end{array}\end{array}$

Other bias Low risk Selective recruitment of cluster participants:

Cluster participants were recruited before group assignment, and the same participants were followed up over time; therefore low risk of selective recruitment of cluster participants; no other obvious sources of bias

"Patients were assessed for eligibility and invited to participate before practice allocation" 
3D: intervention that was both patient- and practitioner-focused and addressed organisational change.

CBT: cognitive-behaviour therapy.

CDSMS: Chronic Disease Self-Management Support programme.

EHR: electronic health record.

EQ-5D-5L: EuroQoL Group Quality of Life Questionnaire based on a five-level scale.

GP: general practitioner.

IMD: XXX.

ITT: intention-to-treat.

MI: motivational interview.

MTBQ: Multi-morbidity Treatment Burden Questionnaire.

NHS: National Health Service.

NICE: National Institute for Health and Care Excellence.

QOF: Quality and Outcomes Framework.

SD: standard deviation.

SE: standard error.

SMART: Specific; Measurable; Achievable; Realistic; Time-bound plan,

Characteristics of excluded studies [ordered by study ID]

\begin{tabular}{|c|c|}
\hline Study & Reason for exclusion \\
\hline Alkema 2007 & Wrong setting \\
\hline Beck 2013 & Wrong intervention \\
\hline Berglund 2013 & Wrong setting \\
\hline Berglund 2015 & Wrong setting \\
\hline Bernabei 1998 & Wrong setting \\
\hline Bielaszka-DuVernay 2011 & Wrong intervention \\
\hline Blom 2016 & Wrong patient population \\
\hline Bosma 2011 & Wrong patient population \\
\hline Boult 2008 & Wrong intervention \\
\hline Boult 2011a & Wrong intervention \\
\hline Boult 2011b & Wrong intervention \\
\hline Boult 2013 & Wrong intervention \\
\hline Boyd 2007 & Wrong intervention \\
\hline Boyd 2008 & Wrong intervention \\
\hline Caughey 2017 & Wrong setting \\
\hline Cheema 2017 & Wrong intervention \\
\hline Cheng 2018 & Wrong patient population \\
\hline Chi-Jane 2013 & Wrong intervention \\
\hline
\end{tabular}




\begin{tabular}{|c|c|}
\hline Study & Reason for exclusion \\
\hline Chow 2014 & Wrong setting \\
\hline Coburn 2012 & Wrong patient population \\
\hline Dorr 2008 & Wrong intervention \\
\hline Dowrick 2018 & Wrong study design \\
\hline Dye 2018 & Wrong intervention \\
\hline Elzen 2007 & Wrong patient population \\
\hline Engelhardt 2009 & Wrong patient population \\
\hline Fortin 2016 & Wrong patient population \\
\hline Freund 2011 & Wrong setting \\
\hline Fried 2017 & Wrong study design \\
\hline Ganz 2010 & Wrong patient population \\
\hline Glaser 2017 & Wrong patient population \\
\hline Hanlon 1996 & Wrong intervention \\
\hline Harrison 2012 & Wrong patient population \\
\hline Ivey 2018 & Wrong patient population \\
\hline Jerant 2009 & Wrong patient population \\
\hline Joos 1996 & Wrong setting \\
\hline Junius-Walker 2012 & Wrong patient population \\
\hline Kangovi 2017 & Wrong patient population \\
\hline Kennedy 2013 & Wrong patient population \\
\hline Kim 2017 & Wrong intervention \\
\hline Lin 2012 & Wrong patient population \\
\hline LudmanEvette 2013 & Wrong patient population \\
\hline Légaré 2015 & Wrong patient population \\
\hline Markle-Reid 2018 & Wrong setting \\
\hline Panagioti 2018 & Wrong intervention \\
\hline Sudore 2017 & Wrong patient population \\
\hline Valdivieso 2018 & Wrong intervention \\
\hline
\end{tabular}




\begin{tabular}{ll}
\hline Study & Reason for exclusion \\
\hline Von 2011 & Wrong patient population \\
\hline Wetzels 2005 & Wrong patient population \\
\hline Willeboordse 2017 & Wrong patient population \\
\hline Wissow 2004 & Wrong patient population \\
\hline Wrede 2013 & Wrong patient population \\
\hline
\end{tabular}

Characteristics of ongoing studies [ordered by study ID]

\section{Steel 2016}

\begin{tabular}{ll}
\hline Trial name or title & Goal-setting in care planning for people with multi-morbidity \\
\hline Methods & $\begin{array}{l}\text { Cluster-randomised controlled feasibility trial of goal-setting compared with control in } 6 \text { general } \\
\text { practices }\end{array}$ \\
\hline Participants & Adults with 2 or more long-term health conditions and at risk of unplanned hospital admission \\
\hline Interventions & $\begin{array}{l}\text { General practitioners (GPs) undergo training and patients are asked to consider goals before an ini- } \\
\text { tial goal-setting consultation and a follow-up consultation } 6 \text { months later. The control group re- } \\
\text { ceives usual care planning }\end{array}$
\end{tabular}

\section{Outcomes}

Health-related quality of life (EQ-5D-5L), capability (ICEpop CAPability measure for Older people), Patient Assessment of Chronic Illness Care and healthcare use

\begin{tabular}{ll}
\hline Starting date & March 2015 \\
\hline Contact information & n.steel@uea.ac.uk \\
\hline
\end{tabular}

Notes

\section{DATA AND ANALYSES}

\section{Comparison 1. Interventions for involving patients in decision-making about their health care vs usual care for} older patients with multi-morbidity

\begin{tabular}{lllll}
\hline Outcome or subgroup title & $\begin{array}{l}\text { No. of } \\
\text { studies }\end{array}$ & $\begin{array}{l}\text { No. of } \\
\text { partici- } \\
\text { pants }\end{array}$ & Statistical method & Effect size \\
\hline $\begin{array}{l}1 \text { Health status: high self-rated health (CDC 'Healthy Days } \\
\text { Measure') at } 6 \text { months }\end{array}$ & 1 & 41 & $\begin{array}{l}\text { Risk Ratio (M-H, Random, } \\
95 \% \mathrm{Cl})\end{array}$ & $\begin{array}{l}1.4[0.36, \\
5.49]\end{array}$ \\
\hline $\begin{array}{l}2 \text { Health status: health-related quality of life (EQ-5D-5L mea- } \\
\text { sure) at } 15 \text { months }\end{array}$ & 1 & 1546 & $\begin{array}{l}\text { Mean Difference (Ran- } \\
\text { dom, 95\% Cl) }\end{array}$ & $\begin{array}{l}0.0 \text { [-0.02, } \\
0.02]\end{array}$ \\
\hline
\end{tabular}




\begin{tabular}{|c|c|c|c|c|}
\hline Outcome or subgroup title & $\begin{array}{l}\text { No. of } \\
\text { studies }\end{array}$ & $\begin{array}{l}\text { No. of } \\
\text { partici- } \\
\text { pants }\end{array}$ & Statistical method & Effect size \\
\hline $\begin{array}{l}3 \text { Treatment burden (Multi-morbidity Treatment Burden } \\
\text { Questionnaire) at } 15 \text { months }\end{array}$ & 1 & 1251 & $\begin{array}{l}\text { Mean Difference (Ran- } \\
\text { dom, } 95 \% \mathrm{Cl} \text { ) }\end{array}$ & $\begin{array}{l}-0.46[-1.78, \\
0.86]\end{array}$ \\
\hline $\begin{array}{l}4 \text { Patient enablement and engagement: patient activation } \\
\text { (Patient Activation Measure) at } 6 \text { months }\end{array}$ & 1 & 41 & $\begin{array}{l}\text { Mean Difference (IV, Ran- } \\
\text { dom, } 95 \% \mathrm{CI} \text { ) }\end{array}$ & $\begin{array}{l}0.60[-9.23 \\
10.43]\end{array}$ \\
\hline $\begin{array}{l}5 \text { Patient enablement and engagement: medication adher- } \\
\text { ence (Morisky Medication Adherence Scale) at } 6 \text { months }\end{array}$ & 1 & 1546 & $\begin{array}{l}\text { Mean Difference (Fixed, } \\
95 \% \mathrm{Cl})\end{array}$ & $\begin{array}{l}0.06[-0.05 \\
0.17]\end{array}$ \\
\hline $\begin{array}{l}6 \text { Patient evaluation of care/the intervention: care related to } \\
\text { priorities (adapted question from General Practice Patient } \\
\text { Survey) at } 15 \text { months }\end{array}$ & 1 & 1211 & $\begin{array}{l}\text { Odds Ratio (Random, } \\
95 \% \mathrm{Cl} \text { ) }\end{array}$ & $\begin{array}{l}1.85[1.44 \\
2.38]\end{array}$ \\
\hline $\begin{array}{l}7 \text { Carer evaluation of care: carer experience (Carer Experi- } \\
\text { ence Questionnaire) at } 15 \text { months }\end{array}$ & 1 & 94 & $\begin{array}{l}\text { Mean Difference (Ran- } \\
\text { dom, } 95 \% \mathrm{Cl} \text { ) }\end{array}$ & $\begin{array}{l}6.51[0.25 \\
12.77]\end{array}$ \\
\hline $\begin{array}{l}8 \text { Resource use and cost: number of nurse consultations (re- } \\
\text { view of medical records) at } 15 \text { months }\end{array}$ & 1 & 1517 & $\begin{array}{l}\text { Rate Ratio (Random, 95\% } \\
\mathrm{Cl} \text { ) }\end{array}$ & $\begin{array}{l}1.37[1.17 \\
1.61]\end{array}$ \\
\hline $\begin{array}{l}9 \text { Quality of care: number of indicators of high-risk prescrib- } \\
\text { ing (review of medical records) at } 15 \text { months }\end{array}$ & 1 & 1521 & $\begin{array}{l}\text { Rate Ratio (Random, 95\% } \\
\text { Cl) }\end{array}$ & $\begin{array}{l}1.04[0.87 \\
1.25]\end{array}$ \\
\hline
\end{tabular}

Analysis 1.1. Comparison 1 Interventions for involving patients in decision-making about their health care vs usual care for older patients with multi-morbidity, Outcome 1 Health status: high self-rated health (CDC 'Healthy Days Measure') at 6 months.

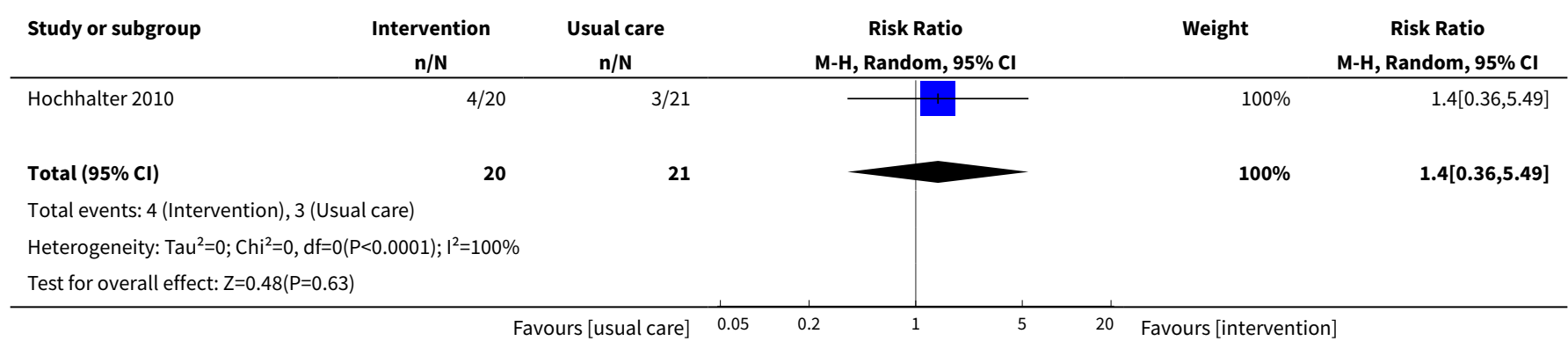

Analysis 1.2. Comparison 1 Interventions for involving patients in decision-making about their health care vs usual care for older patients with multi-morbidity, Outcome 2 Health status: health-related quality of life (EQ-5D-5L measure) at 15 months.

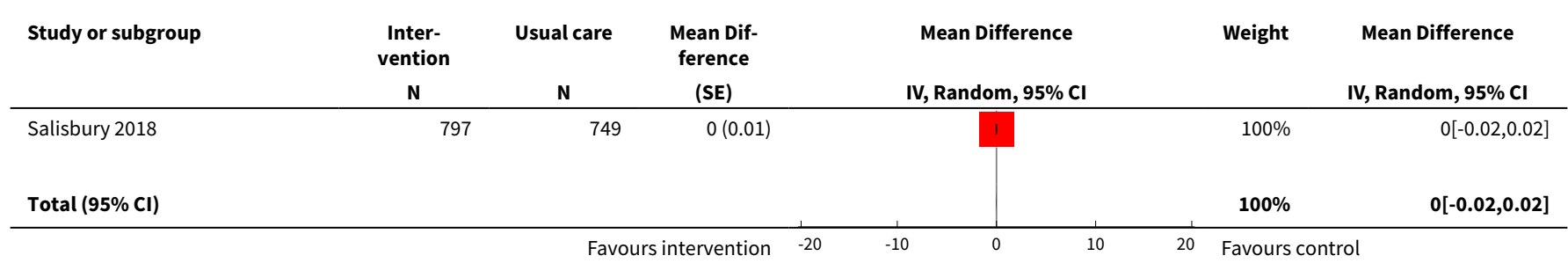




\begin{tabular}{llcc|ccc} 
Study or subgroup & $\begin{array}{c}\text { Inter- } \\
\text { vention } \\
\text { N }\end{array}$ & Usual care & $\begin{array}{c}\text { Mean Dif- } \\
\text { ference } \\
\text { (SE) }\end{array}$ & & \multicolumn{2}{c}{ Mean Difference Random, $\mathbf{9 5 \%} \mathbf{C l}$} \\
\hline $\begin{array}{l}\text { Heterogeneity: Not applicable } \\
\text { Test for overall effect: Not applicable }\end{array}$ & & & & & \\
\hline
\end{tabular}

Analysis 1.3. Comparison 1 Interventions for involving patients in decision-making about their health care vs usual care for older patients with multi-morbidity, Outcome 3 Treatment burden (Multi-morbidity Treatment Burden Questionnaire) at 15 months.

\begin{tabular}{|c|c|c|c|c|c|c|}
\hline Study or subgroup & $\begin{array}{c}\text { Inter- } \\
\text { vention } \\
\mathbf{N}\end{array}$ & $\begin{array}{l}\text { Usual care } \\
\text { N }\end{array}$ & $\begin{array}{c}\text { Mean Dif- } \\
\text { ference } \\
\text { (SE) }\end{array}$ & $\begin{array}{c}\text { Mean Difference } \\
\text { IV, Random, 95\% CI }\end{array}$ & Weight & $\begin{array}{c}\text { Mean Difference } \\
\text { IV, Random, } 95 \% \mathrm{CI}\end{array}$ \\
\hline Salisbury 2018 & 625 & 626 & $-0.5(0.674)$ & & $100 \%$ & $-0.46[-1.78,0.86]$ \\
\hline Total (95\% Cl) & & & & & $100 \%$ & $-0.46[-1.78,0.86]$ \\
\hline \multicolumn{7}{|c|}{ Heterogeneity: $\mathrm{Tau}^{2}=0 ; \mathrm{Chi}^{2}=0, \mathrm{df}=0(\mathrm{P}<0.0001) ; \mathrm{I}^{2}=100 \%$} \\
\hline
\end{tabular}

Analysis 1.4. Comparison 1 Interventions for involving patients in decision-making about their health care vs usual care for older patients with multi-morbidity, Outcome 4 Patient enablement and engagement: patient activation (Patient Activation Measure) at 6 months.

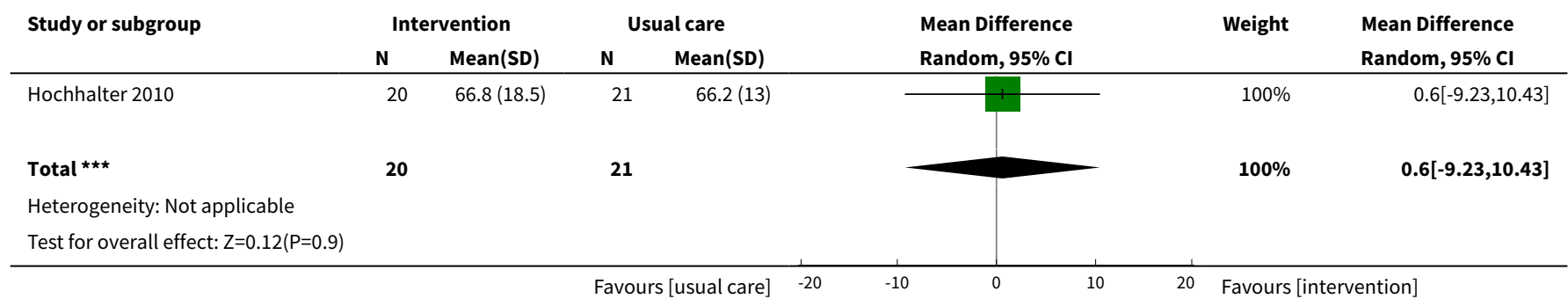

Analysis 1.5. Comparison 1 Interventions for involving patients in decision-making about their health care vs usual care for older patients with multi-morbidity, Outcome 5 Patient enablement and engagement: medication adherence (Morisky Medication Adherence Scale) at 6 months.

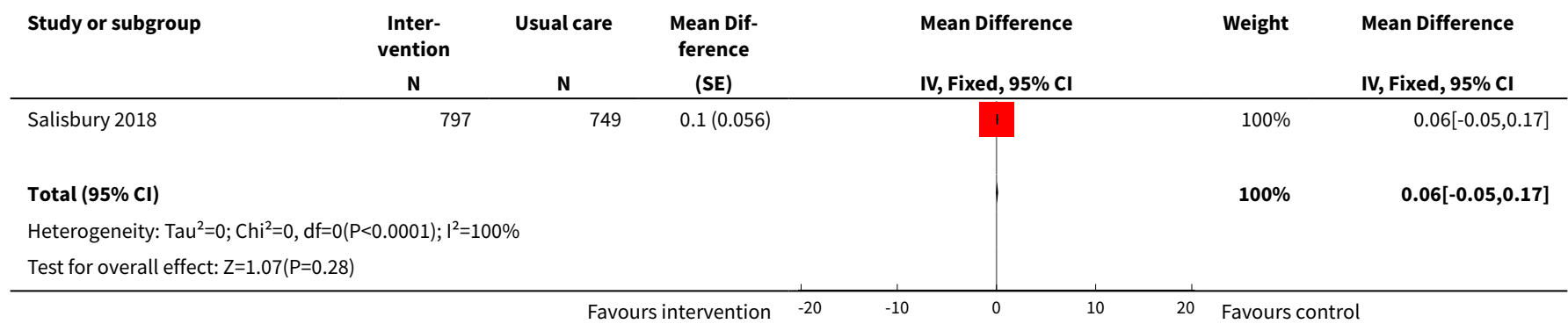


Analysis 1.6. Comparison 1 Interventions for involving patients in decision-making about their health care vs usual care for older patients with multi-morbidity, Outcome 6 Patient evaluation of care/the intervention: care related to priorities (adapted question from General Practice Patient Survey) at 15 months.

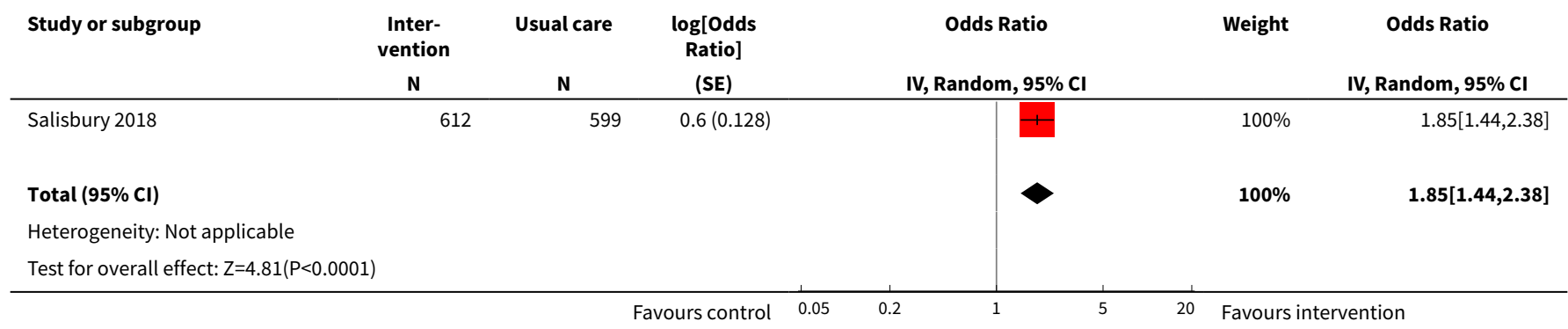

Analysis 1.7. Comparison 1 Interventions for involving patients in decision-making about their health care vs usual care for older patients with multi-morbidity, Outcome 7 Carer evaluation of care: carer experience (Carer Experience Questionnaire) at 15 months.

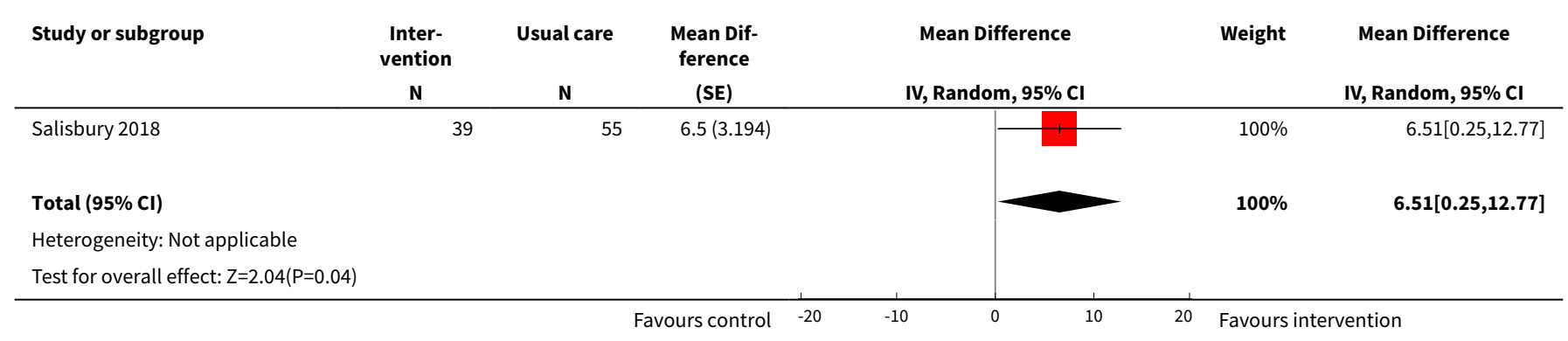

Analysis 1.8. Comparison 1 Interventions for involving patients in decision-making about their health care vs usual care for older patients with multi-morbidity, Outcome 8 Resource use and cost: number of nurse consultations (review of medical records) at 15 months.

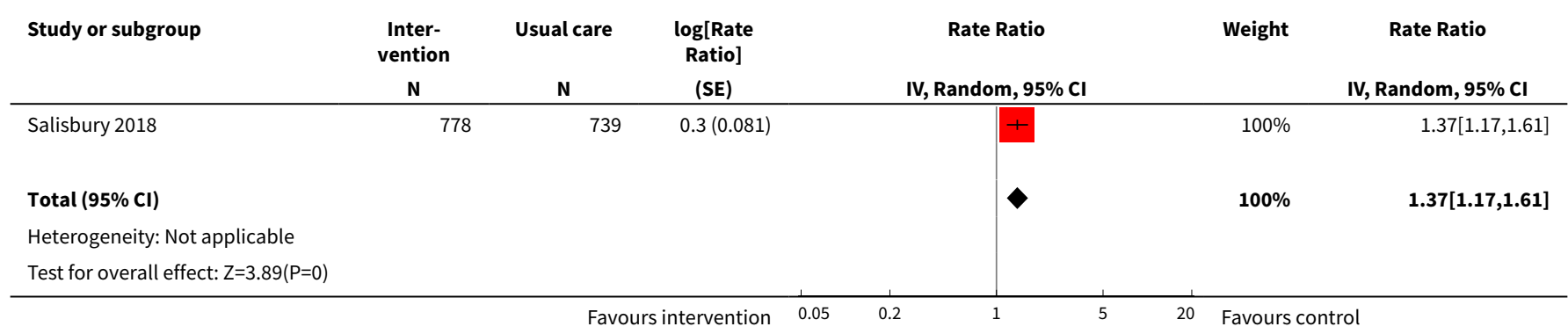


Analysis 1.9. Comparison 1 Interventions for involving patients in decision-making about their health care vs usual care for older patients with multi-morbidity, Outcome 9 Quality of care: number of indicators of high-risk prescribing (review of medical records) at 15 months.

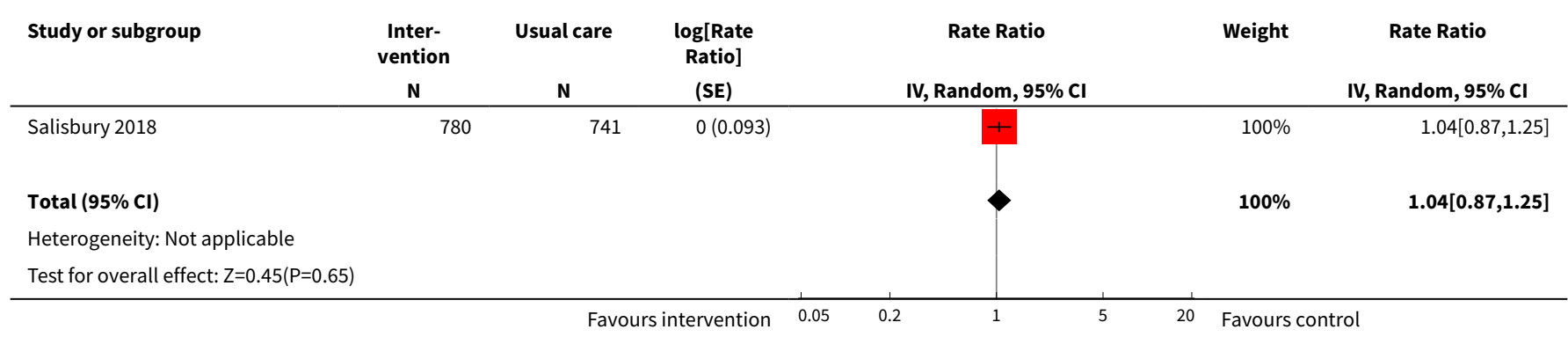

Comparison 2. Interventions for involving patients in decision-making about their health care vs attention-control conditions for older patients with multi-morbidity

\begin{tabular}{|c|c|c|c|c|}
\hline Outcome or subgroup title & $\begin{array}{l}\text { No. of } \\
\text { studies }\end{array}$ & $\begin{array}{l}\text { No. of } \\
\text { partici- } \\
\text { pants }\end{array}$ & Statistical method & Effect size \\
\hline $\begin{array}{l}1 \text { Health status: high self-rated health (CDC 'Healthy Days Mea- } \\
\text { sure' and another similar 5-point scale, dichotomised) at } 6 \\
\text { months }\end{array}$ & 2 & & $\begin{array}{l}\text { Risk Ratio (M-H, Ran- } \\
\text { dom, } 95 \% \mathrm{Cl})\end{array}$ & $\begin{array}{l}\text { Totals not } \\
\text { selected }\end{array}$ \\
\hline $\begin{array}{l}2 \text { Patient enablement and engagement: patient activation (Pa- } \\
\text { tient Activation Measure) at } 6 \text { months }\end{array}$ & 1 & 43 & $\begin{array}{l}\text { Mean Difference (IV, } \\
\text { Random, } 95 \% \mathrm{CI} \text { ) }\end{array}$ & $\begin{array}{l}1.20[-8.21, \\
10.61]\end{array}$ \\
\hline $\begin{array}{l}3 \text { Patient enablement and engagement: self-efficacy (Self-Effi- } \\
\text { cacy for Managing Chronic Disease Scale) at } 6 \text { months }\end{array}$ & 1 & 254 & $\begin{array}{l}\text { Mean Difference (IV, } \\
\text { Random, } 95 \% \mathrm{CI} \text { ) }\end{array}$ & $\begin{array}{l}0.29[-0.21, \\
0.79]\end{array}$ \\
\hline $\begin{array}{l}4 \text { Patient evaluation of care/the intervention: changed man- } \\
\text { agement of their health (patient self-report, 3-point scale di- } \\
\text { chotomised) at } 6 \text { months }\end{array}$ & 1 & 231 & $\begin{array}{l}\text { Risk Ratio (M-H, Ran- } \\
\text { dom, } 95 \% \mathrm{Cl})\end{array}$ & $\begin{array}{l}1.82[1.35 \\
2.44]\end{array}$ \\
\hline $\begin{array}{l}5 \text { Resource use and cost: number of general practice visits (pa- } \\
\text { tient self-report via questionnaire) at } 6 \text { months }\end{array}$ & 1 & 254 & $\begin{array}{l}\text { Mean Difference (IV, } \\
\text { Random, } 95 \% \mathrm{CI} \text { ) }\end{array}$ & $\begin{array}{l}0.51[-0.34, \\
1.36]\end{array}$ \\
\hline
\end{tabular}

Analysis 2.1. Comparison 2 Interventions for involving patients in decision-making about their health care vs attention-control conditions for older patients with multi-morbidity, Outcome 1 Health status: high selfrated health (CDC 'Healthy Days Measure' and another similar 5-point scale, dichotomised) at 6 months.

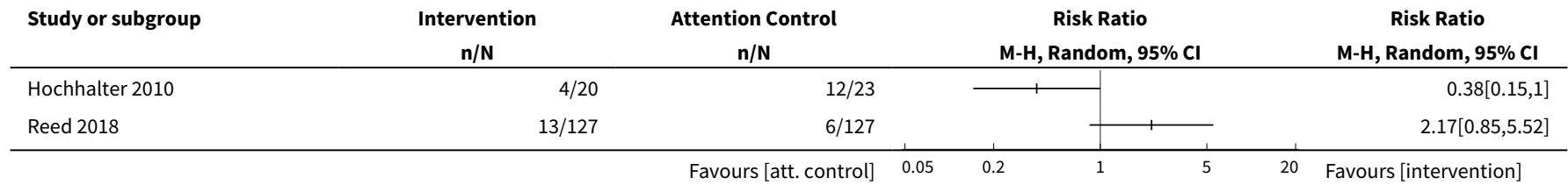


Analysis 2.2. Comparison 2 Interventions for involving patients in decision-making about their health care vs attention-control conditions for older patients with multi-morbidity, Outcome 2

Patient enablement and engagement: patient activation (Patient Activation Measure) at 6 months.

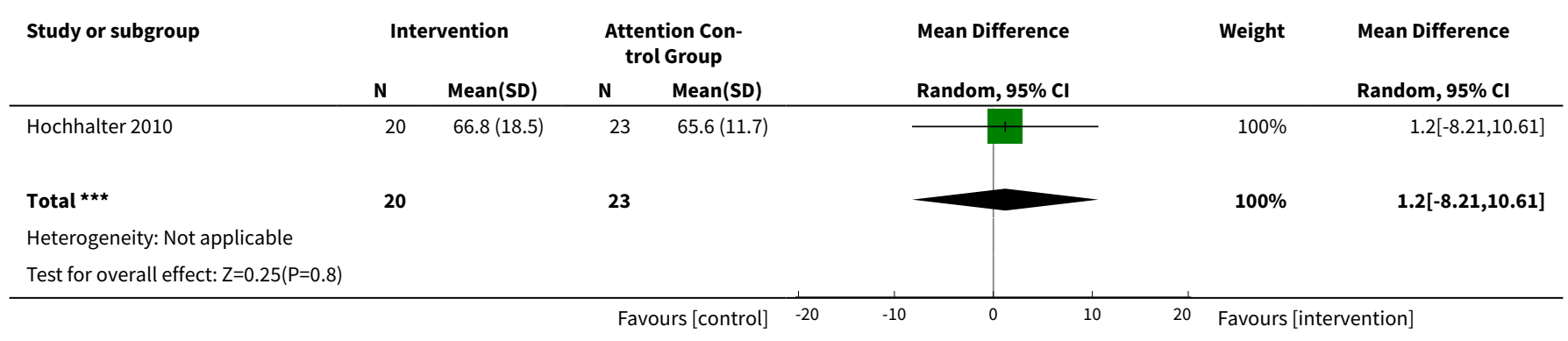

Analysis 2.3. Comparison 2 Interventions for involving patients in decision-making about their health care vs attention-control conditions for older patients with multi-morbidity, Outcome 3 Patient enablement and engagement: self-efficacy (Self-Efficacy for Managing Chronic Disease Scale) at 6 months.

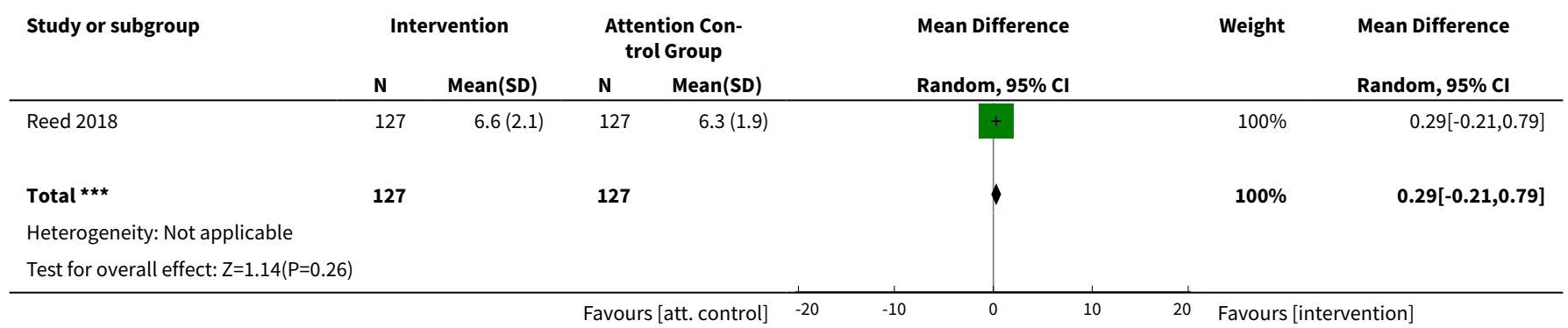

Analysis 2.4. Comparison 2 Interventions for involving patients in decision-making about their health care vs attention-control conditions for older patients with multi-morbidity, Outcome 4 Patient evaluation of care/the intervention: changed management of their health (patient self-report, 3-point scale dichotomised) at 6 months.

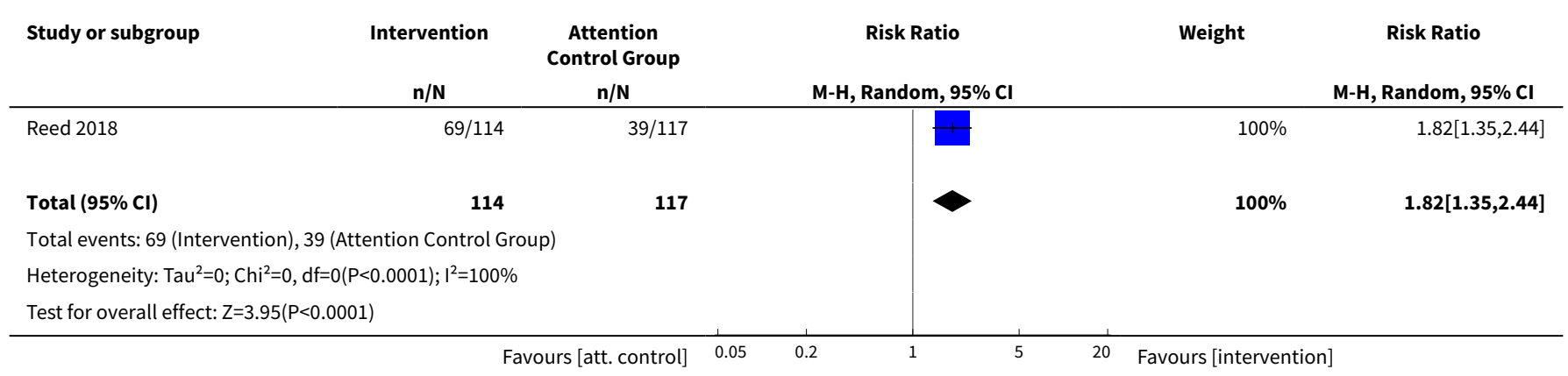


Analysis 2.5. Comparison 2 Interventions for involving patients in decision-making about their health care vs attention-control conditions for older patients with multi-morbidity, Outcome 5 Resource use and cost: number of general practice visits (patient self-report via questionnaire) at 6 months.

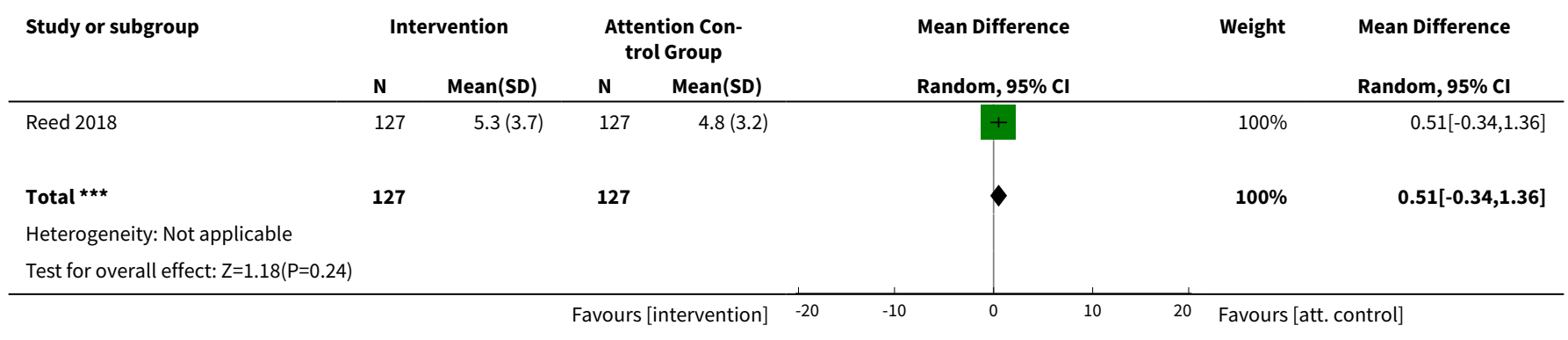

\section{ADDITIONAL TABLES}

Table 1. Comparison of our proposed review with existing systematic reviews of similar interventions

$\begin{array}{llll}\begin{array}{l}\text { Systematic } \\ \text { review }\end{array} & \text { Structure } & \text { Processes } & \text { Outcomes }\end{array}$

\section{Interventions Smith 2016 excluded interventions that} for improving included people with comorbid condioutcomes in tions when the intervention was targetpatients with ed solely at 1 condition. We will include multi-morbid- studies in which older people with mulity in primary care and community settings (Smith 2016) ti-morbidity were exposed to an intervention to facilitate patient involvement in their health care, and in which outcomes were reported with respect to this population, even if the intervention was not originally designed for older patients with multi-morbidity
Smith 2016 did not design its search strategy to find studies of interventions to facilitate the involvement of older patients with multi-morbidity in decision-making about their care, which is the aim of our review.

Smith 2016 was not specifically interested in the processes within, and supporting, a general practice consultation, which is the focus of our review
Our review will differ from Smith 2016 in terms of our primary outcome of whether or not patient involvement in the decision-making process occurred during a consultation, was not a primary outcome, or was a specific focus of a secondary outcome. Smith 2016 excluded the outcomes of attitude and knowledge when reporting studies, both of which are highly relevant to the delivery of patient-centred care, and to patient involvement in decision-making about their health care during a primary care consultation. Our review will include these outcomes to inform clinicians and policy makers about interventions supporting improved patient knowledge of their conditions and treatments, improved patient enablement for self-care, positive changes in patients' health beliefs and lifestyle choices, patient satisfaction with health care and trust in the practitioner, and improved practitioner communication skills including shared decision-making. Attitudes towards the intervention and 
Table 1. Comparison of our proposed review with existing systematic reviews of similar interventions (Continued) compliance with it will also be important in the development of future interventions to facilitate the involvement of older patients with multi-morbidity in decision-making about their health care

$\begin{array}{ll}\begin{array}{l}\text { Interventions } \\ \text { for providers }\end{array} & \text { Dawmena } 2012 \text { included studies of in- } \\ \text { to promote a } & \text { sion-making; however, this study focuses } \\ \text { patient-cen- } & \text { only on studies of interventions directed } \\ \text { tred approach } & \text { at healthcare professionals, or at health- } \\ \text { in clinical con- } & \text { care professionals and patients togeth- } \\ \text { sultations } & \text { er. Our review would additionally include } \\ \text { (Dawmena } & \text { studies of interventions targeting only pa- } \\ \text { 2012) } & \text { tients, in particular, the very important } \\ & \text { and vulnerable patient population of old- } \\ & \text { er patients with multi-morbidity }\end{array}$

Personalised care planning for adults with chronic or long-term health conditions (Coulter 2015)

\section{The type of care planning evaluated by} Coulter 2015 does not routinely take place within a primary care consultation alone but is more likely to be initiated by a secondary care specialist liaising with the primary care team. Primary care will be the focus of our review

\section{Interventions} before consultations for helping patients address their information needs (Kinnersley 2008)
Kinnersley 2008 focused on interventions targeted only at patients, whereas we are interested in interventions aimed at patients, practitioners, or both, as well as any elements of organisational change
Coulter 2015 looked at personalised care planning, and inclusion criteria for this study capture a subset of studies evaluating elements of patient involvement in decision-making. Our review criteria are much broader in terms of studies to facilitate patient involvement
Kinnersley 2008 looked at studies of interventions to support patients in information-gathering from a doctor or a nurse during a consultation. Whilst this is an important aspect of patient involvement, it is only 1 element of a complex process. We therefore feel that the inclusion criteria used in this review will have missed many studies that are of relevance to our review

\section{Interventions for improving the adoption of shared de- cision-making by healthcare professionals (Légaré 2018)
This review covers an important top- ic in the research area of shared deci- sion-making. However, it focuses on- ly on studies of interventions designed to improve the healthcare profession- al's adoption of shared decision-making and excludes many studies focusing on patient-mediated involvement in deci- sion-making

\footnotetext{
Interventions for improving patients' trust in doctors and groups of doctors (Rolfe 2014)
}

\author{
We know from our own work that \\ there are associations between pa- \\ tients' trust in the doctor and their in- \\ volvement in decision-making about \\ their care. Studies of interventions to \\ promote patient involvement in de- \\ cision-making would be included by \\ Rolfe 2014. However, the scope of this \\ review is very broad, and it does not
}


Table 1. Comparison of our proposed review with existing systematic reviews of similar interventions (Continued) address our aim: to systematically review studies of interventions that facilitate patient involvement, focusing on older people with multi-morbidity

\section{AP PEN DICES}

\section{Appendix 1. MEDLINE search strategy}

1. exp aged/

2. Aging/

3. (Late life or elder* or aged or old age or geriatric or seniors).ti,ab,kw.

4. ((old or older or aging or aged or senior or elder ${ }^{\star}$ ) adj3 (person or persons or people or adult ${ }^{\star}$ or subject ${ }^{\star}$ or patient $^{\star}$ or consumer $^{\star}$ or male or males or female* or men or women)).ti,ab,kw.

5. or/1-4

6. "Physician-Patient Relations"/

7. "Professional-Patient Relations"/

8. exp Decision Making/

9. Decision Support Techniques/

10. Decision Support Systems, Clinical/

11. Cooperative Behavior/

12. $\exp$ Communication/

13. (consensus or partnership $\left.{ }^{\star}\right) . t i, a b, k w$.

14. ((share or shared or sharing or support* or inform* or making or behavior ${ }^{\star}$ or aid $\left.{ }^{\star}\right)$ adj2 (decision* or deciding or choice $)$ ).ti,ab,kw.

15. "Group Processes"/

16. or/6-15

17. exp Patients/

18. caregivers/

19. exp Family/

20. Friends/

21. or $/ 17-20$

22. and $/ 16,21$

23. exp Community Participation/

24. Stakeholder Participation/

25. exp Patient-Centered Care/

26. ((patient ${ }^{\star}$ or consumer or user $^{\star}$ or carer ${ }^{\star}$ or caregiver $^{\star}$ or client ${ }^{\star}$ or famil ${ }^{\star}$ or lay ${ }^{\star}$ ) adj3 (partner or participat $^{\star}$ or centre $^{\star}$ or center $^{\star}$ or

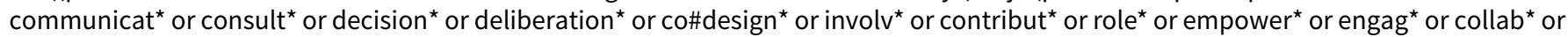
advoca* $^{\star}$ or organi\#ation ${ }^{\star}$ or respons ${ }^{\star}$ or question ${ }^{\star}$ or educat ${ }^{\star}$ or inform ${ }^{\star}$ or train* or shar $^{\star}$ or joint or choice* or preference $\left.{ }^{\star}\right)$ ).tw.

Interventions for involving older patients with multi-morbidity in decision-making during primary care consultations (Review) 
27. or/22-26

28. exp Comorbidity/

29. exp polypharmacy/

30. (multidisease ${ }^{\star}$ or multi-disease ${ }^{\star}$ or multimorbidit* or comorbid $^{\star}$ or multi-morbidit* or co-morbid $^{\star}$ ).ti,ab,kw.

31. ((concomit ${ }^{\star}$ or concurren ${ }^{\star}$ or multi ${ }^{\star}$ or multiple) adj3 (ill* or condition ${ }^{\star}$ or morbidit ${ }^{\star}$ or syndrom ${ }^{\star}$ or disorder $^{\star}$ or disease $\left.^{\star}\right)$ ).ti,ab,kw.

32. exp Chronic Disease/

33. ((chronic ${ }^{\star}$ or elderly or age $\left.{ }^{\star}\right)$ adj3 (disease* or ill* or care or condition? or disorder ${ }^{\star}$ or health* or medication ${ }^{\star}$ or syndrom ${ }^{\star}$ or symptom* or chronic $\left.\left.{ }^{\star}\right)\right) . t i, a b, k w$.

34. ((coocur\$ or co-ocur\$ or coexist\$ or co-exist\$ or multipl\$) adj3 (disease? or ill\$ or care or condition? or disorder\$ or health\$ or medication\$ or symptom\$ or syndrom\$)).ti,ab,kw.

35. or/28-34

36. exp Primary Health Care/

37. General Practice/

38. General Practitioners/

39. exp Home Care Services/

40. physicians, family/

41. Physicians, primary care/

42. Private Practice/

43. "Family Practice"/

44. Community Health Services/

45. Community Health Nursing/

46. Community Pharmacy Services/

47. Community Health Workers/

48. Preventive Health Services/

49. Primary care nursing/

50. Community medicine/

51. Community health centres/

52. Health Promotion/

53. health promotion.ti,ab,kw.

54. ((home* or visit* or preventive* or general or family or primary or community) adj3 (health or practice* or medicine or physician* or nursing or pharmacy or program* or service* or care)).ti,ab,kw.

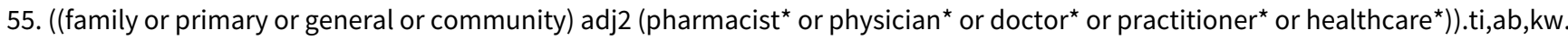

56. ((nurse* or nursing) adj2 (practice ${ }^{\star}$ or practitioner $^{\star}$ or prescriber $\left.\left.^{\star}\right)\right) . t i, a b, k w$.

57. (GPs or GPSI or GPwSI).ti,ab,kw.

58. or $/ 36-57$

59. randomized controlled trial.pt.

Interventions for involving older patients with multi-morbidity in decision-making during primary care consultations (Review) 
60. controlled clinical trial.pt.

61. randomized.ab.

62. placebo.ab.

63. drug therapy.fs.

64. randomly.ab.

65. trial.ab.

66. groups.ab.

67. or/59-66

68. quasi experimental study/

69. pragmatic clinical trial/

70. or/67-69

71. (animals not (humans and animals)).sh.

72. 70 not 71

73. and $/ 5,27,35,58,72$

\section{Appendix 2. The Cochrane Library search strategy}

ID Search

\#1 MeSH descriptor: [Aged] explode all trees

\#2 MeSH descriptor: [Aging] this term only

\#3 (Late life or elder* or aged or old age or geriatric or seniors):ti,ab,kw (Word variations have been searched)

\#4 ((old or older or aging or aged or senior or elder ${ }^{\star}$ ) N3 (person or persons or people or adult* or subject* or patient* or consumer ${ }^{\star}$ or male or males or female* or men or women)):ti,ab,kw (Word variations have been searched)

\#5 $\{$ or \#1-\#4\}

\#6 MeSH descriptor: [Physician-Patient Relations] this term only

\#7 MeSH descriptor: [Professional-Patient Relations] this term only

\#8 MeSH descriptor: [Decision Making] explode all trees

\#9 MeSH descriptor: [Decision Support Techniques] this term only

\#10 MeSH descriptor: [Decision Support Systems, Clinical] this term only

\#11 MeSH descriptor: [Decision Support Systems, Clinical] this term only

\#12 MeSH descriptor: [Cooperative Behavior] this term only

\#13 MeSH descriptor: [Communication] explode all trees

\#14 partnership*:ti,ab,kw (Word variations have been searched)

\#15 ((share or shared or sharing or support* or inform* or making or behavior ${ }^{\star}$ or aid $^{\star}$ ) next (decision* or deciding or choice*)):ti,ab,kw (Word variations have been searched)

$\# 16$ or \#6-\#15\}

\#17 MeSH descriptor: [Patients] explode all trees

\#18 MeSH descriptor: [Caregivers] explode all trees

Interventions for involving older patients with multi-morbidity in decision-making during primary care consultations (Review) 
\#19 MeSH descriptor: [Family] explode all trees

\#20 MeSH descriptor: [Friends] explode all trees

\#21 \{or \#17-\#20\}

$\# 22$ and \#16, \#21\}

\#23 MeSH descriptor: [Community Participation] explode all trees

\#24 MeSH descriptor: [Stakeholder Participation] this term only

\#25 MeSH descriptor: [Patient-Centered Care] explode all trees

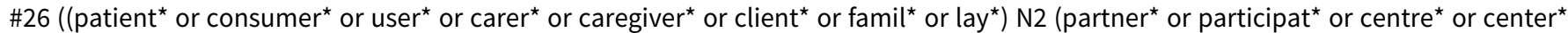
or communicat* or consult* or decision* or deliberation* or co-design* or involv* or contribut ${ }^{\star}$ or role* or empower or engag $^{\star}$ or collab $^{\star}$ or advoca* or organization* or organisation* or respons* or question* or educat* or inform* or train* or shar* or joint or choice* or preference $\left.{ }^{\star}\right)$ ):ti,ab,kw (Word variations have been searched)

\#27 \{or \#22-\#26\}

\#28 MeSH descriptor: [Comorbidity] explode all trees

\#29 (multidisease* $^{\star}$ or multi-disease* or multimorbidit* or comorbid $^{\star}$ or multi-morbidit* or co-morbid ${ }^{\star}$ ):ti,ab,kw (Word variations have been searched)

\#30 MeSH descriptor: [Polypharmacy] explode all trees

\#31 ((concomit* or concurren* or multi* or multiple) N3 (ill* or condition* or morbidit* or syndrom* or disorder ${ }^{\star}$ or disease $\left.\left.^{\star}\right)\right)$ :ti,ab,kw (Word variations have been searched)

\#32 MeSH descriptor: [Chronic Disease] explode all trees

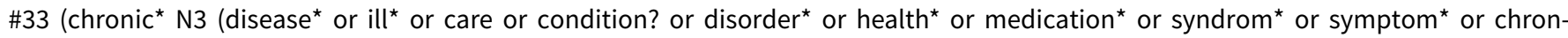
ic $\left.{ }^{\star}\right)$ ):ti,ab,kw (Word variations have been searched)

\#34 ((coocur ${ }^{\star}$ or co-ocur ${ }^{\star}$ or coexist ${ }^{\star}$ or co-exist* or multipl $\left.{ }^{\star}\right)$ N3 (disease? or ill* or care or condition? or disorder* or health* or medication ${ }^{\star}$ or symptom* or syndrom $\left.\left.{ }^{\star}\right)\right): t i, a b, k w$ (Word variations have been searched)

\#35 \{or \#28-\#34\}

\#36 MeSH descriptor: [Primary Health Care] explode all trees

\#37 MeSH descriptor: [General Practice] this term only

\#38 MeSH descriptor: [General Practitioners] this term only

\#39 MeSH descriptor: [Home Care Services] explode all trees

\#40 MeSH descriptor: [Physicians, Family] this term only

\#41 MeSH descriptor: [Physicians, Primary Care] this term only

\#42 MeSH descriptor: [Private Practice] this term only

\#43 MeSH descriptor: [Family Practice] this term only

\#44 MeSH descriptor: [Community Health Services] this term only

\#45 MeSH descriptor: [Community Health Nursing] this term only

\#46 MeSH descriptor: [Community Pharmacy Services] this term only

\#47 MeSH descriptor: [Community Health Workers] this term only

\#48 MeSH descriptor: [Preventive Health Services] this term only

\#49 MeSH descriptor: [Primary Care Nursing] this term only

Interventions for involving older patients with multi-morbidity in decision-making during primary care consultations (Review) 
\#50 MeSH descriptor: [Community Medicine] this term only

\#51 MeSH descriptor: [Community Health Centers] this term only

\#52 MeSH descriptor: [Health Promotion] this term only

\#53 health promotion:ti,ab,kw (Word variations have been searched)

\#54 ((home* or visit* or preventive* or general or family or primary or community) N3 (health or practice or medicine or physician* or nursing or pharmacy or program* or service* or care)):ti,ab,kw (Word variations have been searched)

\#55 ((nurse* or nursing) N2 (practice* or practitioner* or prescriber $\left.{ }^{\star}\right)$ ):ti,ab,kw (Word variations have been searched)

\#56 (GPs or GPSI or GPwSI):ti,ab,kw (Word variations have been searched)

\#57 ((family or primary or general or community) N2 (pharmacist ${ }^{\star}$ or physician* or doctor ${ }^{\star}$ or practitioner ${ }^{\star}$ or healthcare $\left.{ }^{\star}\right)$ ):ti,ab,kw (Word variations have been searched)

\#58 \{or \#36-\#57\}

$\# 59$ and \#5, \#27, \#35, \#58\}

\section{Appendix 3. CINAHL search strategy}

\begin{tabular}{|c|c|c|}
\hline$\#$ & Query & Results \\
\hline S65 & S54 AND S64 & 3,543 \\
\hline S64 & $\mathrm{S} 55$ or $\mathrm{S} 56$ or $\mathrm{S} 57$ or $\mathrm{S} 58$ or $\mathrm{S} 59$ or $\mathrm{S} 60$ or $\mathrm{S} 61$ or $\mathrm{S} 62$ or $\mathrm{S} 63$ & Display \\
\hline S63 & 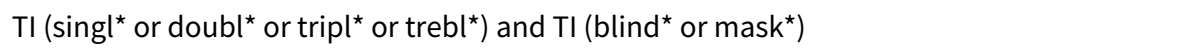 & Display \\
\hline S62 & $\mathrm{AB}\left(\right.$ singl $\left.\right|^{\star}$ or doubl ${ }^{\star}$ or tripl ${ }^{\star}$ or trebl $\left.l^{\star}\right)$ and $\mathrm{AB}\left(\right.$ blind $^{\star}$ or mask $\left.^{\star}\right)$ & Display \\
\hline S61 & $\mathrm{AB}\left(\right.$ random ${ }^{\star}$ or trial or placebo $\left.{ }^{\star}\right)$ or $\mathrm{TI}\left(\right.$ random $^{\star}$ or trial or placebo $\left.{ }^{\star}\right)$ & Display \\
\hline S60 & MH Quantitative Studies & Display \\
\hline S59 & MH Placebos & Display \\
\hline S58 & MH Random Assignment & Display \\
\hline S57 & MH Clinical Trials+ & Display \\
\hline S56 & PT Clinical Trial & Display \\
\hline S55 & "randomi?ed controlled trial" or PT randomized controlled trial & Display \\
\hline S54 & S5 AND S27 AND S35 AND S53 & 22,788 \\
\hline S53 & $\begin{array}{l}\text { S36 OR S } 37 \text { OR S } 38 \text { OR S39 OR S } 40 \text { OR S41 OR S } 42 \text { OR S43 OR S44 OR S45 OR S46 OR S47 } \\
\text { OR S48 OR S49 OR S50 OR S } 51 \text { OR S52 }\end{array}$ & 789,958 \\
\hline S52 & TX (GPs or GPSI or GPwSI) & 5,759 \\
\hline S51 & TX ((nurse* or nursing) N2 (practice ${ }^{\star}$ or practitioner ${ }^{\star}$ or prescriber $\left.\left.{ }^{\star}\right)\right)$ & 163,450 \\
\hline S50 & $\begin{array}{l}\text { TX ((family or primary or general or community) N2 (pharmacist }{ }^{\star} \text { or physician* } \text { or doctor }^{\star} \\
\left.\left.\text { or practitioner }{ }^{\star} \text { or healthcare }{ }^{\star}\right)\right)\end{array}$ & 63,366 \\
\hline
\end{tabular}


(Continued) TX ((home* or visit $^{\star}$ or preventive ${ }^{\star}$ or general or family or primary or community) N3
(health or practice ${ }^{\star}$ or medicine or physician ${ }^{\star}$ or nursing or pharmacy or program ${ }^{\star}$ or service* or care))

\begin{tabular}{|c|c|c|}
\hline S48 & TX health promotion & 93,464 \\
\hline S47 & (MH "Health Promotion+") & 41,722 \\
\hline S46 & (MH "Community Health Centers+") & 3,875 \\
\hline S45 & (MH "Community Medicine") & 100 \\
\hline S44 & "Primary care nursing" & 239 \\
\hline S43 & "Preventive Health Services" & 215 \\
\hline S42 & (MH "Community Mental Health Services+") & 8,330 \\
\hline S41 & (MH "Community Health Nursing+") & 24,882 \\
\hline S40 & (MH "Community Health Services+") & 282,870 \\
\hline S39 & (MH "Home Health Care+") & 35,210 \\
\hline S38 & (MH "Physicians, Family") & 10,534 \\
\hline S37 & (MH "Family Practice") & 13,037 \\
\hline S36 & (MH "Primary Health Care") & 38,524 \\
\hline S35 & S28 OR S29 OR S30 OR S31 OR S32 OR S33 OR S34 & 260,013 \\
\hline S34 & $\begin{array}{l}\text { TX ((coocur\$ or co-ocur } \$ \text { or coexist } \$ \text { or co-exist } \$ \text { or multipl\$) N3 (disease? or ill\$ or care or } \\
\text { condition? or disorder } \$ \text { or health\$ or medication } \$ \text { or symptom\$ or syndrom\$)) }\end{array}$ & 219 \\
\hline S33 & $\begin{array}{l}\left.\text { TX ((chronic* or elderly or age }{ }^{\star}\right) \text { N3 (disease }{ }^{\star} \text { or ill* or care or condition? or disorder* or } \\
\left.\left.\text { health }^{\star} \text { or medication } \text { or syndrom }^{\star} \text { or symptom } \text { or chronic }^{\star}\right)\right)\end{array}$ & 207,000 \\
\hline S32 & (MH "Chronic Disease") & 36,416 \\
\hline S31 & $\begin{array}{l}\text { TX ((concomit* or concurren }{ }^{\star} \text { or multi* or multiple) N3 (ill }{ }^{\star} \text { or condition* or morbidit }{ }^{\star} \text { or } \\
\left.\left.\text { syndrom }^{\star} \text { or disorder }^{\star} \text { or disease }{ }^{\star}\right)\right)\end{array}$ & 17,150 \\
\hline S30 & $\begin{array}{l}\text { TX } \text { (multidisease }^{\star} \text { or multi-disease }{ }^{\star} \text { or multimorbidit* } \text { or comorbid }^{\star} \text { or multi-morbidit }{ }^{\star} \text { or } \\
\text { co-morbid }^{\star} \text { ) }\end{array}$ & 51,501 \\
\hline S29 & (MH "Polypharmacy") & 2,365 \\
\hline S28 & (MH "Comorbidity") & 30,417 \\
\hline S27 & S22 OR S23 OR S24 OR S25 OR S26 & 660,109 \\
\hline S26 & 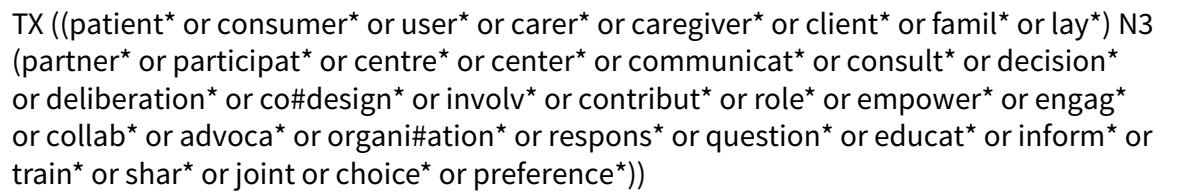 & 620,182 \\
\hline
\end{tabular}


(Continued)

\begin{tabular}{|c|c|c|}
\hline S25 & (MH "Patient Centered Care") & 18,385 \\
\hline S24 & (MH "Consumer Participation") & 12,197 \\
\hline S23 & "Community Participation" & 882 \\
\hline S22 & S16 AND S21 & 73,996 \\
\hline S21 & S17 OR S18 OR S19 OR S20 & 337,406 \\
\hline S20 & "Friends" & 9,930 \\
\hline S19 & (MH "Family+") & 137,904 \\
\hline S18 & (MH "Caregivers") & 22,491 \\
\hline S17 & (MH "Patients+") & 196,044 \\
\hline S16 & S6 OR S7 OR S8 OR S9 OR S10 OR S11 OR S12 OR S13 OR S14 OR S15 & 464,650 \\
\hline S15 & $\begin{array}{l}\left.\text { ((share or shared or sharing or support }{ }^{\star} \text { or inform }{ }^{*} \text { or making or behavior } \text { or aid }^{*}\right) \text { N2 } \\
\text { (decision* or deciding or choice }) \text { ) }\end{array}$ & 94,478 \\
\hline S14 & TX consensus or partnership* & 47,038 \\
\hline S13 & (MH "Group Processes+") & 157,942 \\
\hline S12 & (MH "Communication+") & 166,424 \\
\hline S11 & (MH "Cooperative Behavior") & 3,769 \\
\hline S10 & (MH "Decision Support Systems, Clinical") & 2,135 \\
\hline S9 & (MH "Decision Support Techniques+") & 4,463 \\
\hline S8 & (MH "Decision Making+") & 72,720 \\
\hline S7 & (MH "Professional-Patient Relations+") & 63,673 \\
\hline S6 & (MH "Physician-Patient Relations") & 19,830 \\
\hline S5 & S1 OR S2 OR S3 OR S4 & 811,443 \\
\hline S4 & $\begin{array}{l}\left.\text { TX ((old or older or aging or aged or senior or elder }{ }^{\star}\right) \text { N3 (person or persons or people } \\
\text { or adult } \text { ar subject }^{\star} \text { or patient }{ }^{\star} \text { or consumer }{ }^{\star} \text { or male or males or female }{ }^{\star} \text { or men or } \\
\text { women)) }\end{array}$ & 160,270 \\
\hline S3 & TX (Late life or elder* or aged or old age or geriatric or seniors) & 783,674 \\
\hline S2 & (MH "Aging+") & 28,816 \\
\hline S1 & (MH "Aged+") & 434,411 \\
\hline
\end{tabular}

\section{Appendix 4. Embase search strategy}

1. aged/ 
2. exp aging/

3. (Late life or elder* or aged or old age or geriatric or seniors).ti,ab,kw.

4. ((old or older or aging or aged or senior or elder ${ }^{\star}$ ) adj3 (person or persons or people or adult ${ }^{\star}$ or subject* or patient ${ }^{\star}$ or consumer ${ }^{\star}$ or male or males or female* or men or women)).ti,ab,kw.

5. or/1-4

6. doctor patient relation/

7. professional-patient relationship/

8. decision making/

9. exp decision support system/

10. clinical decision support system/

11. exp cooperation/

12. exp interpersonal communication/

13. (partnership* or consensus).ti,ab,kw.

14. ((share or shared or sharing or support* or inform* or making or behavior ${ }^{\star}$ or aid $\left.{ }^{\star}\right)$ adj2 (decision* or deciding or choice*)).ti,ab,kw.

15. exp group process/

16. or/6-15

17. exp patient/

18. caregiver/

19. exp family/

20. friend/

21. or $/ 17-20$

22. and $/ 16,21$

23. community participation/

24. stakeholder engagement/

25. exp patient care/

26. ((patient ${ }^{\star}$ or consumer ${ }^{\star}$ or user ${ }^{\star}$ or carer $^{\star}$ or caregiver $^{\star}$ or client ${ }^{\star}$ or famil ${ }^{\star}$ or lay $^{\star}$ ) adj3 (partner ${ }^{\star}$ or participat $^{\star}$ or centre $^{\star}$ or center or $^{\star}$ communicat ${ }^{\star}$ or consult* or decision ${ }^{\star}$ or deliberation ${ }^{\star}$ or co\#design ${ }^{\star}$ or involv* or contribut ${ }^{\star}$ or role* or empower ${ }^{\star}$ or engag $^{\star}$ or collab $^{\star}$ or advoca* or organi\#ation* or respons* or question* or educat* or inform* or train* or shar ${ }^{\star}$ or joint or choice* or preference $\left.{ }^{\star}\right)$ ).tw.

27. or/22-26

28. comorbidity/ or comorbidity assessment/

29. polypharmacy/

30. (multidisease ${ }^{\star}$ or multi-disease ${ }^{\star}$ or multimorbidit* or comorbid $^{\star}$ or multi-morbidit* or co-morbid $^{\star}$ ).ti,ab,kw.

31. ((concomit ${ }^{\star}$ or concurren ${ }^{\star}$ or multi* or multiple) adj3 (ill* or condition* or morbidit ${ }^{\star}$ or syndrom ${ }^{\star}$ or disorder $^{\star}$ or disease $\left.^{\star}\right)$ ).ti,ab,kw.

32. exp chronic disease/

33. ((chronic ${ }^{\star}$ or elderly or age $\left.{ }^{\star}\right)$ adj3 (disease* or ill $^{\star}$ or care or condition? or disorder ${ }^{\star}$ or health ${ }^{\star}$ or medication* or syndrom $^{\star}$ or symptom ${ }^{\star}$ or chronic*)).ti,ab,kw. 
34. ((coocur\$ or co-ocur\$ or coexist\$ or co-exist\$ or multipl\$) adj3 (disease? or ill\$ or care or condition? or disorder\$ or health\$ or medication\$ or symptom\$ or syndrom\$)).ti,ab,kw.

35. or/28-34

36. exp primary health care/

37. exp general practice/

38. general practitioner/

39. exp home care/

40. private practice/

41. community care/

42. general practice/

43. exp community health nursing/

44. pharmacy/

45. health auxiliary/

46. exp preventive health service/

47. community medicine/

48. health center/

49. exp health promotion/

50. health promotion.ti,ab,kw.

51. ((home* ${ }^{\star}$ or visit* or preventive* or general or family or primary or community) adj3 (health or practice* or medicine or physician* or nursing or pharmacy or program* or service* or care)).ti,ab,kw.

52. ((family or primary or general or community) adj2 (pharmacist ${ }^{\star}$ or physician ${ }^{\star}$ or doctor $^{\star}$ or practitioner or healthcare $\left.\left.^{\star}\right)\right) . \mathrm{ti}, \mathrm{ab}, \mathrm{kw}$.

53. ((nurse* or nursing) adj2 (practice ${ }^{\star}$ or practitioner $^{\star}$ or prescriber $\left.\left.^{\star}\right)\right) . t i, a b, k w$.

54. (GPs or GPSI or GPwSI).ti,ab,kw.

55. or/36-54

56. randomized controlled trial/

57. controlled clinical trial/

58. single blind procedure/ or double blind procedure/

59. crossover procedure/

60. random ${ }^{\star}$.tw.

61. placebo*.tw.

62. ((singl ${ }^{\star}$ or doubl $\left.{ }^{\star}\right)$ adj (blind ${ }^{\star}$ or mask $\left.\left.k^{\star}\right)\right)$.tw.

63. (crossover or cross over or factorial ${ }^{\star}$ or latin square).tw.

64. (assign* ${ }^{\star}$ or allocat* or volunteer $\left.^{\star}\right)$.tw.

65. or $/ 56-64$

66. and $/ 5,27,35,55,65$ 


\section{Appendix 5. ProQuest Dissertations search strategy}

(noft(( (patient ${ }^{\star}$ or consumer ${ }^{\star}$ or user ${ }^{\star}$ or carer ${ }^{\star}$ or caregiver $^{\star}$ or client ${ }^{\star}$ or famil ${ }^{\star}$ or lay $\left.^{\star}\right)$ NEAR (partner ${ }^{\star}$ or participat ${ }^{\star}$ or centre $^{\star}$ or center $^{\star}$ or communicat* or consult* or decision* or deliberation ${ }^{\star}$ or co\#design* or involv* or contribut ${ }^{\star}$ or role $^{\star}$ or empower $^{\star}$ or engag $^{\star}$ or collab* $^{\star}$

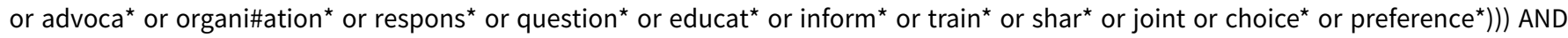

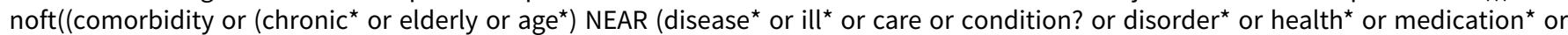
syndrom* or symptom* or chronic $\left.\left.\left.{ }^{\star}\right)\right)\right)$ AND noft(((primary or community) NEAR (health or care $\left.\left.)\right)\right)$ AND noft((old or older or aging or aged or senior or elder ${ }^{\star}$ ) NEAR (person or persons or people or adult* or subject ${ }^{\star}$ or patient ${ }^{\star}$ or consumer ${ }^{\star}$ or male or males or female* or men or women))

\section{Appendix 6. PsycINFO search strategy}

1. exp aging/

2. (Late life or elder* or aged or old age or geriatric or seniors).ti,ab.

3. ((old or older or aging or aged or senior or elder ${ }^{\star}$ ) adj3 (person or persons or people or adult ${ }^{\star}$ or subject ${ }^{\star}$ or patient $^{\star}$ or consumer or $^{\circ}$ male or males or female* or men or women)).ti,ab.

4. or/1-3

5. exp decision making/

6. decision support systems/

7. cooperation/

8. exp communication/

9. (consensus or partnership $\left.{ }^{\star}\right)$ ti,ab.

10. ((share or shared or sharing or support ${ }^{\star}$ or inform ${ }^{\star}$ or making or behavior ${ }^{\star}$ or aid $\left.{ }^{\star}\right)$ adj2 (decision* or deciding or choice $)$ ).ti,ab.

11. exp group dynamics/

12. or $/ 5-11$

13. exp patients/

14. caregivers/

15. exp family/

16. social support/

17. or/13-16

18. and $/ 12,17$

19. community involvement/

20. ((patient ${ }^{\star}$ or consumer ${ }^{\star}$ or user ${ }^{\star}$ or carer $^{\star}$ or caregiver $^{\star}$ or client ${ }^{\star}$ or famil ${ }^{\star}$ or lay $^{\star}$ or stakeholder ${ }^{\star}$ ) adj3 (partner ${ }^{\star}$ or participat $^{\star}$ or $^{*}$ centre $^{\star}$ or center ${ }^{\star}$ or communicat ${ }^{\star}$ or consult* or decision* or deliberation* or co\#design* or involv* or contribut ${ }^{\star}$ or role* or empower ${ }^{\star}$ or engag ${ }^{\star}$ or collab* or advoca* or organi\#ation ${ }^{\star}$ or respons ${ }^{\star}$ or question* or educat ${ }^{\star}$ or inform ${ }^{\star}$ or train ${ }^{\star}$ or shar ${ }^{\star}$ or joint or choice ${ }^{\star}$ or preference $\left.{ }^{\star}\right)$ ).tw.

21. or $/ 18-20$

22. comorbidity/

23. polypharmacy/

24. (multidisease or multi-disease $^{\star}$ or multimorbidit* or comorbid $^{\star}$ or multi-morbidit* or co-morbid ${ }^{\star}$ ).ti,ab.

25. ((concomit* or concurren* or multi ${ }^{\star}$ or multiple) adj3 (ill* or condition* or morbidit* or syndrom or disorder* or disease $\left.{ }^{\star}\right)$ ).ti,ab.

26. exp chronic illness/ or "chronicity (disorders)"/ 
27. ((chronic* or elderly or age $\left.{ }^{\star}\right)$ adj3 (disease* or ill* or care or condition? or disorder ${ }^{\star}$ or health* or medication ${ }^{\star}$ or syndrom $^{\star}$ or symptom $^{\star}$ or chronic $\left.)^{\star}\right)$.ti,ab.

28. ( (coocur\$ or co-ocur\$ or coexist\$ or co-exist\$ or multipl\$) adj3 (disease? or ill\$ or care or condition? or disorder\$ or health\$ or medication\$ or symptom\$ or syndrom\$)).ti,ab.

29. or $/ 22-28$

30. primary health care/

31. general practitioners/

32. general practitioners/

33. home care/

34. private practice/

35. family physicians/

36. exp Community Services/

37. exp Community Health/

38. primary health care/

39. Health Care Delivery/

40. health promotion/

41. health promotion.ti,ab.

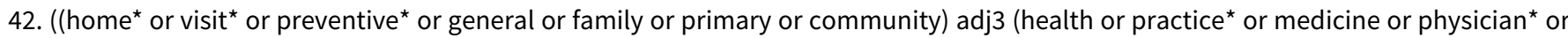
nursing or pharmacy or program* or service* or care)).ti,ab.

43. ((family or primary or general or community) adj2 (pharmacist* or physician $^{\star}$ or doctor $^{\star}$ or practitioner ${ }^{\star}$ or healthcare $\left.\left.^{\star}\right)\right)$.ti,ab.

44. ((nurse ${ }^{\star}$ or nursing) adj2 (practice* or practitioner $^{\star}$ or prescriber $\left.^{\star}\right)$ ).ti,ab.

45. (GPs or GPSI or GPwSI).ti,ab.

46. or $/ 30-45$

47. random*.ti,ab,hw,id.

48. intervention.ti,ab,hw,id.

49. trial.ti,ab,hw,id.

50. placebo*.ti,ab,hw,id.

51. groups.ab.

52. ((singl ${ }^{\star}$ or doubl* or trebl* or tripl $\left.{ }^{\star}\right)$ and (blind ${ }^{\star}$ or mask $\left.\left.^{\star}\right)\right)$.ti,ab,hw,id.

53. (cross over or crossover).ti,ab,hw,id.

54. latin square.ti,ab,hw,id.

55. (assign* or allocat* or volunteer $\left.{ }^{\star}\right) . t i, a b, h w, i d$.

56. (control or controlled).ti,ab,hw,id.

57. treatment effectiveness evaluation/

58. mental health program evaluation/

59. exp experimental design/ 
60. "2100".md.

61. or/47-60

62. animal.po.

63. 61 not 62

64. and $/ 4,21,29,46,63$

\section{CONTRIBUTIONS OF AUTHORS}

Joanne Butterworth is the first review author and the review's guarantor. She led on conception and design of the study, searches, screening, data extraction, and analysis, and has given final approval for the review to be published, holding responsibility for conducting any updates of the review.

Rebecca Hays contributed heavily to conception and design of the study and to drafting the protocol. She was involved in screening and contributed heavily to data extraction and analysis. Rebecca commented critically on the text of the review before giving approval of the document to be published.

Sinead McDonagh contributed heavily to both title and abstract screening and full-text screening for the review. She commented critically on the text of the review before giving approval of the document to be published.

Suzanne Richards was involved in conception and design of the study. She provided advice and guidance on searches, screening, data extraction, and analysis, contributed to drafting the review, and has commented on it critically for intellectual content before providing approval of the document to be published.

Peter Bower and John Campbell provided advice and guidance during all review processes, commented critically on the review text for intellectual content, and have given their approval of the document to be published.

\section{DECLARATIONSOF INTEREST}

JB: none known.

$\mathrm{RH}$ : none known.

SM: none known

SR: none known.

PB has received grants from the Department of Health, Medical Research Council, and National Institute of Health Research, and royalty payments from Cambridge University Press. PB was a co-author on one of the included studies (Salisbury 2018); Peter Bower was not involved in data extraction and/or quality assessment of the study for which he is a named co-author.

JC: none known.

\section{SOURCES OF SUPPORT}

\section{Internal sources}

- No sources of support supplied

\section{External sources}

- NIHR, UK.

This review is part-funded by two National Institute for Health Research (NIHR) doctoral research fellowships, supporting both Joanne Butterworth and Rebecca Hays. The views expressed are those of the author(s) and not necessarily those of the NIHR or the Department of Health and Social Care.

\section{DIFFERENCES BETWEEN PROTOCOLANDREVIEW}

\section{Changes to proposed outcome categories}

At the time of writing the proposal, the review authors were not able to predict every outcome measure that might be reported by included studies. It was therefore necessary to make some minor adjustments to our proposed categories to capture the extracted data accurately. 
- The 'patient evaluation of care' category was extended to include patients' evaluations of the intervention being delivered ('patient evaluation of care/the intervention').

- The category 'quality of care' was added as it was felt that this outcome was not adequately captured by the earlier categories.

- When extracting data, the review authors noticed that the majority of measures falling into the 'physical health status' category were also relevant to the 'psychological and psychosocial health status' category; therefore, these two original categories were combined to become 'health status'.

- Several measures that fitted the 'knowledge and skills' category could also be placed in the 'health behaviours' category. The predefined 'knowledge and skills' category was therefore broadened by combining these categories, and the new category was renamed 'patient engagement and enablement'.

- The category 'organisational change as a result of evaluation of the intervention' was removed as the review authors considered this to be less applicable to the types of included studies (RCTs, quasi-RCTs) and better suited to action research methods.

- The category 'healthcare use and costs' was broadened to include costs to patients and society.

Thus the main outcomes for the 'Summary of findings' table became (1) evidence of patient involvement in decision-making; (2) health status; (3) patient engagement and enablement; (4) patient evaluation of care/the intervention; (5) practitioners' knowledge and skills; (6) resource use and cost; and (7) adverse outcomes (patient, practitioner, or observer perceptions of less patient involvement in decision-making than before the intervention).

\section{Changes to proposed method of managing multiple outcomes assigned to the same category}

As originally outlined in the proposal, two review authors independently assigned the outcomes reported in each included study to the review's outcome categories. Frequently, more than one outcome measure was assigned to each category per included study. To ensure that the review remained relevant to clinicians, researchers, and policy makers, the process for managing this scenario was adapted slightly from the protocol. This decision was made based on the review authors' concerns that the outcome with the median effect estimate might not always be the outcome of most relevance to patients, or from a primary care perspective. These concerns arose because of the apparent clinical and methodological heterogeneity of the included studies and the variety of outcomes measured. Therefore, the review authors:

- prioritised outcomes reported in published papers to date (additional criteria since publication of protocol);

- selected the primary outcome as reported by study authors;

- when no primary outcome was identified, selected the outcome specified in the sample size calculation;

- when there were no sample size calculations, selected the outcome that appeared to relate most closely to the primary outcome of the review (additional criteria since publication of the protocol);

- when outcomes did not directly relate to the primary outcome, selected the patient-reported measure, and if no patient-reported measure was available, selected the measure most relevant to primary care (additional criteria since publication of protocol); and

- if all of the above were not appropriate, ranked the effect estimates and selected the outcome with the median effect estimate. 